\title{
Geistliche und Weltliche Poemata
}

Anna Ovena Hoyers

Follow this and additional works at: https://scholarsarchive.byu.edu/sophpm_poetry

Part of the German Literature Commons

\section{BYU ScholarsArchive Citation}

Hoyers, Anna Ovena, "Geistliche und Weltliche Poemata" (1650). Poetry. 9.

https://scholarsarchive.byu.edu/sophpm_poetry/9

This Article is brought to you for free and open access by the Poetry and Music at BYU ScholarsArchive. It has been accepted for inclusion in Poetry by an authorized administrator of BYU ScholarsArchive. For more information, please contact scholarsarchive@byu.edu, ellen_amatangelo@byu.edu. 


\section{Anna Ovena Hoyers}

\section{Geistliche und Weltliche Poemata}


Anna Ovena Hoyers: Geistliche und Weltliche Poemata

Erstdruck der Gesamtausgabe: Amsterdam (Ludwig Elzevier d.J.) 1650.

Textgrundlage ist die Ausgabe:

Anna Ovena Hoyers: Geistliche und Weltliche Poemata, Amsteldam[!]: Bey Ludwig Elzevieren, 1650.

Die Paginierung obiger Ausgabe wird hier als Marginalie zeilengenau mitgeführt. 


\section{Inhalt}

Gespräch Eines Kindes mit seiner Mutter ………................................ 5

An den Christlichen Leser ............................................................. 5

Geistlich Gespräch zwischen Mutter und Kindt .................................. 6

Einfältige Warheit ..................................................................................... 45

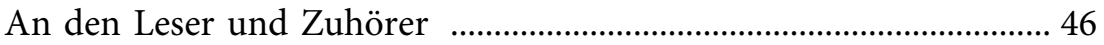

[Einfältige Warheit] ................................................................................ 51

Schreiben an die Herrn Titultrager von Hohen Schulen ................... 69

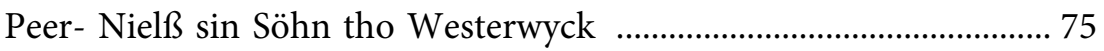

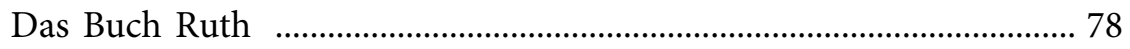

[VVeinet nicht sondern Harret der Hülff des Herrn] ....................... 78

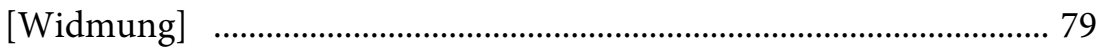

[Allen Guthertzign Boas Brüdern] ..................................................... 84

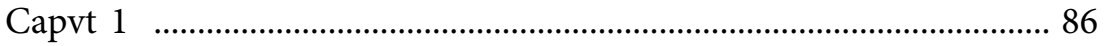

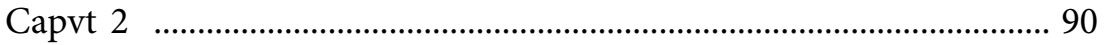

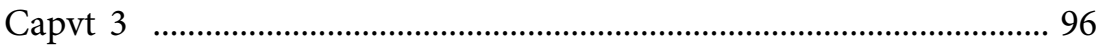

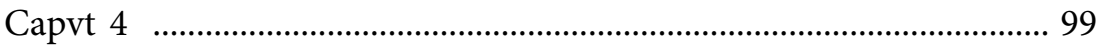

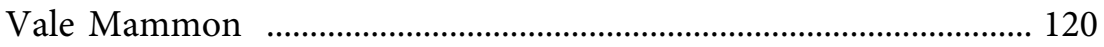

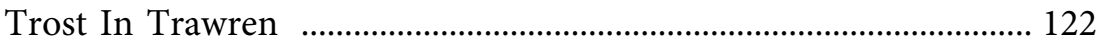

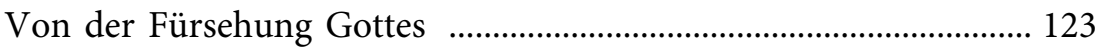

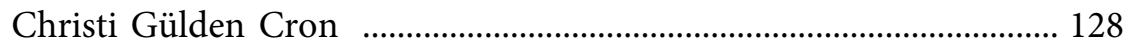

[Auffmuntrung zum Christlichen streit] ............................................ 128

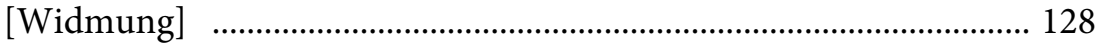

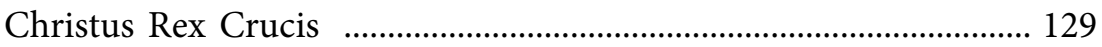

[Freut euch im Herren allezeit] ..................................................... 133

Rath an alle Alte Wittwen .............................................................. 140

Kurtz Bedencken von der Alten Weiber Heyrath ............................ 147

Judicium Vber Caspari Schweckfelds Buch vom Worte Gottes ..... 151

Casparus Schvvenckfeldius ................................................................. 155

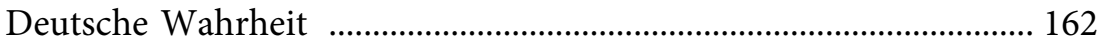

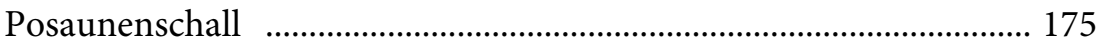

Schreiben an die Gemeyn im Land Holstein ................................... 223

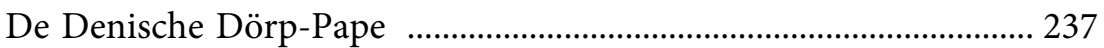

Schreiben an die Gemein in Engellandt ........................................... 255

Lob-Liedlein zu Ehren der Schwedischen Cronen ........................... 265

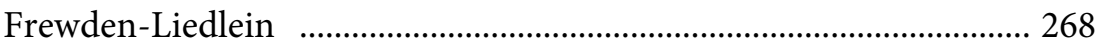


Zwey Geistliche Lieder 272

Das Erste 272

Das ander 276

Liedlein von den Gelt-liebenden Welt-Freunden 285

Liedlein 289

Neuw-Jahrs-Liedlein 292 


\section{Gespräch/ Eines Kindes mit seiner Mutter.}

Von dem wege zur wahrer Gottseligkeit.

Gestellet durch Annam Ovenam Hoyers.

Im Jahr des Hern Christi, MDCXXVIII.

\section{An den Christlichen Leser}

[von Johann Angelius von Werdenhagen]

Dies Buch dürch eine Fraw beschribn/

Wird man gwiß darumb mehr beliebn/

Weiln dergleichen nie gesehen/

Von Frawn so geistreich ausgehen:

Man wolls nur lesen und betrachtn/

Vnd auff der Spötter Red nicht achtn/

Die da sagen: es sey nicht fein/

Das ein Fraw ein Scribent will sein:

Christus ja meist Mariam preist/

Ob schon Martha ihm Kocht und Speist/

Weiln sie erwehlt das beste Theil/

In dehm sie gesucht der Seelen Heil:

Wie diese Fraw auch hat gethan/

Als darvon diß Buch zeugen kan/

Das auch die Weißheit nicht zuholln

Von Welt-gelehrten und Hohen-Schuln/

Sondern vom Heyligem Geist allein

Mus erbeten und gelernet sein/

Gott woll das sich niemand wol schämn

Von Frawn guth Exempel zu nehmn:

Wollst nur Leser diß perlegirn/

Vnd darnach darvon Iudicirn/

Der Heyliger Geist dich illustrir,

Vnd dich zum Reich Gottes recht führ.

Amen. 
Geistlich Gespräch/ Zwischen Mutter und Kindt,

Warin das wahre Christenthumb bestehe/ vnd wie es zu führen sey

Das Kindt spricht:

Mvtter ich hör offt von euch sagen/

Man soll sich gantz der Welt entschlagen/

Vnd nit nach eiteln dingen fragen/

Sondern der tugend stets nachjagen.

M.

Ist recht mein Kind/ nim diß in acht/

Vnd meine Wort bey dir betracht.

K.

Ja liebe Mutter ich begehr

$\mathrm{Zu}$ folgen ewer guten Lehr/

Sagt aber wo ich tugend find.

M.

Im Leben Iesu, liebes kindt:

Iesu Leben ist tugend voll/

Darin man sich stets üben soll.

K.

Gern will ich mich darin begeben/

Wie komm ich aber zu dem leben?

$M$. 
Den Creutzweg liebes kind must gehn

Darin wirstu sein leben sehn.

K.

Hertzliebe Mutter sagt mir dann/

Wie mach ichs doch? Wie fang ichs an.

Wo find ich diesen weg doch best?

M.

Kindt wann du deinen willen lest/

Suchst nicht dein eigen Nutz und Ehr/

Vnd liebst dich selbst auch nicht zu sehr/

Sondern folgest dem Herrn schlecht/

3 So gehst den Weg des Lebens recht/

Zur tugend ist kein ander straß/

$\mathrm{Al} ß$ Gottes lieb und eigen haß.

K.

Mutter ewr red ich wol versteh/

Aber das thut dem Fleische weh.

$M$.

Ja Kindt/ du must gedencken dran/

Es hat dem Herrn auch weh gethan/

Alß Er den Weg dir hat bereit/

Einzugehn in die Herligkeit;

Wapne dich mit demselbign Sinn/

Vnd folg ihm trewlich nach hirinn.

K.

O Mutter/ ich bin viel zu schwach/

Dem Herrn Iesu zu folgen nach. 
Kindt/ sey nicht zaghafft zu dem werck/

Der Herr Iesus wird sein dein sterck/

Er will was du nicht kanst erfüllen/

Behalt du nur den guten willen/

Folg ihm mannlich im guten lauff/

Sein krafft hilfft deiner schwacheit auf/

Es ist sein werck/ mein kindt/ nicht dein/

Menschliche krefft sind viel zu klein.

$K$.

Mutter das ist auch meine klag/

Befind es bey mir alle Tag/

Offt ich den guten willen hab/

Fang an, fall doch bald wieder ab/

Vnd werd zum guten träg und laß/

Sagt Mutter/ woher kompt doch das?

M.

Kindt das ist unser schwacheit schult/

Damit hat Gott der Herr gedult/

Wann man den fürsatz nur behelt/

Vnd nicht bleibt ligen wann man felt/

So wil Gott allzeit helffen gern/

Durch sein krafft unser stärck vermehrn/

Es ist und bleibt allzeit getrew/

Hab du nur hertzlich leit und rew/

Vnd steh vom fall bald wieder auf/

Bitt Gott umb sterck im guten lauf/

Dann durchs Gebett man viel außricht/

Sanct Iacob der Apostel spricht:

Darum beth fleißig alle tag/

Vnd wann du fallst ja nicht vertzag/

Erheb dich wieder im gemüth/

Vertraw fest Gottes lieb und güth/ 
Vnd lern fürsichtig sein hernach/

Alßdann der fall nicht schaden mag.

K.

Ja Gott lob/ ich hab rew und leid/

Im hertzen schmertz und traurigkeit/

Wegen meiner schwacheit und Sünd/

Die ich täglich bey mir befind.

Begehr mich aufzurichten wieder/

Wann ich gefallen bin danieder/

Hab auch den fürsatz fest zustehn/

Denn bösen nicht mehr nachzugehn/

Ich bitt auch Gott umb gnad allzeit/

Vnd meid die Sund nach mügligkeit:

Noch dennoch nicht mein bessrung ist

So groß alß mein Will jederfrist/

Am wollen ich kein mangel spür.

Mein kind das hör ich gern von dir:

Zweiffel nicht an der hülff des Herrn/

Er wird dich deiner bitt gewehrn.

Vertraw nur ihm in allen dingen/

Sein ist das Wollen und Vollbringen.

Der nun in dir durch seine gnad/

Das gut Werck angefangen hat/

Wird es auch krefftig vollenführen/

Harr seiner hülff du wirst es spühren:

Dann wan Gott will so wirds gut werden/

Bitt daß sein Will gescheh auff Erden.

Dein gang sey langsam oder schnell/

Solches dem lieben Gott heimstell:

Wenn du nur immer furter gehst/

5 Vnd nimmer still im guthen stehst/

So kompstu wol fort mit der zeit.

Beharr nur in bestendigkeit. 
Mutter ihr macht mir einen Muht/

Gott helff mir fort mein will ist guht/ Aber hertz-Mutter eins hab ich Im hertzen daß noch krencket mich/ Wann ich gedenck daran/ alßdann Ich mich nicht recht wol trösten kan.

Mein liebes kind sag ohn bedencken Was ist es doch das dich thut krencken?

Ja Mutter ich wills euch anzeigen/

Vnd mein betrübnüß nicht verschweigen/

Diß ist es das mich krenckt so sehr/

Weil ich von meiner kindtheit her

Mein zeit so übel zugebracht/

Die Welt viel mehr als Gott geacht/

Vnd viel Sünd hab auff mich geladen/

Weiß ich nicht ob ich bin in gnaden/

Dann weil ich schändtlich hab gelebt

Muhtwillig wieder Gott gestrebt/

Kan mir kein Mensch zusagen frey/

Das ich bey Gott in gnaden sey/

Vnd kan ich auch nicht wissen eben/

Ob mir sind alle Sünd vergeben/

Weiß nicht was Gott will von mir machen

Weil ich so offt in guten sachen

Wanckel und unbestendig bin

Vnd so gar leichtlich fall dahin/

Auch leider weinig bessrung spür

Die schwacheit ist zu groß bey mir/

$\mathrm{O}$ wie rewt mich die Edle zeit/

Die hin ist gangn in Eitelkeit/ 
In welcher ich viel schöner gaben

Vom lieben Gott hab mügen haben/

Wann ich diß alls zu hertzen nem

6 Ich mich zu Tod bald grem und schem/

Möcht ich nur innerlich empfinden

Die Vergebunge meiner Sünden/

Vnd Gottes gnad versichert sein/

So wehr ich frey von dieser pein/

Aber hie mangelts leider mir.

Kindt/ was hör ich für wort von dir?

Weist nicht das Gotts barmhertzigkeit/

Den armen Sündern ist bereit?

Ist Christus doch auf Erden kommen

Hat unser schwacheit angenommen

Vnd will die Sünder selig machen

Vnd hülff beweisen allen schwachen/

Die starcken darffen seiner nicht/

Er selbst/ der Herr/ gar tröstlich spricht/

So ist er iho auch kommen dir

Des frew dich und danck ihm dafür/

Du bist ja einer von den schwachen/

Darum laß dich gesundt auch machen/

Dieser Artzt kan all schaden heilen/

Vnd will auch allen hülff mittheilen/

Komm zu ihm und laß dich verbinden/

Vnd reinigen von deinen Sünden/

Du fühlest iho derwegen pein/

Vnd begehrst auch gesundt zu sein/

Eil bald zu ihm in deinen schmertzen/

Vnd lern demütig seyn von hertzen/

Dann Er/ der Herr/ ist sehr sanfftmütig/

Hertzlich demütig/ fromm und gütig/

Folg ihm hierin/ nim auf sein joch/

Wie lockt er dich so freundtlich doch/

Veracht sein tröstlich zusag nicht/ 
Die er in seinem Wort verspricht:

Kompt her zu mir/ er rufft und schreyt/

Alle die ihr mühselig seyt/

Vnd alle die ihr seyt beladen/

Ich nem euch auff/ heil ewern schaden/

Ich der Herr bin ewr Artzt allein/

Kompt alle her beid groß und klein.

Das Wort kompt alle her zu mir/

Nimm du mit an/ es gilt auch dir/

Er will sie all/ auch dich erquicken/

Lern dich in seine weiß recht schicken:

Sein joch ist sanfft sein last ist leicht/

$\mathrm{Al} ß$ solches uns sein Wort anzeigt/

Dasselbig wol zu hertzen nimm/

Gehorch/ und folg des Herren stimm/

Vnd trag ihm willig nach dein Creutz/

Drückt es dich schon/ gedüldig leids/

Vnd ob du wol wirst offtmahls schwach/

Davon dir kein gedancken mach/

Viel mehr in schwacheit frölich sey/

Dann Christus steht den schwachen bey/

Vnd ist umb ihrent willen kommen/

Alß du zuvor wol hast vernommen.

Sanct Pauli wort nimm auch in acht/

Da er zu den Corinthern sagt/

Mich selbst zu rühmn enthalt ich mich/

Daß nicht hoch werd geachtet ich/

Aber allein Christo zu ehrn/

Rühm ich mich meiner schwacheit gern/

Bin frölich und guts muts darin/

Dann starck ich in der schwacheit bin.

Hör diß mein kindt/ lern es verstehn/

Gott lest dir auch dein schwacheit sehn/

Nicht darumb daß du solt vertzagen/

Vnd dich zu Tod derwegen plagen/

Sondern dich allzeit achten klein/

Vnd lernen fein dehmütig seyn;

In allen dingen ihm vertrawn/ 
Vnd nicht auff eignen kräfften bawn:

Dein krafft er offt zu schanden macht/

8 Daß du auff ihn allein gebst acht/

In deiner schwacheit hastu stärck

Durch Christi krafft/ mein kind das merck/

Es hufft und steht dir bey allzeit/

Darumb sey guts muts in schwacheit

Sein krafft ist mächtig in den schwachen/

Ergib dich ihm/ Er wirds wol machen/

Mit seiner hülff stets bey dir seyn/

Folge nur seiner stimm allein/

Vnd bleib bestendig biß ans End/

Im Creutz dich nicht vom ihm abwend:

Das Creutz ein zeichen ist der gnaden/

Bringt jederman nutz/ niemand schaden/

Es ist des Herren Iesu Fahn/

Nims an und sey ihm unterthan/

Vnd such allzeit sein lob und ruhm/

So bist du im Wahren Christenthum/

Vnd wol versichert Gottes huldt/

Hast auch vergebung aller schuldt:

Dann all dein Sünd und Missethat/

Der Herr ans Creutz geschlagen hat/

Weil sie dich rewen hertzlich sehr/

Vnd du sie auch wilt thun nicht mehr:

Sein unschuld hat Er dir gebracht/

Dadurch von Schuld dich loß gemacht/

Dein Schand hat Er ans Creutz gehenckt/

Vnd dir dafür sein Ehr geschenckt/

Er hat getödt dein Sündlichs leben/

Vnd dir sein Leben wieder geben/

Welches ist voller Heyligkeit/

Darin zu üben dich allzeit/

Nimms an und folg Christo dem Herrn/

$\mathrm{Di}$ ist die prob, thustu es gern/

So darffstu nicht im zweiffel stehn/

Gott hab dich gnädig angesehn/

All deine Sünd vergeben sind 
Vnd bist ein Außerwehltes kindt/

Die Er erwehlt hat/ Paulus spricht/

Lest Er auch unberuffen nicht/

Vnd die den Beruff folgen schlecht/

Macht Er auch Heylig und Gerecht/

Die Gerechten er Herlig macht/

Mein kind/ nimm diese Wort in acht/

Du weist das du beruffen bist/

Hast auch zur Nachfolg lieb und lüst/

Hassest das Sündlich leben sehr/

Was wiltu dennoch zweiffeln mehr?

Gottes gnad und barmhertzigkeit

Geht vor der bessrung her allzeit/

Die Busse auß der gnad herkömpt

Vnd davon ihren anfang nimmt/

Wo lieb und lust zur bessrung ist/

Da wohnt im hertzen Iesus Christ

Vnd wircket die Buß/ liebes kindt/

Wo man nun Iesum Christum findt/

Da ist auch warlich Gottes gnad/

Da gnad ist/ thut kein Sünd mehr schad.

Des Vatters zug wirst iho gewahr/

Daran hast auch ein zeichen klar/

$\mathrm{Da}$ du von ihm seyst angenommen

Vnd in der gnad zu Christo kommen:

Den der zu mir kompt Christus spricht/

Werd ich von mir außstossen nicht/

So viel du in der Buß zunimpst

Du täglich näher zu ihm kömpst/

Vnd bist zur herrligkeit erwehlt/

Dein thun in Christo Gott gefelt/

Weh dem der hoffnung fallen lest/

Mache nur dein erwehlung fest/

Vnd betrübe dich hinfort nimmer/

Allein damit dich stets bekümmer

$\mathrm{Daß}$ du zu wandlen dich befleist/

Alß Gottes Geist im Wort dir heist/

Dein bestes thu in allen sachen/ 
Das übrig wird der Herr wol machen

Vnd dein zeit die in eiteln dingen

Hingangen ist/ wiederumb einbringen

Vnd erstatten in kurtzer frist

Was guts von dir verseumet ist/

Steh ihm in allen nur gelassen/

Er wird dich führn auff rechter strassen

Zum lebens brunn auff grüner awn/

Da wirst deins hertzen lust anschawn/

Auch alles leiden überwinden/

Vnd ruh für deine Seele finden.

K.

O Mutter wie wol tröst ihr mich/

Krafft ewer Red empfinde ich

Dann alles was ihr mir gesagt

Befind ich wahr wann ichs betracht/

Vnd hat im Wort des Herren grund

Was ich gehört auß ewerm mund/

Hab darumb auch kein ursach mehr/

$\mathrm{Zu}$ trauren wie ich gthan bißher/

Dann Gottes gnad der itzund ihr

Erinnert mich/ ich täglich spühr

Sein güth/ barmhertzigkeit und trew

Wird auch bey mir all morgen new/

$\mathrm{Zu}$ dancken solcher grossen güth/

Habt ihr erwecket mein gemüth/

Vnd mich mit trost erquicket woll/

Ewr wort ich nicht vergessen soll.

Behalt sie kindt/ zu deiner sterck/

Vnd was die Schrifft dir sagt das merck/

Liß fleißig das New Testament/

Alles darin geht zu dem Endt/

Das wir sollen gedult/ trost/ lehr/ 
Vnd hoffnung haben in beschwer/

Dann dir und mir auch mit angeht/

Alles das drinn geschrieben steht/

Lern die exempel recht verstehn/

Darin wirst überflüßig sehn/

Wie Gott so freundlich und geneigt/

Den Armen Sündern sich erzeigt/

Sieh doch an den Verlohrnen Sohn/

Ein exempel lieblich und schon/

Wie nimpt der Vatr ihn an so gern/

Sah ihn an da er noch war fern/

Vnd da er näher zu ihm kömpt

Sieh wie freundlich Er ihn annimpt/

O Vaters hertz ernst ist es dir/

Solches in allen dingn ich spür!

Dein unendlich Barmhertzigkeit

Ist bereit wann wir noch sind weit/

Uns anzunehmn und zuumbfahn/

Wann wir umbkehrn uns zu dir nahn.

Du liebhaber der Menschen kinder

Erbarmst dich aller armen Sünder!

Das find ich in der Schrifft ohn zahl/

Auch täglich scheinbar uber all.

Liß die Propheten auch mein kindt/

Herrlichen trost darin man findt/

Schmeck und sieh wie from ist der Herr/

Wie freundtlich/ süß und lieblich Er

Sein unverdiente gnad beweist/

Vnd über uns reichlich außgeust/

Wie ist Er uns doch so geneigt/

Sieht welch ein lieb uns Gott erzeigt.

Iohannes der Apostel spricht/

Wer wolt der lieb sich frewen nicht?

Sieh doch mein Kind und nimm in acht/

Gott der unendlich ist von macht/

Vnd niemands hülffe nötig hat/

$\mathrm{Zu}$ erhalten sein Majestat,

Machet sich so gering und klein 
12 Alß wann Er nicht könt ohn uns seyn/

Sein lieb Er zuerkennen gab/

Sanke zu uns sein Wort herab:

Das Wort war Gott/ Gott war das Wort/

Ist von Anfang/ bleibt immerfort/

Gott und bey Gott in Ewigkeit/

Das ist Fleisch worden in der zeit/

$O$ wunder über wunderthat!

O unaußsprechlich große gnad!

Gott ist ein wahrer Mensch gebohrn/

Hat doch sein Gottheit nicht verlohrn/

Gott von Gott, Liecht von liecht außgangn/

Ist von dem Heilign Geist empfangn/

Gebohrn aus einer Jungfrawn rein/

Ein wahrer mensch mit Fleisch und bein.

Bedenck mein kind was Wort diß sind/

Gott ist Gebohrn ein menschen kindt

Von einem unbefleckten Weib/

Lest sich sehn im menschlichen Leib/

Vnd nimmt sich unsers Elends an/

Ist unter das Gesetz gethan.

Anfang ohn Anfang/ End ohn Ende/

Gibt sich hin in der Menschen hende/

Der Sünder straff tregt der Gerecht/

Wird willig ein knecht aller knecht/

Der aller Herren ist ein Herr/

Was hat er uns thun sollen mehr?

O welch ein Lieb und grosse Gnad/

Die er an uns beweiset hat!

Mutter gebt nur recht zuverstehn/

Auß was ursach ist diß geschehn?

Vnd warumb hats so müssen sein? 
Die ursach/ mein kindt, ist allein

Gottes Lieb/ wie die Schrifft vermeidt/

Also hat Gott geliebt die Welt/

$\mathrm{Da}$ er sein'n einign liebsten Sohn

Gab/ und zu uns vom Himmels Thron/

Herab ließ kommen hie auf Erden/

Auff das wir nicht verlohren werden/

Wer gläubt der wird gerichtet nicht/

Der nicht gläubet ist schon gericht.

Kein ander ursach liebes kindt/

Alß die Göttliche lieb man findt/

Allein auß lauter lieb umb sonst

Mittheilt er uns sein gnad und gunst/

$\mathrm{Zu}$ dem End/ und darumb allein

Das wir sein Kinder sollen seyn/

Ihm dienen in Gottseligkeit

Vnd Heiligkeit zu jederzeit.

Wir gingen irrend wie die Schaf/

Vnd hatten verdient ewig straff/

Weil wir muhtwillig durch den fall

Von ihm wahrn abgewichen all/

Er hat uns aber auffgericht/

Strafft uns nach unsern Sünden nicht/

Nimmt Christum an für einen bürgen

Vnd lest denselben für uns würgen/

Durch ihn sind wir nun frey gemacht/

Zum leben wiederumb gebracht/

Der gibt für uns sein Leib und Leben/

Auff das wir uns ihm wieder geben

Mit leib und leben gleicher massen/

In allem unserm thun und lassen;

Er hat zu seinem Lob und Ruhm

Uns ihm gemacht zum Eigenthum/

Will nicht das jemand werd verlohrn/

Dann darumb ist er Mensch gebohrn/

Vnd hat ein Menschen Kindt seyn wollen/

Auff das wir durch ihn werden sollen

Kinder Gottes/ from/ rein und pur/ 
Theilhafftig Göttlicher Natur,

In allem gleich wie er gesinnt/

14 Daß ist die End ursach mein kindt/

Darumb er sich auß lauter gnad

Für uns dahin gegeben hat/

Macht uns durch sein barmhertzigkeit/

$\mathrm{Zu}$ allem guten werck bereit/

Das wir ihn damit sollen preisen

Gottseligkeit dadurch beweisen/

Dann sein Gebürt/ Todt/ Aufferstehn/

Auffart und was sonst ist geschehn/

Das alles soll uns dazu dienen/

Dazu ist Gottes gnad erschienen

Vnd unsers Heilands freundligkeit/

Das Er ihm selbst ein Volck bereit/

Das fleißig wehr zu guten Werckn/

Diese Wort mein kindt wolstu merckn/

Dich der Welt lieb und lust entschlagen/

Christi leben aus lieb nachjagen;

Weil du zu guten Wercken bist

Von Gott geschaffn in Iesu Christ,

Paulus zu den Ephesern spricht/

Nach seiner Lehr dich fleißig richt/

Laß im stand guter Werck dich finden

Vnd hüte dich für allen Sünden/

Von tag zu tag/ je mehr und mehr/

Durch wahre Buß zu Gott dich kehr/

Vnd dancke seiner grossen gnad/

Die er uns alln erzeiget hat/

Ja Lob und Danck sey ihm dafür/

Auch Ewiglich gesagt von mir;

Genugsam ich ihn all mein tag/

Für seine güth nicht preisen mag/

Dann mir insonderheit sag ich/

Erzeigt er sich stets Vätterlich/ 
Wann ich all sein Wolthat betracht/

Das Er zum menschen mich gemacht/

Durch fromme Eltern mir das leben

Vnd wolgestalten Leib hat geben/

Stete fürsorg für mich gehabt/

Mit Witz und Verstandt mich begabt/

Von der kindheit und Jugend auff/

Auch mitten im Sündlichen lauff/

Mich gnädiglich gesehen an/

Ich ihn nicht genug rühmen kan/

All seine gutthat nach gebühr

Sind zu erzehln unmöglich mir/

Auß vielerley Gefährligkeit

Er mir geholffen hat allzeit/

Heilt mein kranckheit macht mich gesundt/

Erhelt noch biß auff diese stund/

Vnd wann ich sündig/ bald Er mich

Heimsucht und züchtigt Vätterlich;

Nimpt dadurch hin mein missethat/

Lest nach der steup mich finden gnad/

In dem und damit er mich strafft/

Er viel guts bey mir wirckt und schafft/

Sünd er im Fleisch durch Sünd verdampt/

Beweist an mir sein Mittlers-Ampt/

Offnet mir seines Worts verstandt/

Vnd macht mir mein jrrthumb bekandt/

In allem Creutz mir trost zusendet/

Vnd alles böß zum besten wendet/

Lockt/ leitet/ lehrt und helt mich auff/

Daß ich den breiten weg nicht lauff/

Gibt mir sein'n willen zuerkennen/

Lest mich nach seinem Nahmen nennen;

Solcher und andren wohlthat mehr/

Die er mir hat erzeigt bißher/

Ich ihm nach würd nicht dancken kan/

Lebt ich auch tausendt Jahr fortan:

Gelobt sey sein barmhertzigkeit

In dieser und zukünfftign zeit/ 
Mutter erfreut euch doch mit mir/

16 Vnd sagt dem Herren danck dafür/

Der Vatter liebt mich in dem Sohn/

Gleich wie den Sohn ist das nicht schon?

Das hertz in meinem leib thut springen/

Für freuden heb ich an zu singen:

Gott hat mein Sünd mir hingenommen/

Dadurch bezahlt sind mein schult-summen/

Vnd sie ans Creutz geschlagen/

Ich bin mit Gott vertragen/

Wills frölich mit ihm wagen/

Ihm Ewiglich Dancksagen/

Vnd hinfort nicht mehr klagen/

Noch mich mit sorgen plagen.

Mein liebes kindt dein freud ist mein/

Billig sollen wir danckbahr seyn/

Mit freuden Gott Lob-Opffer schencken/

Vnd seiner Wolthat stets gedencken/

Diß sind wir ihm ja schüldig nun/

Solten wirs dann nicht willig thun/

Vnd unsern höchsten fleiß ankehrn/

$\mathrm{Zu}$ folgen diesem frommen Herrn?

K.

Ja Mutter hertzlich gern wil ich

In seiner nachfolg üben mich/

Gedültig unterm Creutz mich neigen/

Den berg der tugend anzusteigen/

Meinen willn hab ich ihm ergebn/

Seinem willn willig nach zu lebn;

Vnd ist meins hertzen wunsch alzeit/

Das ich müg sein dazu bereit:

Aber der weg macht mir offt bang/

Weil er beschwerlich ist und lang/ 
Voller gefahr und hindernuß/

Da man hindurch passiren muß;

Die gantze Welt mit ihrer list/

Auch Satan mir zu wieder ist/

Imgleichen viel der guten freund/

Mir auch im lauff entgegen seind/

Sagen/ ich soll mich nicht so krencken/

Sondern eins andern mich bedencken/

Mein Sinn nicht von der Welt abziehn/

Ihr lüst und freud so bald nicht fliehn/

Auffs alter in den künfftign tagen

Mich erst mit den gedancken plagen/

$\mathrm{Hab}$ zeit und weil genug hernach

Darin ich Gott gefallen mag;

Soll mich des Creutzes nehmen an/

Wann ich kein freud mehr haben kan:

Diese und derogleichen Wort

Hab ich mit schmertzen offt gehort/

Erfahren nach des Satans tück/

Der Welt betrug und bubenstück/

Bin dadurch offt zu fall gebracht/

Am guten fürsatz irr gemacht;

Gelobt sey Gott zu aller zeit/

Der mich vom übel hat befreyt/

Vnd wieder vom fall auffgericht/

Sein Gnad wol mich verlassen nicht/

Sondern mir beystehn/ und mich stercken

In allen ihm gefällign wercken.

Mein liebes kindt fahr du nur fort/

Vnd halt dich fest an Gottes Wort;

Sey unverdrossen, werd nicht treg

$\mathrm{Zu}$ wandlen auff des Herren weg/

Ohn tadel wirstu kommen fort/

So du dich heltst nach seinem Wort/

Sich nicht zurück im guten lauff/ 
Laß dich durch kein ding halten auff/

Sich keines menschen freundschafft an/

Ein mensch den andern hindern kan/

Will niemandt mit, geh du allein/

Sieh auff dich selbst/ laß andre seyn/

Steh nicht still/ und werd nit verdrossen/

18 Eil fort ehe die thür wird verschlossen/

Itzt hastu noch zu wandlen zeit/

Verseum dich nicht weils noch heist heut.

Des Herren Jesu krafft vertraw/

Vnd auf sein gnaden hülff fest baw/

Im glauben daß Er krefftiglich

Kan dempfen all die wieder dich/

Nimm nur zur hand sein wehr und Waffen/

So wird kein feind was an dir schaffen/

Sein Wort ist ein zweyschneidig Schwert,

Das nimm in acht/ und halt es werth/

Wieder all deine Feind zu fechtn/

Gebrauchs zur lincken und zur rechtn/

Des Glaubens Schilt stets für dich halt/

So schadt dir nicht Satans gewalt/

Tritt keck den weg hinan/ alßdann

Der Feind an dir nichts haben kan;

Du must aber guth achtung geben/

Für sicherheit dich hüten eben/

Der Feind ist listig/ nicht zu trawn/

Darumb must fleißig umb dich schawn'/

Bey Nacht und Tag stets halten wach/

Daß Er dich nicht zu schanden mach/

Dann gar offt er danieder felt/

Sich gleich alß uberwunden stelt/

Bald aber ehe man sichs versicht/

Hat er sich wieder aufgericht/

Vnd viel mehr alß zuvor gesterckt/

Kan auch offt da mans nit vermerckt

Einem ein dein leicht unterschlagen/

Daß mans sein lebtag hat zu klagen/

Diß nimm in acht und hüte dich/ 
Folg mir/ ich mein es Mutterlich/

Vnd theil dir mit getrewen rath/

Glaub der die es erfahren hat/

Vnd laß dich warnen jeder zeit/

Für drey Feinde insonderheit/

Augen-lust/ Fleisches-lust/ hoffart/

Drey Teuffelinnen einer ahrt/

Diese sind wieder dich geruft

Zufellen dich mit ihrer lust/

Werden ein lieblichs Netz dir stellen/

Vnd sich freundlich zu dir gesellen/

Hüt dich dafür mein liebes kindt/

Es ist des Teuffels Hoffgesind/

Vnd sind die aller ärgsten feind/

Stellen sich doch lieblich als freund.

Der mensch ist leicht durch sie betrogen

Vom guten fürsatz abgezogen/

So er nicht durch die Göttlich güt/

In steter forcht helt sein gemüth/

So ist es bald umb ihn geschehn/

Darumb must fleißig für dich sehn;

Gib den augen zu viel nicht raum/

Bey leib halt auch dein fleisch im zaum;

Lieb die Dehmuth so bist verwahrt

Vnd wol versichert für hoffart/

Augenlust macht die menschen blindt/

Vnd ist ein ursach grosser Sündt/

Unzehlig viel durch sie betrogen

Sind von dem guten abgezogen/

Gefallen in groß Sünd und Schandt/

Haben das leben nie erkant/

Lieblich anblick der augen ist

Ein führerin zur fleisches lüst/

Fleisches lüst aber pein gebiert/

Vnd die Seel ins verderben führt/

Sie macht die menschen gar zu Schwein/

Die doch nach Gott gebildet seyn/

Vnd so man nicht thut Buß beyzeit/ 
Bringt kurtze freud/ in Ewigs leid.

Hoffart das aller schädlichst Thier/

20 Brütet aus zorn/ mißgunst/ rachgir/

Streit/ neid und laster mehr ohn zahl/

Hoffart bringt grosse Leut zu fall/

Darumb mein kindt sich dich wol für

Das diese drey nicht schaden dir/

So du wirst diese ubermannen

Jagst auch all andern leicht von dannen

Die wieder dich sich legen auff/

$\mathrm{Zu}$ hindern deinen guten lauff/

Wirst frey und sicher wol passiren

Das dich kein laster wird verführen/

Dann wann die Obersten erschlagen/

Sind die Soldaten leicht zu jagen/

Darumb von aller Eitelheit

Wende dein augen ab bey zeit/

Das dich derselben lust nicht blende

Vnd von dem guten weg abwende/

Die schön gestalt der Welt-Leut fleuch

Vnd ihrer freundtschafft dich entzeuch/

Dann bey dir schön ist groß gefahr/

Bedenck diß und dich wol bewahr/

Hab in all deinem thun auffmerckn/

Das du in geberd wort und werckn/

Züchtig und eingezogen seyst/

Dein Fleisch macht unterthan dem Geist/

Halt maß allzeit in allen sachen/

In Essen/ Trincken/ Schlaffen/ Wachen/

Durchs Gebedt halt im zaum dein Fleisch/

Forcht Gott allzeit/ so bleibstu keusch/

Fleisches lust wird bald von dir scheiden/

Gedenck nur offt an Christi Leiden

Vnd wapne dich mit seinem leben

So wird Hoffart auch urlaub geben/

Wieder sie kanst mit Dehmuth kempffen/

Den zorn mit Christi Sanfftmuth dempffen.

Geduld alls leiden überwindt/ 
Forcht dich gar nicht mein liebes kindt/

Erzeig dich nur Mannlich im streit/

Des Lebens Kron ist dir bereit/

Groß zusag der belohnung finden/

In Heilger Schrifft/ die uberwinden.

Mutter es sey mit Gott gewagt/

$\mathrm{Zu}$ streiten bin ich unverzagt/

Ewr Lehr die ihr mir habt gegeben/

Will ich behalten wol und eben/

Für meiner feinde list mich hüten/

Nicht forchten mich für ihrem wüten/

Wann Gott mit mir ist/ sagt wer kan

Mir böses thun und schaden dann?

Seiner gnad will vertrawen ich/

In seiner forcht stets halten mich/

Sein Heiligr Geist wol mich regieren

Nach seinem Wort und willen führen

In allem mein Geleyts-mann seyn/

Mich von den Sünden machen rein/

Mit glaub/ lieb hoffnung/ zucht gedult

Vnd Sanfftmuth zieren durch sein huld.

O Iesu wend die Hoffart ab/

Mit deiner Demuth mich begab/

Hilff mir all läster uberwinden/

Das sie kein platz mehr bey mir finden/

O gedult Iesu, mein Artztney/

Steh du in allem Creutz mir bey/

Laß mich nicht ungedultig werden

In worten/ wercken und geberden/

Wann mir was wiederlichs zusteht/

Vnd traurigkeit zu handen geht/

O keuscher Iesu, dein keuscheit/

Geb mir auch allzeit das geleyt/

Enthalt mein hertz in deiner zucht/

Das darin wachß kein böse frucht/ 
Ohn dich kan für Gott niemand taugen/

22 Regier du mein gesicht der augen/

Der du meins lebens führer bist/

Wend von mir ab all augen lüst/

O reiner Iesu, mich regier/

Das mich kein Fleisches lust verführ/

Mein Sündtlich begierd/ zwing und zehm/

Das mich kein Eitelheit einnehm/

Laß mich bedencken offt dein leiden/

So werd ich all Welt freud wol meiden/

Sey du meins hertzen freud allein/

Laß mich ohn dich nicht frölich seyn/

Dir Herr Iesu, ergeb ich mich/

Dein will ich bleiben Ewiglich.

Also mein liebes kindt/ also/

Deiner red bin ich hertzlich froh/

Der Herr Iesus sterck den fürsatz/

Vnd sey deins lebens freuden schatz/

Halt im Gebett nur fleißig an/

Es wird kein hülff dir manglen dann/

Der Herr wird seyn dein liecht und Heil/

Deins lebens krafft, dein gutes theil/

Dein schilt/ dein schutz/ fried/ freud und ruh/

Keins feindes trotz darffst forchten $\mathrm{du} /$

Darumb mein kindt für allen dingen/

Halt an mit Bethen/ Lesen/ Singen/

Wirstu dein zeit damit zubringen/

So wird all dein thun wolgelingen.

Mutter das ist mein höchste freud/

Vnd meins lebens ergetzligkeit/

In Gott ich all mein hoffnung setz/

Nim nicht dafür all irdisch schetz/ 
Was ist die Welt mit ihrem pracht?

Für dreck ich ihren hochmuth acht;

Was ist doch ihr reichthumb und schön?

Ein schatt/ ein larv/ ein leer gethön/

Da nichts bey ist dann Eitelkeit/

Wo tugend nicht gibt das geleyt/

Was ist wollust/ die viel verblendt?

Ein vollust man sie billig nennt/

Ein uberzuckert tödtlich speise

Damit Satan fangt seine meuse/

Das allerhöchste gifft der Welt/

Ein Netz das er sein'n Vögeln stellt/

Ein garn und strick das er fürhangt/

Darin leichtfertig hertzen fangt/

Für Gott ist kein ding so abschewlich/

Den Heilign Engeln nichts so grewlich/

Den keuschen menschen from und Ehrlich/

Nichts so verdrießlich und beschwerlich/

Als die schändtliche wollust ist/

Ich gleich sie dem Kuhkoth und mist/

Den Fladen die im Felde ligen/

Bey Sommers zeit/ darin die Fligen

Heuffig herumb spatziren gehn/

Nach schönen Blumen nicht umbsehn/

Suchen im koth ergetzligkeit/

Wissen von keiner andern freud/

Ihr keiner über sich gedenckt/

So tieff sind sie darin versenckt/

Wolln sich nicht in die höh erheben/

Vnd mit den Flügeln aufwerts schweben:

Eben also sind die dreck Gecken/

Die sich mit vollust koth beflecken/

Vnd dahin neigen all ihr dichten/

Die flügl der andacht sie nicht richten/

Sich damit auffwerts zu erheben/

Bleiben an ihrem unflat kleben/

Vnd werden darin umbgezogen/

Von ihrer eignen lust betrogen/ 
Wollen was Himlisch ist/ nicht schmecken/

Viel lieber koth als honich schlecken.

Fragen nichts nach dem besten leben/

24 So gar sind sie der Welt ergeben/

Fliegen mit ihren flüglen nicht/

Ihr keiner in die höh sich richt:

Darumb sie auch alß arme fliegen

Im koth ihr tag wol bleiben ligen/

Vnd müssen in unendtlichs leiden/

Ewiglich von Gott abgescheiden

In unaußsprechlich Hellen pein

Mit Leib und Seel verlohren seyn:

Dann wer sich nicht in zeit der gnaden

Lest warnen für der Seelen schaden/

Von Gott durch sein Gesetz erschrecken/

Vnd aus dem schlaff der Sünden wecken/

Sondern von seiner lüst umbtrecken/

Vnd bleibt in seiner Sünden stecken/

Denn wird Gott in des Satans hecken

Mit Ewiger ungnad bedecken.

Mutter ist diß nicht zu beklagen?

K.

Ja kindt/ das magst mit warheit sagen/

Schrecklich ist Ewig seyn verlohrn/

Besser wehr das man nie gebohrn.

Danck du dem lieben Gott dafür/

Der diß gibt zuerkennen dir.

Gelobet sey sein grosse gnad/

Die dir so weit gehülffen hat/

Das du diß also kanst ansehn

Vnd der Welt eitelkeit verstehn.

K.

Ja Gott sey ewig lob gesagt/

Der mich davon hat frey gemacht/ 
Vnd lassen sehn ein bessers liecht/

Darnach ich meinen wandel richt:

Laß fahren hin die blinde Welt/

Ihr wesen mir nicht mehr gefelt.

Ade Reichtumb/ ade wolleben/

Kein wahre frewd kont ihr mir geben/

Nach einem grössern gut ich tracht

Vnd streb/ mit bitten Tag und Nacht:

Nim dafür an kein irdisch gut/

Das Ewig mir gefallen thut:

Alle Weltlust ist Eitelkeit/

Vermischt mit leid/ geht mit der zeit/

Ohn Ende aber und ohn schmertzen

Ist die Göttliche freud im hertzen/

Vermehrt sich alle tag ohn klag/

Man findt darin kein leit noch plag/

Ein traurigs Hertz ist nicht dabey/

Denn Gottes freud macht sorgen frey/

Nimpt alles leit dem hertzen ab/

Darnach ich ein verlangen hab.

Ade du blinde Welt fahr hin/

Such dir nun leut nach deinem Sinn/

Hast itzo mehr an mir kein theil/

Zerbrochen ist dein strick und seil/

Ohn schaden bin ich dir entflogen/

Durch Gottes gnad heraus gezogen.

Iesu sey danck zu allen stunden/

Der dich in mir hat uberwunden/

Itzt werd ich deiner tück gewahr/

Dein taused list ich nun erfahr:

Eröffnet sind die augen mir/

O Gott mich ferner auch regier/

Richt meinen gang das ich nicht gleit/

Vnd steh mit hülff mir bey allzeit/

Sterck mich in allem guten Herr/

Vnd die noch irren auch bekehr. 
Ja kind das wird der Herr auch thun

Die sich ihm willig lassen nun/

Weils noch heist heut in dieser zeit/

Abstehn von aller Eitelheit/

Die Welt und ihre lüsten fliehen/

Vnd sich vom Herren lassen ziehen/

Den willen ihm zum Opffer geben/

Vnd seiner stimm aufmercken eben:

Dann gehorsam vors Opffer geht/

Als Samuel spricht, der Prophet.

In gnaden Gott von Abraham,

Den willen für die werck annam/

Abraham war danckbar dem Herrn/

26 Opffert ein Widder ihm zu ehrn.

Wer guts zu thun im willen hat/

Der tracht auch stets nach guter that/

Vnd der auch tracht darnach allzeit/

Findt wol dazu gelegenheit/

Das alles wirckt allein der Herr/

Ihm sey Ewig Lob/ Preiß und Ehr/

Von mir und dir mein kindt gesagt/

Sein gnad Er uberfliessend macht/

Mittheilt uns seine schätz und gaben/

Den kern der Heiligen Schrifft wir haben/

Nach unsers Hertzen wunsch und will/

Herrliche Bücher auch die füll/

Welche der Satan lange zeit/

$\mathrm{Zu}$ hindern unser Seelen freud

Hat verdrückt/ versteckt und verdeckt/

Die Leut vom lesen abgeschreckt/

Gott aber der sein warheit nicht

$\mathrm{Zu}$ grund lest gehn/ bringt sie ans Liecht/

Macht scheinend zu den letsten zeiten

Sein Liecht und weißheit allen Leuten/

Wer nicht will seyn muhtwillig blindt:

Dem ist geholffen liebes kindt. 
Zum Abendmahl ist eingeschlacht/

All dinge sind bereit gemacht/

Wir haben über nichts zuklagen/

Der Herr lest heuffich uns auftragen/

Sein Brünlein hat wasser die füll/

Wer nur hin gehn und schöpfen will.

Rufft nicht die weißheit draußen heut/

Vnd lest einladen zur Hochzeit?

Der Herr steht selbst wart mit verlangen/

Will uns als liebe Gäst empfangen/

Wann wir nur möchten fertig seyn/

Da fehlt es aber an allein/

Der mangel ist auf unser seiten/

Das wir uns wollen nicht bereiten/

Oder von Gott bereiten lassen.

Er lest uns nachgehn auf den gassen/

Durch seine außerwehlten knecht/

Getrewe Diener/ from/ gerecht/

Die Er zu Botten hat bestellt/

Uns zu beruffen von der Welt;

Ihnen geöffnet das verständtnüß/

Vnd gegeben der Schrifft erkäntnüß:

Die sie in diesen letsten Tagen/

Uns offenbahren und fürtragen/

Vnd alß getrewe fromme knecht

Ihr pfund auf Wucher legen recht/

Auch in den Weinberg grossen fleiß

Anwenden Gott zu lob und preiß/

Die soll man halten hoch und werth/

Weil sie von Gott selbst sind gelehrt/

Gesalbet mit dem öhl der freuden/

Können das böß vom guten scheyden/

Weil sie den schlüssel Davids haben/

Sind mit Weißheit und hohen gaben

Für allen andern hochgeziert/

Vnd vom Geist Gottes illustrirt/

Der sie zu allem guten treibt/

Vnd stets mit gnad bey ihnen bleibt. 
Gottes weißheit macht kluge Leut/

Der sie früh sucht findt sie beyzeit/

Darumb kindt dich zu ihnen kehr/

Gib ihren Worten gern gehör/

Liß ihre Schrifften auch dabey/

Vnd bitt Gott das er gnad verleih

$\mathrm{Zu}$ erkennen die warheit klar/

Die bißher ist verdunckelt gar/

Vnd bleibt noch heut zu tag verschwiegen

Von Welt gelehrten/ die mit lügen

Glossiren und falsch allegiren/

28 Viel Leut vom rechten weg abführen.

Für die soltu gewarnet seyn/

Nicht achten ihr ansehn und schein;

Sie haben Gott noch nie erkandt/

Sind auch von ihm nicht außgesandt/

Oder von seinem Geist gelehrt;

Hüth dich dafür sie sind verkehrt/

Las dich durch sie ja nicht verleiten.

K.

Mutter ich bitt wollt mirs andeuten/

Auff das ich mich müg huten wol/

Wobey ich sie recht kennen soll.

Ich weiß noch nicht zu unterscheiden

Was ich annehmen soll und meiden/

Vnd bey wem ich die warheit find/

Weil so vielerley Secten sind.

Wo sind die Gotts Gelehrten Leut/

Die von Gott haben die Weißheit/

$\mathrm{Zu}$ welchen ich soll halten mich?

Ein jede Sect berühmet sich

Die Warheit sey auff ihrer seit/

Rufft/ kommt zu uns/ hie ist Weißheit/

Wir/ wir sind von Gott ausgesandt/

Sein Wort zu machen euch bekandt:

Unser vocation ist recht/ 
Wir sind die wahren Gottes Knecht/

Unser Lehr müsset ihr beyfallen

Diese wort höret man von allen/

Lutheraner und Calvinisten/

Auch Flaccianer und Papisten/

Vnd ander viel ihrs gleichen mehr:

Ein jeder sagt in seiner Lehr

Sey die Göttliche warheit rein/

Bey andern nicht/ sie sinds allein/

Bey den man soll die weißheit suchen/

Die andern alle sie verfluchen/

Wissen sämptlich die Schrifft zu führen/

Können fein zierlich sie glossiren/

Drauß Disputirn und arguiren/

Ihr Lehr damit zu defendiren/

Nennen sich Christen all mit nahmen/

Halten doch einig nicht zusamen;

Viel sind Luthero zugethan/

Ander hangen Calvino an/

Achten ihn für den besten Lehrer/

Die andern all für Schrifft verkehrer.

Viel geben beyfall den Papisten,

Vnd halten sie für rechte Christen/

Rühmen sehr hoch ihr Lehr und leben;

Ander sich Flaccio ergeben/

Jederman erhebt sein Partey,

Dieser steht dem, der jenem bey/

Die Schrifft nach seiner meinung lenckt/

Diß alles mich von hertzen krenckt/

$\mathrm{Daß}$ ich auch bin in meinem sinn/

Fast zweiffelhafft gemacht hirin/

Weiß nicht wem ich mich soll verbinden/

$\mathrm{Da}$ ich müg rein die warheit finden;

Liebe Mutter sagt mirs/ bitt ich/

Welchem soll ich ergeben mich?

Vnd wem soll ich hirin beyfallen? 
Liebes kindt/ keinem von den allen/

Sie haben nicht die warheit rein/

Kommn nicht mit Christo uberein/

Sind alle noch von ihm sehr weit/

Weil sie leben in zanck und streit:

Dann da man streit/ ist Christus nicht/

Ein Christ nicht streit/ verdampt noch richt/

Das Christenthumb besteht in leiden/

Vnd nicht in streiten/ haddern/ neiden/

Man findet nicht bey Christi Freunden/

Das sie sich Hassen und anfeinden/

Sondern fried/ lieb und einigkeit/

30 Sanfftmuth/ gedult/ freundschafft ohn neit/

Das Fleisch Creutzigen sampt den lüsten/

Sind die zeichen der wahren Christen/

Wo du sie findest liebes kindt/

Alda die rechte Christen sind;

Sonst/ nirgend/ darauff gib nur acht/

Das leben Christi wolbetracht/

Wo man desselben gleicheit sicht/

Da ist er selbst/ dran zweiffel nicht/

Solcher glaube ist am gewisten.

Mutter so findt man wenig Christen/

Unter allen die ich genandt/

Dann mehr ist als zu viel bekandt/

Wie sie gelebt in zanck und streit

Lange jahr biß auff diese zeit/

Haben ein andr alß Hund gebissen/

Vnd wie die Wölfe sich zerrissen/

Als ihre Schrifften diß außweisen/

Das werck den Meister pflegt zupreisen/

Ich find allda kein einigs zeichen/

Das Iesu Christo möchte gleichen. 
Ja kindt das ist wahr allzumahl/

Man sieht es leider über all/

Das die von Hohen Schulen kommen/

Vnd von menschen Lehr eingenommen/

Sind mit stoltz und hoffart besessen/

Ehrsüchtig/ geitzig/ Gotts vergessen/

Häßig/ fräßig/ leicht zuentrüsten/

Unrein und folgen ihren lüsten,

Predign umb Gelt/ lieben die Welt/

Vnd thun nicht das Gott wolgefelt/

Sind vieler schand' und laster voll/

Darumb man solche meiden soll/

Sich nicht nach ihren nahmen nennen/

Oder zu ihrer Sect bekennen:

Dann mans an ihren früchten sicht/

Das sie sein Christi Jünger nicht/

Bey der lieb kennet man allein/

Spricht der Herr/ die mein Jünger seyn/

Wie man den baum kennt bey den früchten/

Darnach soll sich ein jeder richten/

Ein guter Baum bringt gute Frücht/

Ein fauler arge/ Christus spricht::

Nach seiner art ein jedes ist/

Von Dornen man kein Trauben liest/

Vnd von den Disteln keine Feigen/

Thut ferner uns der Herr anzeigen.

Das böse kan nichts gutes bringen/

Merck diß mein kindt/ in allen dingen:

Was gut ist/ kömpt von Gott allein/

Bey ihm wohnt alle Weißheit rein/

Darauß die rechte Lehr herfleußt/

Vnd sich in fromme hertzen geust;

Sie will nicht sein bey den verkehrten/

Welt-weisen/ klugen/ Schrifftgelehrten/

Die nach ansehn und hoheit trachten/

Vnd Christi Demuth weinig achten:

Solche finden die Weißheit nicht/

Die Gottlosen (als Syrach spricht) 
Vnd hoffertigen sie nicht sehn/

Die heuchler nichts von ihr verstehn/

Man findt sie nicht beym grösten hauffen/

Sie lest sich auch für Gelt nicht kauffen/

Kömpt nicht von Hohen Schulen her/

Als Welt-Weißheit und Menschen Lehr/

Dafür man sein Gelt gibt dahinn/

Vnd sucht wiederumb darauß gewinn.

Die thöricht/ toll und blinde Welt/

Meint das man Weißheit kaufft umb gelt/

Vnd nimt auch wieder geld dafür:

Gott lob/ ein bessers wissen wir/

Für geldt kaufft man kein Himlisch gaben/

32 Die Perl ligt nicht im koth vergraben.

Einn andern Acker muß man pflügen/

Nicht achten der Welt-weisen lügen,

Sie sind in ihrer witz verkehrt/

Keiner das Liecht zu sehn begehrt;

Ihnen geselt ihr krämmerey/

Sie haben vollen bauch dabey.

Also ein blinder fuhrt den blinden/

Ihr keiner wird die weißheit finden:

Dann die nichts wollen wissen mehr

Als menschen weißheit/ kunst und Lehr/

Sind reich und satt in ihrem sinn/

Vnd fahrn in ihrer witz dahinn:

Die sind und bleiben immer Thorn/

Vnd werden nimmer Newgeborn:

Die aber von Gott sind berührt/

Aus der blindtheit zum liecht geführt/

Vnd die Salbung empfangen haben/

Können verstehn die hohen gaben/

Dürffen nicht lernen von jemandt/

Weil ihnen alles ist bekandt/

Die Salbung lest sie jrren nicht/

Iohannes der Apostel spricht:

Dann die ist wahr, lehrt allerley

Ohn falsch/ kein lügen ist dabey. 
Kömpt aus den Geist von oben her/

Bringt allein mit die reine Lehr/

Die sich gantz kräfftiglich erweist:

Dann was aus diesem Brunnen fleust/

Vnd von dem Heilign Geist entspringt/

Gewaltig zum gemüth eindringt;

Wird vom Geist wieder angenommen/

Hat safft/ und schafft viel nutz und frommen.

Aber der Menschen Lehr verschwindt/

Kein krafft das hertz davon empfindt/

Geht wie sie kömpt/ bald wieder hinn/

Des lebens kern ist nicht darinn.

Wie offt bist wol zur Kirchen gangen?

Sag was hastu für nutz empfangen?

Welcher Pfaff sagt vom innern wort?

Hast von der Salbung auch gehort?

Von der Tauff mit dem Geist und fewr?

Wie ist doch diese Lehr so theur?

Keiner thut uns davon bericht/

Man hörts in ihren kirchen nicht/

Ihr keiner uns den Mosen lehrt/

Vnd die Propheten recht erklert:

Wer macht dir auch das Buch bekandt/

So Offenbarung wird genandt?

Wer ist von allen ders außlegt/

Vnd die Geheimnüß deutet recht?

Wer kennet doch den Geist der Schrifft?

Wer ist der seinen Sinn recht trifft?

Darinn die höchste weißheit steckt/

Das alles bleibt für uns verdeckt/

Keiner zum innern grund uns führt/

Vnd das Gemüth recht contentirt/

Nenn mir von allen Pfaffen einen

Ders thut/ ich weiß du findest keinen.

K. 
Mutter ich muß fürwar bekennen/

Ich weis euch keinen hie zu nennen/

Hör diß von ihnen nicht erkleren/

Sie lestern vielmehr die so lehren/

Verfluchen/ Ketzern und verjagen/

Mügen davon nicht hören sagen.

Das schelten auch nicht lassen kan

Der Pöbel und gemeine mann/

Nennet verführer und Phantasten,

Ja treumer und Enthusiasten,

Alle die von der Salbung lehren.

Kindt da muß man sich nicht ankehrn/

Der Pöbel nicht recht judicirt/

34 Weil man kein Weißheit bey ihm spürt/

Es ist auch Satans ahrt allzeit/

Das er das best zum ärgsten deut:

Dann da warheit am grösten ist/

Setzt er meist zu mit seiner list/

Vnd lest durch Neit von seinen schwätzern/

Sie auffs höhst schmehen und verketzern/

Das man sie setzen soll in zweiffel/

Ein solcher Bößwicht ist der Teuffel/

Er bleibt ein Feind der warheit immer/

Vnd wird auch mit ihr einig nimmer/

Dann Christus und der Belial

Können nicht stehn auff einem stall.

Die Pfaffen machen es allein/

Das so sehr lestert die gemein/

Weil sie sich nach dem Priester richt/

Was der Pfaff für recht helt und spricht/

Das muß recht sein/ wehrs noch so krum/

Also urtheilt der Pöbel thum/

Sich wie es Christo ist ergangen/

Was lohn Er von der Welt empfangen/

Vnd wie ihn die Gottlose rott 
Hat veracht/ verlacht und verspott/

Die Hohen-Priestr und Schrifftgelerten/

Deuten zum ärgsten/ und verkehrten

Alls was Er lehrt mit wort und that/

Klagten ihn an für ihren raht/

Vnd habn ihn endtlich lassen tödten;

So ists auch gangen den Propheten/

Aposteln und Euangelisten/

So gehts noch heut den frommen Christen/

Den Außerwehlten und Gerechten/

Gottes Botten/ getrewen knechten/

$\mathrm{Zu}$ uns gesant im gleichen auch/

Diß ist der Welt weiß und gebrauch.

Sie machts nicht anders frommen leuten/

Sieh dich nur umb zu diesen zeiten/

Keiner kan sich so grob versündign/

Als der die Warheit thut verkündign;

All ander werden angenommen/

Warheit aber ist nicht willkommen/

Die grösten stehn zusammen auf

Wieder sie/ hindern ihren lauff.

Pilatus und Herodes seind

Ein ander lang gewesen feind;

Sie würden aber Freund gar bald/

Da es wieder den Herren galt.

Diß man bey allen Secten findt/

$\mathrm{Ob}$ sie wol sonst uneinig sind/

Vnd gegn einander hefftig rasen/

Dennoch aus einem Munde blasen/

Wann es der warheit gelten soll.

Ja Brüderlich/ freundtlich und wol

Halten sie Einigkeit zusammen/

In dem sie die warheit verdammen:

Ders mit ihr helt und ihr beyfelt/

Ist veracht und ein spott der Welt/

Ja ein Fegopffer aller Leut/

Darauf jeder mit fingern deut.

Das muß man sich nicht irren lassen/ 
Wann man will gehn die rechte strassen.

Die Welt wirds keinem anders machen/

Darumb laß dich nur mit verlachen;

Acht nicht das sie dich schilt und richt/

Bleib bey der warheit zweiffel nicht/

Was von der Welt verdammet wird/

Das wird vom Herren absolvirt;

Wer der Welt freund seyn will merck diß/

Der ist Gotts feindt das ist gewiß/

Weh euch (Lucæ am sechsten steht)

Wann jedermann wol von euch redt/

Niemandt kan dienen recht zwey Herrn/

36 Zugleich Gott und den Teuffel Ehrn:

Den einen wird man liebn allein/

Vnd dem andern ungünstig seyn/

Spricht der Herr/ thut hiemit anzeigen/

Der sich ihm geben will zu eigen/

Muß sich der welt freundschafft entschlagen/

Vnd nach derselben nicht mehr fragen.

Wie weinig findt man liebes kindt/

Die dazu recht geneiget sind/

Wer ist der nicht Welt lieb nachstelt/

Vnd viel von ihrer freundschafft helt?

Wer will ihr gern den rücken kehrn/

Vnd geben sich gantz Gott dem Herrn?

Wer folget Christo willig nach/

Leidet gedültig schimpf und schmach?

Das schlechtste heufflein nur allein/

Stelt sich hier zu gantz willig ein:

Dann was unedel wird geacht/

Was schwach ist/ (der Apostel sagt)

Vnd das die Welt für thöricht helt/

Hat Gott zu seinem lob bestelt/

Dadurch will Er zu schanden machen

Das starck/ und der Welt witz verlachen.

Diß häufflein helt Gott lieb und werth/

Hie ist das Volck das weißheit lehrt/

Das Königliche Priesterthum/ 
Das Volck zu Gottes lob und ruhm/

Das heilig außerwehlt Geschlecht:

Hie findestu die Gottes knecht/

Davon der Prophet Daniel

Hat geweisagt mit worten hell/

Im zwölfften da er so andeut:

Viel werden kommn zur letzten zeit/

Grossen verstandt und Weißheit finden/

Der Schrifft geheimnüß zu entbinden/

Die von Gott schon sind aus gesandt/

Der blinden Welt noch unbekandt/

Stellen sich willig bey uns ein/

Ohn eusserlichen pracht und schein.

Ich zweiffel nicht du wirst sie kennen/

Man darff dir keinen nahmen nennen/

Betracht ihr Lehr/ sieh an ihr Leben

Vnd liß die Heilig Schrifft darneben/

So wirstu es in allem spühren

Wie fein sie damit concordiren:

Darumb halt dich zu diesem hauffen/

Da kan man ohn Gelt Weißheit kauffen

Vnd umbsonst haben Milch und Wein/

Stell dich nur beyzeit willig ein/

Sey gehorsam/ laß dich gern weisen/

Als dann wird dich die weißheit speisen/

Sich wie ein Mutter zu dir nahen/

Dich als ein junge Braut umbfahen

Vnd dir ein schöne kron auffsetzen/

Mit ihrer lieb dich stets ergetzen/

Sie wird groß Reichthumb dir zu bringen/

Lieb und such sie für allen dingen/

Lern der Welt Eitelheit verschmehen/

Den schmalen steig zum Himmel gehen/

Welt hoheit/ Ehr und ansehn fliehen/

Die Sinne im Gemüth einziehen/

So wirstu sie gewiß erlangen/

Mit dem Gebet mustu anfangen/

Durch bitten/ suchen und anklopffen/ 
Still seyn und harren/ auf Gott hoffen/

Wird uns die thür zur weißheit offen/

Merck diß so hast es recht getroffen/

Kan dißmahl dir nicht sagen mehr/

Ich mein es gut/ folg meiner lehr.

Ja Mütter ich danck euch dafür/

Den weg habt ihr gezeiget mir/

Vnd mich so Mütterlich gelert/

38 Auch schöne Bücher mir verehrt/

Drinn ich mich übe früh und spath/

Gott gebe mir sein Göttlich gnad/

Das alles bleib im hertzen kleben/

Vnd viel frucht bring in meinem leben/

Es ligt an iemandts wollen nicht

Oder lauffen/ Sanct Paulus spricht:

Sondern an Gotts barmhertzigkeit/

Da ruff und bitt ich umb allzeit/

Vnd halt mich an sein Zusag fest/

Er will und wird stets thun das best/

Weil ich mich nicht auf eigen sterck

Verlaß/ noch baw auf menschen werck/

Wie guth und heilig sie auch sein/

Sondern auf seine gnad allein/

Darauf wag ichs in Iesu Nahmen

Gott sterck den guten fürsatz/ Amen.

M.

Amen, mein kindt Gott stercke dich/

Das bitt täglich von hertzen ich/

Er mach uns beid in dieser zeit

Bereit/ das wir in Ewigkeit/

Hoch preisen mügen seinen Nahmen

Mit allen Außerwehlten/ Amen. 
Amen.

M.
I.
VV.
M.I.VV.D.VV.I.M.
VV.
I.
M.

Mein IESV VVirck Dein VVerck In Mir/

So will ich Ewig dancken Dir.

Ende. 


\section{Einfältige Warheit/ Kurtz/ slecht und recht beschrieben/}

Von Iohanne Osanaveri Theos. Amat.

Im Iulio, Anno:

$\mathrm{NaCh}$ Vnsers EInIgen gVten Herren IesV gebVrt aVß Der ReInen MarIa.

Einfältige Warheit/ So durch des Satans Neit/

Vnd streit der bösen Leut/ sehr ist verdunckelt heut/

Wird nun bald mit der zeit/ uberall außgebreitt/

Sich sehen lassen weit/ In großer herrlichkeit/

Ihr Außerwehlten seyt Ihrer zukunfft erfreut/

Steht auff/ macht' euch bereit/ und den Herrn Benedeyt.

S.

V.

$S$.

S.V.S.A.S.V.S.

S.

V.

S.

Singet Vnd Spielet Auff Seiten

Vnserm Salvatori,

Er kompt sehr Herrlich einreiten/

41 Voller krafft und Glory.

E.

VV.

S.

E.VV.S.S.S.VV.E.

S.

VV.

E.

Einfältige VVarheit Stellt Sich Schon VVieder Ein/

Gibt durch ihrs liechts klarheit 
Euch einen hellen schein/

Lasst sie in ew'r gemein

Euch lieb und willkomb seyn/

Das ist mein bitt allein.

An den Leser und Zuhörer

An den Gutwilligen frommen Leser und Warheit liebenden Zuhörer

I.

I.N.I.

I.

Im Namen Iesu.

Gottes gnad und barmhertzigkeit/

Durch Iesum Christum uns bereit/

Woll stets über uns walten/

In seiner warheit schirm und schutz/

Wieder all unser feinde trotz/

Leib/ Seel und Geist erhalten.

Diß bitt fur alle frommen ich/

Will ihnen auch hiemit freundlich/

Mein Büchlein offeriren,

Einfältige Warheit genant/

Gottes Geist öffne den verstandt/

Christlich zu judiciren.

Der fromme Leser nehm in acht/

Les' unbelacht und wol betracht/

Was ich hier hab geschrieben/

Folg' meiner Lehr/ geb' Gott die Ehr/

Vnd seh 'sich in der welt umbher/

Wird Er die warheit lieben/

So wird Er sie hie finden klar/

Die ihm wird zeigen offenbar/

$\mathrm{Da}$ heut in diesen zeiten/

Sehr mechtig ist der Antichrist,

Durch seiner Weltgelärten list/ 
Die leute zuverleiten/

Der schlechte Pöbel sonderlich/

43 (Daruber Gott erbarme sich)

Wie man in Dörffern spühret/

Wird durch derselben thun und Lehr/

Vom Liecht im finsternuß umbher/

Alß bey der Naß geführet.

Betrachtet nur der Pfaffen handel/

Wie gleich sie Christo sind im wandel/

So werdet ihrs befinden

Welche die rechte blinden sind/

Die (wie man im Matthreo findt)

Leiten die ander blinden.

Man siehts in Dörffern hin und wieder/

In Stäten/ Höfen/ auff und nieder/

Wie sie mit ihren Wercken

Verleugnen Christi Creutzes krafft/

Hie und auch in der Nachbarschafft/

Ist es scheinbar zu mercken.

Sonderlich wird im Bawern hauß/

Der Pfaffenschalck gelassen aus/

Vnd recht der Fuchs entdecket:

Die Pfaffen doch auff Fürsten häuser/

Vnd in der Stadt/ sind etwas weiser/

Haben ihn baß verstecket;

Weil ihr Zuhörer in gemein

Witziger dann die Bawern seyn/

Wissen sie sich zu schicken:

Fein Gravitet'sch sie ihr Person

Agiren/ und auch ihr Sermon

Mit Griechsch und Latein spicken:

Bleiben bey den Historjen nicht/

So gar schlecht alß im Dörff geschicht/

Können mehr ding einführen;

Die glaubens puncten baß umbrühren/

Scharff pro \& contra disputirn/

Die Ketzer condemniren:

Haben ihr thun mit kunst geziert/ 
Außbündig Logicam studirt/

Darumb sind sie in Ehrn;

Auff Hochzeiten und Gästereyen

Sitzen sie oben bey den Freyen-

Edlen- und großen Herren/

Bey welchen sie alß Hochgelehrt

Gehalten werden lieb und werth/

Dran haben sie gefallen.

Den ersten trunck/ den ersten schnitt/

Den ersten tritt haben sie mit

Im tantz/ fur andern allen.

Da man viel find't der blinden Gäst/

Ist der einäugig noch der best/

Soll billig sitzen oben.

Wer Noë Taub nicht haben kan/

Der muß den Raben nehmen an/

Die schwartze federn loben.

So müssen auch offt große Herrn

Annehmen/ und nothwendig ehrn

Der alten Schlangen sahmen/

Daß nur die Welt in ordnung bleib/

Es geht dennoch ein hinckends Weib

Besser alß funffzehn Lahmen.

Diß muß man sehn und lassen gehn/

Biß (Gott geb daß bald mög geschehn)

Sich ander offenbaren/

Mit Himmlischer Weißheit bekleidt:

Denn ander zeit bringt ander leut/

Das werden wir erfahren.

Ein ander Jahr bringt ander Haer/

Das ist ja wahr/ wir sehn es klar

An Menschen und an Thieren/

Also wird man/ weiß ich gewiß/

Auß der Schrifft zeugnuß/ (mercket diß)

Vollkommen weißheit spühren/

Vnd wird das stückwerck halten auff/

Wann die Weltwitz in ihrem lauff/

So starck nicht mehr Regieret/ 
$\mathrm{Ja} /$ wann sich werden stellen ein

Die nicht von und durch Menschen seyn

Erwehlet und Vociret,

Alß unser' Herren Titultrager/

Warheit verjager/ Frommen plager/

Die nach all ihren willen

Verkauffen ihr' blauw bunte brillen/

Schwatzen daher auß den Postillen/

Beutel und bauch zufüllen.

Diese herren von Hohenschulen/

Die mit Potiphars Haußfraw bulen;

Den langen Rock mit falten/

Ihr gelt/ kunst/ gunst/ authoritet/

Darin all ihr vertrawen steht/

Lieben und gern behalten/

Hat uns der Herr beschrieben recht/

Lest auch durch Paulum seinen Knecht/

Vns zeigen an darneben/

Zur trewen warnung daß man soll

Sich fursehn/ und ihr huten wol/

Nicht folgen ihrem leben.

Denn sie/ wie auß den früchten scheint/

Im hertzen seynd der warheit feindt/

Vnd wandlen nicht rechtschaffen/

Sind faule bäuch und Lehre schleuch/

Sie essen lecker/ schlaffen weich/

Beid Stät und auch Dörffpfaffen.

Die Mauß wie ihre Mutter ist/

Die Katz sie endlich beide frisst/

Pflegt man sprüchweiß zusagen/

Also auch diese herrn Pastorn/

Lateinsche/ Deutsche/ Den'sche thorn/

Einer arth Cappen tragen.

In Gottes weißheit sind sie blindt/

46 Ein blaß voll wind/ drinn Erbsen sind/

Acht ich gleich ihren sachen/

Darfs aber nicht/ wie ich wol kan/

Laut sagen dem gemeinen mann/ 
Möcht mir sonst ungunst machen.

Der Leser geb' nur fleißig acht/

Die Heilig Schrift dabey betracht/

So wird er/ will ich hoffen/

Wol sehn/ und im gewissen frey/

Bekennen daß die warheit sey

In diesem buch getroffen.

Die frommen sind hir nicht gemeynt/

Ich halt sie all' fur liebe freund/

Die sich im guten üben/

Christo nachfolgen schlecht und recht/

Als Kinder und getrewe Knecht/

Von Gottes Geist getrieben.

Ob wol derselben weinig seyn/

Vnd ihr heufflein noch ist sehr klein/

Weil AntiChrist regieret/

Durch sein Schrifftklugen über all/

Vnd von den grösten hat beyfall/

Wie man heut heuffig spühret.

Doch/ weil die Schrifft bezeuget diß/

Glaub ich und halte fur gewiß/

Daß nun bald werden kommen

Die sieben tausend die noch nie

Fur Baal gebeugt ihre knie/

Des freuwet euch ihr frommen.

Ew'r zahl wird werden groß gemacht/

Mein Leser nehmt die wort in acht/

Vnd habt mit mir verlangen/

Nach solcher zeit/ die nicht mehr weit/

Macht euch bereit in reinigkeit

Die warheit zu empfangen.

O lieber Gott/ Herr Zebaoth/

Mach' doch zu spott die lose Rott/

Löß die Fahn von der stangen/

Gib fried O Herr: Dem Satan wehr/

Sein list abkehr/ Daß er nicht mehr

Dein Volck beschwer/

Laß deine Warheit prangen. 
Von hertzen ich diß wunsch und bitt/

Befehl uns Gottes gnad hiemit/

In Iesu Christi Namen.

Herr Iesu komm/ Mach recht das krumm/

Das böse fromm/ Vnd klug das thumm/

Dar bitt' ich umb

$\mathrm{Zu}$ deinen Ehren/ Amen.

Jota.

\section{[Einfältige Warheit]}

Dieweil von vielen Jahren her

Groß streit und spaltung in der Lehr

Unter den Weltgelehrten

Gewesen/ und noch itzo ist;

So alles auß des Satans list/

Herkompt von den verkehrten:

Dadurch viel Leut sind Irr gemacht/

Hab' ich mit schmertzen offt betracht

Den unendlichen schaden/

Der auß solcher unruh' entsteht/

Daruber Gottes Zorn außgeht/

Welchen sie auff sich laden.

Darumb werd nun getrieben ich/

Kan länger nicht enthalten mich/

Allen gutwillig'n Leuten

Die in der Einfalt leben schlecht/

Zuzeigen an die Warheit recht/

Die in den letsten zeiten/

Nach der Propheten zeugnuß klar/

Der Welt soll werden offenbar/

48 Wann der Herr wird außgiessen

Ub'r alles fleisch von seinem Geist/

(Wie unß der Prophet Joël weist)

Dann wird die weißheit fließen/

Die weinig leuten ist bekant/

Drum wird sie in der Schrifft genant: 
Ein' weißheit die verborgen

Von der Welt her für männiglich/

Lesst vor der zeit nicht finden sich/

Vor abend kompt nicht morgen.

Denn gleich wie erstlich nach dem fall

Wie solches kund ist über all/

Die lügen vor der warheit/

Das unrecht vor dem recht her geht/

Der Belial vor Christo steht/

Die finsternuß vor klarheit.

Buchstab vor dem Geist/ wie ihr wisst/

Alß Johannes vor Jesu ist;

Die Figur vor dem Wesen;

Das fleischlich vorm geistlichen auch;

Vor dem Jacob der Esau rauch/

Wie in der Schrift wir lesen.

Also hat auch gleicher gestalt

Der AntiChrist itzt die gewalt/

Zeucht hoch hervor die seinen;

Hindert mit macht der weißheit lauff/

Lesst die warheit nicht kommen auff/

Sein thun soll allein scheinen:

Weißheit muß bey ihm thorheit seyn

Saur süß/ süß saur/ unrein das rein/

Die warheit nennt er lügen;

Die finsternuß sey liecht er spricht/

Kennet den Weg des Lebens nicht/

Kan nichts denn nur betriegen;

Wie auch sein' diener allesampt/

Durch welch' die warheit wird verdammt/

Sie sind Mörder und Diebe;

Gehn nicht zur rechten thür einher/

Folgen dem Herrn nicht in der Lehr/

Wandlen nicht in der Liebe.

Sie lauffen und sind nicht gesant/

Haben noch Christum nie erkant/

Sein stimm auch nicht gehöret;

Wie wol sie von ihm plaudern viel/ 
Kommen sie doch nicht recht zum ziel/

Ihr witz hat sie bethöret.

Die glärten sind (wie Luther sagt)

Die verkehrten/ Gott seys geklagt/

Nennen sich Evangelisch/

Vnd führen einen feinen schein/

Die grösten aber in gemein/

Sind gut Aristotelisch.

Das Heilig Evangelium

Ist ihnen viel zu schlecht und thum;

Im gleichen die Propheten

Vnd Moses/ reden gar zu schlecht/

Nicht Academisch/ wie man pflegt

Auff Universiteten. ${ }^{1}$

$\mathrm{Da} /$ spricht man/ ist geschicklichkeit/

Von dannen kommen kluge Leut/

Die der Welt können dienen/

Durch die man grosse ding verrichtt/

Sie sind die Bäume die man sicht

In allen Garten grünen.

Sie meinen/ schweren drauff ein Eydt/

Bey ihnen sey allein Weißheit

Vnd nirgend sonst zu finden/

Kein größer klugheit wird begehrt/

So gar ist ihr verstandt verkehrt/

Gott erbarm sich der blinden.

Wie lest sich das unwissend volck/

Von ihnen/ durch ein dunkel wolck/

50 So führen ab zur seiten.

O Ihr Elenden steht doch still/

Kehrt wieder/ hört wer hören will/

Lasst euch nicht mehr verleiten.

Ein blinder Mann dem blinden kan

Die rechte bahn nicht zeigen an;

1 Man findet wol Poeten.

Aber keine Propheten/

Auff Universiteten. 
Kenn't nicht sein eigen strassen.

Warumb woll't ihr dann lenger heut/

Im finstern euch alß blinde leut/

Von blinden leiten lassen?

Meint ihr daß das recht weißheit sey/

Wann man viel sprachen lernet frey/

Grichsch und Latein kan schwatzen?

Nein lieben leut/ das fehlet weit/

In sprachen steckt nicht die weißheit/

So müst ihr nicht zuplatzen:

Lasst euch dasselb nicht machen weiß/

Mercket nur auff die Schrifft mit fleiß/

Darin man klar kan finden;

Daß die reine weißheit des Herrn/

Bey der Seelen nicht will einkehrn

Die noch dienet der sünden.

Da man doch wol bey schand und sünd/

Viel sprachen und Welt-weißheit findt/

Hie und an allen orten.

Die weißheit Gottes aber lest

Sich finden nicht im sünden nest/

Steckt nicht in klugen worten/

Wenns darin zuerlangen wer'

Könt man durch der Welt-weisen lehr

Mit geldt leicht dazu kommen:

Nein/ nein/ die sach ist nicht so klar/

Sie ist nicht allen offenbar/

Wohnt allein bey den frommen.

Mir sind bekant beid fraw und Mann/

Die ich (wenns seyn soll) nennen kan/

Bey welchen vielmehr klarheit

In der erkenntnuß Jesu Christ/

(Gott sey gelobt) zufinden ist/

Ja größer geist und warheit/

Alß bey dem der sie lehren soll:

Vnd ob sie wissen besser wol/

Müssen sie dennoch schweigen/

Vnd hören zu in der Gemein/ 
Da der Pfaff hat das wort allein/

Als wen es wer sein eigen.

Wil nicht das jemand einred führ/

Viel weiniger ihn Reformier/

Es darff ihn keiner fragen;

Er allein redet was er will/

All' andern müssen schweigen still/

Niemand darff ihm einsagen/

Spricht er schon daß das krumm sey schlecht/

Das schwartze weiß/ es muß seyn recht/

Er bildets ein den Bauren/

Die nur auff ihren Priester sehn/

Vom recht und krumm nicht viel verstehn/

Ist diß nicht zubetrauren?

Hat es ein solch gelegenheit

Gehabt zu der Apostel zeit?

Hat Paulus so gelehret?

Nein/ das hab' ich gelesen nicht/

Viel anders hat er uns berichtt/

Niemands einred' gewehret.

Christus selbst hielte den gebrauch/

$\mathrm{Da}$ er in seiner Predigt auch

Gern hört antwort und fragen.

Welcher Pfaff folget ihm hierin?

Sehr weinig haben seinen Sinn/

Leider in diesen tagen.

Sanct Paulus will auch daß man soll/

Was uns gelehrt wird/ prüfen wol/

52 Die geister unterscheiden.

Ist einer der diß thut itzundt?

So bald es wird dem Pfaffen kunt/

Will Er ihn nicht mehr leiden.

Macht seinen nahmen sehr verhasst

Daß die Gemein ein argwohn fasst/

Fang't an auff ihn zuschelten/

Er wird von jedermann verachtt/

Ja/ der's mit ihm helt/ wird verlacht/

Muß seiner auch entgelten. 
Sol man die leut so machen fromb?

Heist das/ sagt mirs/ ich bitt darumb/

Die Schäflein Christi weiden?

Merket doch/ kan's ja sehn ein kindt/

$\mathrm{Daß}$ sie recht seelen-würger sind/

Vnd darumb auch zumeiden.

Es möcht nun einer fragen hir

Vnd alß zur antwort bringen für:

Sind sie nicht knecht des Herren/

Die das Alt und New Testament/

Fein fertig von anfang zum end

Wissen und darauß lehren?

$\mathrm{Ja} /$ ich laß sein/ (doch mercket recht)

Man findet gut' und böse knecht/

In einem hauß beysamen/

Viel leben weil ihr Herr ist auß

Im sauß und halten übel hauß/

Heissen doch knecht mit namen;

Wissen auch sein zusagen her/

Wie Gott schuff Himmel/ Erd und Meer/

Mit allem was darinnen;

Vnd wie die Schlang Ewam betrug

Als sie vermeint zu werden klug/

Sie uns anzeigen können.

Von der frucht aber/ die sie aß/

Sag't einer diß/ der ander das/

Sind noch darin nicht einig/

Ob es birn oder äpffel seyn/

Süß oder saur/ groß oder klein/

Meinen daran lieg weinig.

Ferner/ daß sie nach solcher speiß

Getrieben auß dem Paradeyß/

Daß Cain Habel erschlagen;

Wie er gezeichnet ward hernach.

Wer Henoch war/ was Lamech sprach/

Sie fein verstendlich sagen.

Mit der Welt schand und eitelkeit

Vnd der Sündflut zu Noë zeit/ 
Ja/ mit dem Regenbogen/

Auch mit dem Japhet/ Cham und Sem/

Mit dem alten Mathusalem/

Kommen sie auffgezogen:

$\mathrm{Ja} /$ sie verschweigen uns auch nicht/

Was Loth und Abraham verrichtt/

Vom Isaac darneben

Vnd seinem Bruder Ismaël/

Auch was der war fur ein gesell.

Item, was sich begeben

Mit Jacob und Esau/ die beid

Im Mutter leib geführet streit/

Daß Esau rauch geboren/

Der Jacob aber glatt und schon/

Vnd seiner Mutter liebster Sohn/

Von Gott auch außerkoren/

Imgleichen seine kinder all/

Vnd wie viel ihrer an der zahl/

Wissen sie herzunennen/

Rubens und Judæ missethat/

Auch was Dina begangen hat/

Geben sie zuerkennen.

Wie Joseph auch ward hingesant/

Verkaufft in der Egypter Landt/

54 Was ihm da wiederfahren;

Wie er des Königs traum gedeutt/

Vnd seines Vaters hauß erfreut

$\mathrm{Hab}$ in den teuren Jahren;

Das alles sie zu einer lehr

Historscher weiß zu schwatzen her

Vnd wissen auß zu streichen.

Noch eins ich schir vergessen hätt/

Vom Amram und von Jochebeth

Vnd ihrem Sohn imgleichen/

Daß er ein feines knäblein war/

Sein Mutter die heimlich gebahr

Ließ ihn zum wasser führen/

Darauß er doch errettet ward 
Durch Pharaonis tochter zart/

Indem sie ging spatzieren:

Sein leben und die wunderwerck/

Die er verrichtt durch Gottes stärck/

Wie Israël sich mehret/

Wie offt das Volck gesündigt hab/

Wie die straff sey gebeten $a b$

Durch Mosen/ der sie lehret.

Daß Josua nach ihm regiert/

Israël übern Jordan führt/

Fünff König auch gefangen/

Vnd seine feinde über eilt/

Den seinen Stät und Land außtheilt/

Vnd wie es Rahab gangen.

Auch von dem Helden Gideon/

Wissen sie zuerzehlen schon;

Vnd von der sterck Simsonis/

Dadurch er die Philister schlug;

Von Delila/ die ihn betrug:

Vom Tempel Salomonis/

Von Hanna die kein' kinder hatt/

Umb einen Sohn den Herren bath/

Den sie hernach im Tempel

Zum Priester in die Zuchtschul bracht/

Vnd damit allen ältern macht'

Ein trefflich gut Exempel.

Von Davids ehebruch/ mort/ hoffart/

Von Absoloms natur und arth/

Vnd wie er sey umbkommen/

Von allen König'n Israël

Vnd Judæ/ auch daß Jesabel

Ein boses end' genommen.

Solcher Historien viel mehr/

Die zulang hie zusetzen her/

Sie uns fein kündig machen/

Was dem und diesem hat geschadt/

Was der und die verrichtet hat/

Vnd was sonst mehr fur sachen 
Geschehn im Alten Testament.

Damit das stündlein lauff zum end/

Kommen sie auch zum Newen/

Von Iesu Christo unserm Herrn:

Sagen dem volck man soll ihn ehrn/

Sich seiner hertzlich frewen:

Weil Er zum Heyland außerkorn/

Darumb empfangen und geborn/

Uns bey Gott zuvertreten/

Das Er gelitten hat den todt/

Vnd uns errett auß aller noth;

Auch Gott fur uns gebeten.

Dadurch ist/ was Adam verrichtt/

Nun gantz vergeben und geschlichtt/

Unser sünd sind vergraben

In seinem grab. Nun werden wir

(Sprechen sie) Ewig fried hinfür

Darumb mit Gott auch haben.

Durch sein Erstehn am dritten tag/

Hat Er sein leyden/ pein und plag/

56 Auch den todt überwunden.

Ob wir gleich täglich sundig'n noch/

Wirds kein noth mit uns haben doch/

Der Teuffel ist gebunden/

Christus regiert nun überall/

Ist auffgefahrn ins Himmels sahl/

Weiß daß wir arme sünder

Sind/ die durch ihn so teur erkaufft/

Auff seinem Namen auch getaufft/

Liebt uns alß seine Kinder.

Diß soll'n wir alle glauben fest/

Vielmal im Jahr alß liebe Gäst/

$\mathrm{Zu}$ seinem tisch uns machen/

Uns zuerrinnern der wolthat/

So haben wir Sein ewig gnad/

Vnd stehn wol alle sachen.

In dem vertrawen soll man stehn/

Vnd fleißig mit zur Kirchen gehn/ 
Hören von Christi wercken/

Der alles fur uns außgerichtt/

Mehr haben wir sonst nötig nicht/

Damit soll man sich stärcken.

Doch etlich' unterm hauffen sein

Die gute Lehr mit führen ein

Auch zimllich ehrbar leben.

Nach ihrs verstands liecht und gesicht/

Vermahnen/ warnen/ thun bericht/

Straffen die sünd darneben/

Nach frommer Prediger gebühr.

Tragen der Schrifft geheimnüß für/

Nach der maß ihrer gaben.

Nil ultra vires, wie man spricht/

Die leut können weit reichen nicht/

Die kurtze armen haben.

Diese sind nicht gemeint hirin/

Ob sie wol suchen auch gewinn/

Soll mans doch ihnen günnen;

Wenn sie im guten willen stehn/

Auch fort in ihrer Einfalt gehn/

Vnd gern thun was sie können.

Mit solchen wirds noch gut endlich/

Wann's liecht lest heller sehen sich/

Weil sie nicht sind boßwillig.

Der die weißheit nur sucht mit fleiß/

Vnd sich nicht selbst lest duncken weiß/

Wird im erkenntnuß völlig.

Allein von dehnen sagt mein Buch

Die voll hoffart/ geitz und betrug

Nach eignem willen leben/

In fleisches lust und füllerey;

Trachten nach hoheit/ und darbey

Der warheit wiederstreben;

Derselben (leider) viel ich kenn/

Ihrn Namen aber hie nicht nenn/

Die zu ihr's lob's erhaltung/

Der warheit schein den Rücken kehrn/ 
Ihrn fortgang wehrn/ dawieder lehrn/

Vnd richten an viel spaltung.

Von diesen/ wie zuvor gedacht/

Wird Christi Creutzes krafft veracht/

Vnd sein Nahm sehr geschendet.

Sie rühmen ihn wol mit dem mund/

Vnd machen seine thaten kunt/

Sprechen/ Er habs vollendet:

In dem wort/ Consummatum est/

Hinder sich eitel freud er lest/

Hat uns auch fried versprochen:

Drum singt in dulci lubilo,

Et gaudete in Domino,

Die Helle ist zerbrochen:

Des Satans gewalt gantz zerstört:

Wer ist nun der nicht gerne hört

58 Die Schrifft also außlegen?

Wenn man betrachtet diß täglich/

So kan man Christi frewen sich/

Wie sie zureden pflegen.

Daß aber wir recht zum gebrauch

Seins lebens/ mögen kommen auch/

New Creaturen werden;

Vnd nach seiner vollkommenheit

Streben sollen in dieser zeit/

Tödten Adam auff Erden/

Vnd forschen fleißig nach dem Geist/

Auff welchen der Schrifft Buchstab weist/

Davon will keiner wissen/

Sie haltens fur unnötig ding

Daß man die zeit damit zubring/

Vnd darin sey geflissen;

Die wesentliche gegenwart

Christi in uns/ ist viel zuhart/

Mögens nicht hören nennen:

Das kompt daher/ sie sind ohn liecht/

Wissen seins fleisches ursprung nicht/

Wollen ihn auch nicht kennen. 
Der friedlich im land wohnen will

Muß mit der warheit halten still;

Sie mach't die leut nicht frischer:

Im Himmel ist des Herren sitz/

Wozu ist sein einwohnung nütz?

Sprechen die Finsterfischer.

Mit solcher red' sie viel verkehrn/

Verfolgen die/ die warheit lehrn/

Vnd warnen dafur trewlich/

Sagen: wie kan mit fleisch und bein/

Christus leibhafftig in uns seyn?

$\mathrm{O}$ wie grewlich abschewlich

Ist ihnen die heilsame Lehr/

Dem alten Adam viel zuschwer/

Sein todt ist drin verborgen!

Man muß nicht sagen viel vom Kreutz/

Vnd von der nachfolg/ keiner leidts/

Es bringt nur eitel sorgen.

Vom innern wort schweigt man gar still:

Den der davon laut reden will/

Nennen sie einen Kätzer.

In summa was dem fleisch weh' thut/

Das wollen sie nicht heissen gut/

Ja/ sprechen diese schwätzer:

Christi todt wird dadurch verachtt/

Vnd sein verdienst zu nicht gemacht/

Die Lehr ist sehr Phantastisch;

In unser Kirchen nicht bekant/

Kompt her von Brügg auß Niederland/

Lautt gar Enthusiastisch.

Sie werden bey uns allesampt/

In unser Kirchen auch verdampt/

Die solche Lehr einführen:

Wir bleiben schlecht bey unserm Recht/

Damit ist alles wiederlegt/

Mehr sie davon nicht rühren.

Weil die Propheten dunckel seyn/

Führen sie die gar selten ein. 
Geschicht' vor vielen Jahren

(Sprechen sie zum gemeinen Mann)

Gehn nur allein den Juden an/

Sind alt' verlegen wahren.

Die Offenbarung so zuletzt

Am end' der Bibel ist gesetzt/

Lassen sie auch hinstreichen;

Können darin nicht richten sich/

Ist ihnen viel zu wunderlich/

Den verstandt zu erreichen.

Sie sprechen: Solche sachen mag

Man wissen erst am Jüngsten tag/

$60 \mathrm{Biß}$ dahin soll man's spahren;

Gehören nicht in diese zeit/

Sie deuten auff die Ewigkeit/

Da werden wirs erfahren.

Man weiß doch ohn die ding/ so viel

$\mathrm{Alß}$ nötig ist zu unserm ziel/

Soll den kopff nicht mehr brechen/

Furwitzig leut/ die doch ohn das/

Gern wollen zuthun haben was/

Mögen sich damit schwächen.

Bey solchen worten bleibt es dann/

Damit ist friedlich jedermann/

Lest ihm die brill auffsetzen.

Meynt/ die nur fleißig wochentlich

Zur Kirchen lassen finden sich

Sind Seelig leut zuschätzen.

Die Priester man fur Heilign helt/

Sie schwatzen immer hin furs gelt/

Auch von Johann dem Täuffer/

Des alten Zachariæ Sohn/

Begehn sein Fest zierlich und schon/

Weil er ist der Vorläuffer.

Zeigen uns sein darneben an/

Was Peter Fischer fur ein mann/

Auch Paulus sey gewesen;

Vnd daß Petrus mit einem Eydt/ 
Christum verleugnet auß schwacheit/

Sie auß der Schrifft herlesen.

Daß Paulus da er Saulus war/

Verfolget hab der Christen schar/

Vnd sie tractiert unbillig/

Im Eyfer/ doch auß unverstand:

Diß aber sagen sie niemand

Daß sie es thun muthwillig/

Wissentlich/ wieder Christi Lehr/

$\mathrm{Zu}$ erhalten ihr eigen Ehr;

Gott laß sie es erkennen/

Geb ihnen drüber rew und leit/

Auff daß sie nicht in dieser zeit

Mehr fromme hertzen trennen/

Vnd sich dadurch in Ewig Noth

Selbst stürtzen wie Ischarioth:

Der/ wie sie auch erkleren/

Auß Neit und geitz/ umb schlechte ding/

Alß nemlich dreysig Silberling/

Schändlich verriet den Herren.

Daß ferner auch die Jünger all/

Verließen Ihn in solchem fall/

Vnd worden wanckelmütig.

Daß Magdalen erstlich gesehn

Den Herrn bey ihr im Garten stehn/

Der zu ihr sprach sehr gütig.

Auch führen sie ein gleicher maß

$\mathrm{Daß}$ da Lucas und Cleophas

Nach Emahuß hingingen

Der Herr sich ihnen offenbart/

Freundtlich mit seiner gegenwart/

Dadurch sie trost empfingen.

Von Johanna und Salome/

Maria/ dem Weib Cleophæ/

Vnd andern frawen Ehrlich/

Von ihrer Salb köstlich und gut/

Von Thomæ zwillings zweiffelmuth/

Sagen sie uns auch jährlich. 
$\mathrm{Ja} /$ was fur Leut gewesen seyn

Iacobus groß und Jacob klein/

Matthæus und Zachæus.

Philippus und sein Mitgesell/

Der schlecht und recht Nathanaël/

Vnd der blind Barthimæus.

Mehr die nicht werden hie genannt/

Doch auß der Schrifft uns sind bekant/

62 Dergleichen kindsche dingen;

Alles nach dem Buchstaben hin/

Weil sie nicht sehn des Geistes sinn/

Sie auff der Cantzel bringen;

Sonderlich wenn in ihr gemein/

Kein Junckern gegenwertig seyn:

Wo aber die verhanden/

Da sind die Pfaffen ander Leut/

Bringen herfür von nah und weit/

Geschicht auß frembden Landen/

Die in den büchern finden wir/

Vnd ich nicht all kan setzen hir/

Von hohen Potentaten/

Wie sie geführt ihr Regiment/

Treffliche Krieg/ wie excellent/

Ihr anschläg sind gerathen.

Der Alten Römer tapfferkeit/

Die so berühmt ist weit und breit/

Sie auch fein appliciren;

Wie es gefellt den großen Herrn/

Vnd andern/ die ohn das doch gern

Kriegs-wesen approbiren.

So schicken sie sich in die zeit/

Vnd wissen nach gelegenheit

Zierlich an tag zugeben/

Daß sie gelernet recht die kunst/

Dadurch man kan erhalten gunst/

Erlangen gelt darneben.

Zu dem End streckt sich ihr Sermon/

Das heist alß dann gepredigt schon/ 
Die Lehr ist gut gewesen.

Ey/ spricht man dann/ wie zierlich kan

Dieser Mann alles bringen an/

Wie wol ist er belesen.

Damit gehn sie zur Kirchen auß/

Folgen dem Pfaffen ins Trinckhauß/

Den Leib auch zuversorgen.

Weil ihre Seel bekommen satt/

Genug Vorrath zu zehren hat/

Vier tag' nach übermorgen.

Dann Predigt wieder Herr Johann/

Da hat das Weib den rechten Mann/

Der topff sein'n Deckel funden/

Sein rechte Schäflein auch der hirt/

Sehr liebe Gäst' sind/ da der Wirt

Mit ligt oben und unden.

So ist versorget die Gemein/

Christo der weg bereitet fein/

So stercket man die Müden.

Hat nur der Pfaff den Beutel voll/

Von seinen Schafen milch und woll/

So ist er wol zufrieden:

Bekümmert weinig sich darumb/

$\mathrm{Ob}$ die Zuhörer werden fromb/

Wenn sie ihm nur vertrawen;

Vnd glauben alles was er spricht

Schlecht hin/ und förschen weiter nicht/

Das heist die Kirche bawen.

So soll man der Gemein vorstehn/

Lassen den Bock im garten gehn/

Die Reben auffubinden.

Die Butter ist verwahret fein/

Wenn die Katzen ihr hüter seyn.

O Gott erleucht die blinden!

War es so zu Sanct Pauli zeit?

Lehren so Gottes Diener heut?

O ô Ihr blinden Leiter!

Mietling/ fur gelt gedingte knecht/ 
Der Schlangen arth nennt man euch recht/

Ja/ des Satans vorreiter.

Wenn ihr die Schaf allein mögt schern/

So last ihr gern die Schwein dem Herrn/

64 Wie will euch diß bekommen?

Wenn unser Heyland und Ertzhirt

Sich zum gericht einstellen wird/

$\mathrm{Zu}$ lohnen böß und frommen?

Wollt doch in ewr gewissen gehn/

Zusehn ob ihr da könnt bestehn/

Wann Christus in den seinen/

Ansehnlich voller krafft und stärck/

$\mathrm{Zu}$ prüfen aller Menschen werck/

Gantz schrecklich wird erscheinen.

Viel anders alß ihr der Gemein

Fürpredigt und euch bildet ein/

Wird Er sein Reich einnehmen.

Warlich ihr werdt zur selben zeit

Fur seiner Heilign Herrlichkeit/

Euch hertzlich müssen schemen.

Diß schreibt man euch/ ja singt und sagt/

Wird doch verlacht/ Gott seys geklagt/

Drumb wird euch Gott verblenden

Von tag zu tagn/ je mehr und mehr/

$\mathrm{Zu}$ schanden machen ewer Lehr/

Euch kräfftig Irrthum senden.

Ihr Schäflein aber/ die ihr seyt

Weit abgeleitt von rechter weid/

Erkennet ewern schaden.

Mercket auff ewers hirtten stimm/

Verlasst den Mietling kehret umb/

Heut/ heut/ in zeit der gnaden.

Suchet Weißheit/ ergreifft verstandt/

Gott hat sein Diener außgesant/

Durch die Er euch will lehren/

Vnd ewer Irrweg' machen kunt/

Sie führen euch zum rechten grundt/

Haltet sie doch in Ehren. 
Auß Gottes gunst fleust her ihr kunst/

Die sie euch theilen mit umbsonst/

Als der Herr hat befohlen.

Suchen darinn nicht ihrn gewinn/

Kein Opffer durfft ihr bringen hin/

Ihr Jahr-gelt sie nicht holen.

Erkennt des Herren lieb und trew/

Thut ware buß/ habt hertzlich rew;

Dancket Gott allenthalben/

Der Euch so gern erleuchten will

Mit seinem Liecht/ drumb haltet still/

Lasst euch die augen salben.

Daß Ihr mögt sehn den Morgenstern/

Vnd finden in der Schrifft den kern/

Der euch noch ist verborgen/

Kompt doch herzu und seht wie schon

Der glantz herfur bricht auß Zion/

Wartet nicht biß auff morgen.

Ein finster tag kompt bald hernach/

Ein dunckel wolck mit Weh und Ach/

Lasst euch in zeit doch sagen:

Liebet Weißheit/ wandelt im Liecht/

Weil ihrs noch habt/ verseumt euch nicht/

Lang warten bringt wehklagen.

Itzt ist das Liecht euch angesteckt/

Die Weißheit Gottes klar entdeckt/

Steht draußen auff der Gassen/

Weh euch in alle Ewigkeit/

So ihr nicht heut in dieser zeit/

Sie wollt zu euch einlassen.

Gewarnet seyt ihr mannigmal/

Von Gottes kindern überall

Vermahnt/ euch zu bekehren/

Die Warheit ist euch kunt gemacht/

Ihr aber habt sie außgelacht/

Bißher nicht wollen hören.

Es wird euch gehn/ ihr werdets sehn/

$\mathrm{Al} ß$ in der nachbarschafft geschehn/ 
66 Lasst ihr euch nicht erweichen.

Exempel habt fur augen ihr/

Die Gott zur warnung stellet für/

Auch lässt Er sehn viel zeichen.

Wie fest euch ewer Pfaffen auch

Beystehn/ nach der Mietling gebrauch/

Wann sie den Wolff sehn kommen/

Wie sie verlauffen Röck und Huet/

Lassen im stich den guten Muth/

Das hat man wol vernommen.

Seyt nicht mehr blindt/ taub/ stumm und thumm/

Kehret doch umb und werdet fromb/

Verlasst Secten und Rotten;

Die allein suchen ihrn gewinn/

Vnd immerhin in ihrem sinn/

Der Botten Gottes spotten.

\section{Schreiben von I.O.T.A. an die Herrn Titultrager von Hohen Schulen/}

\section{M.F.I. und M.F.D.P.}

Auff das Büchlein wieder Nicol. Te.

O Ihr verkehrte Pfaffenknecht/

Fritz Hannsen und Fritz Dame/

O Schlangen art/ Ottern geschlecht/

Ja Satans eigner same/

Wie dürfft ihr euch so keck und frey

Der warheit wiedersetzen?

Vnd mit ewer Schulfuchserey/

67 So mannig Seel verletzen?

Dem g'meinen Mann nehmt ihr das liecht/

Setzt ihm auff ewer brillen/

Bildt ihm ein er hab sein gesicht/

Klar auß ewren Postillen.

Weh' euch die ihr das recht verkehrt/

$\mathrm{Daß}$ gute böse nennet/

Daß ihr nicht seyt von Gott gelehrt/ 
Man klar dabey erkennet.

Vnd welches geistes kinder ihr/

Ist scheinbar hie zusehen.

Das best in ewrem buch ich spühr/

Ist schelten/ lästern/ schmehen/

Die Schrifft verkehren freventlich/

Das Geistlich fleischlich deuten.

Blindt seyt ihr warlich/ das sag' ich/

Wollt dennoch ander leiten.

Habt in euch nicht das ware liecht/

Versteht nicht Geistlich sachen.

Fleischlich ihr seyt/ fleischlich ihr richtt/

Ewr thorheit muß man lachen.

In den Schulen habt ihr studirt,

Das kan niemand verneinen/

Da kein heilger gefunden wird/

Noch soll man von euch meynen/

Daß ihr die heiligsten allein/

Die Gott ja hat geschaffen;

Betriegt die leut mit ewerm schein/

O Ihr fleischliche Pfaffen.

Wer hat zu lehren euch gesant?

Wer hat euch promoviret?

Hats Gott gethan? ey seyts bekant/

Wer hat euch doch vociret?

Mich dünckt furwar ihr seyt vexiert/

Es merckens schon die kinder/

$\mathrm{Daß}$ ein Blinder den Blinden führt/

Ein Sünder lehrt die Sünder.

Sagt mir/ das fragen steht ja frey/

Solt von den Hohen schulen/

Da man lernet all' Büberey/

Gassaten gehn und Bulen/

Fressen/ sauffen/ dergleichen mehr/

Das ihr nicht dürfft bekennen/

Die ware Weißheit kommen her/

Nach der ihr euch lasst nennen:

Ehrwürdig/ hoch- und wolgelehrt? 
Ja wollohn allen zweiffel:

Wer das glaubet der ist verkehrt/

Es bildt euch ein der Teuffel;

Der Pfaffen frißt/ Soldaten scheißt/

Des geist hat euch gesalbet/

Denn wie die Kuh'/ daß sprich wort heist/

Leufft/ also sie auch kalbet.

Der Probst gibt genug zu verstehn/

$\mathrm{Daß}$ er fleißig gelesen;

Man kans am lincken aug ihm sehn/

Wie andächtig er g'wesen;

Hat auch des nachts wol bey der leucht

Nicht geschont seiner augen/

Man sichts sie sind ihm itzt noch feucht/

Solt Er dennoch nicht taugen?

Ohn zweiffel ja/ wer sagt das nicht?

Keiner kan es verneinen/

Daß die Welt nach dem ansehn richtt/

Die nur fein prächtig scheinen

Im langen Priesterlichen kleid/

Haben ein groß ansehen:

Wann sie in ihrer Ehrbarkeit/

Da auff dem Höltzlein stehen.

Den schalck bedeckt ihr Pfaffen Rock/

Fein artig sie agiren

Wann sie da stehn im holen block/

69 Das Maul den leuten schmieren/

Lästern ohn schew die Warheit frey/

Keiner darff wiedersprechen:

Er mag auch gleich seyn wer er sey/

Sie wissens bald zurechen:

Die Furnehmsten auff ihrer seit/

Willig auff ihr begehren

Sind/ zu vertreiben solche Leut/

Die gutes thun und lehren:

Auff daß man ihre thorheit nicht

Zum bösen möge deuten;

Oder ihr schalckheit komm' ans liecht/ 
Vnd kunt werd' allen leuten.

Aber ihr Herren thut gemach/

Man muß es dennoch wagen/

$\mathrm{Zu}$ straffen euch in dieser sach/

Vnd frey die warheit sagen.

$\mathrm{Ja} /$ soltens auch die kinder thun/

Das Weiber-volck imgleichen/

So muß es doch gesagt seyn nun/

Der Warheit müst ihr weichen;

Gebt euch gutwillig nur darein/

Sie wird doch Meister bleiben/

Und bald durch ihren hellen schein

Ew'r finsternuß vertreiben/

Vnd euch zu schanden machen gar/

Mit ewerm Kuckuck Meyer.

Sein Kram hat auch kein gute wahr/

Nur faul und stinckend Eyer;

Die er im Eyderstetschen land

Vermeynte zu verkauffen/

Vnd do er nicht sein' Kauff-leut fand/

Must ers wiedrumb verlauffen.

Mit dem Kuckuck er fliegen kam/

Ließ sich in Tönning nieder/

Auch mit dem Kuckuck abscheidt nam/

Floh hinweg mit ihm wieder.

Solten diese recht' Priester seyn

Vnd von Gott ordiniret/

Die so verlauffen ihr gemein?

Heist das nicht leut vexieret?

Noch soll glauben ein jedermann/

Sie seyn des Herrn Gesanten:

Wer sie nicht will dafursehn an/

Sondern nennt sie Vaganten/

Die lauffen kommen ungesant/

Denselben sie abschaffen;

Damit friedlich in Stät und Land

Bleiben die Herrn Gotts affen.

Habt guten muth ein' kleine zeit/ 
Er wird euch bald vergehen;

Die ihr so sehr habt außgeschreit/

Werden dennoch bestehen.

Es helffet ewr vertreiben nicht

Daß ihr sie abgesondert.

Warheit kompt doch endlich ans liecht/

Wird dadurch nicht gemindert.

Gott steht allzeit auff ihrer seit/

Lesst sie nicht untertrücken:

Weiß sie/ wens euch wer noch so leit/

Mit g'walt herfur zuzücken.

Er furdert der gerechten sach/

Die ihr meynt zuvertreiben;

Ewr thun muß durch sie an den tag/

Kan nicht verborgen bleiben.

Heran ihr Pfaffen all heran/

Lasst euch zur Schulen führen/

Von Herrn Tetinge und Lohmann/

Lernet weißheit studiren/

Vnd gebt euch unter Gotts gewalt/

In ihrer Lehr beyzeiten;

Sonst wird sich ewer ansehn bald

71 Verlieren bey den Leuten.

Diese beid werden euch gewiß

Also Examiniren/

Daß jedermann/ glaubet mir diß/

Ewern betrug wird spühren.

Einer zum andern sagen dann

In den bald künfftign tagen/

Seht/ lieber seht die Pfaffen an/

Wie sie itzt sind geschlagen.

Ihr eigen ruth hat sie verletzt/

Die sie andern gebunden:

Ihr eigen Schwertt das sie gewetzt/

Hat sie gantz überwunden:

In die grub sie gefallen sind

Die sie andern gegraben.

Gott lob/ itzt sicht/ der nicht ist blindt/ 
Wie sie gelehret haben.

Dann wird Ew'r gantze Priesterschafft

Fallen üb'r einen hauffen/

Verliehren ihr ansehn und krafft/

Den Pfaffen Rock verlauffen/

So wollen frölich singen wir

Vnd unserm Gott dancksagen/

Wenn überwunden ist das thier/

Das fromme pflegt zuplagen.

Hallelujah in sußem thon/

Der Herz sey hochgelobet:

Da liegt die Hur zu Babylon/

Die so sehr hat getobet.

Der Herr bekehr noch in der zeit/

Wo bessrung ist zu hoffen;

Weil noch seine Barmhertzigkeit

Vnd gnadenthür steht offen.

Gott laß euch ewer blintheit sehn/

Eröffne ewer augen:

Geb' euch ew'r thorheit zu verstehn/

So ihr begehrt zu taugen:

Wünsch und bitt diß von hertzen ich.

Wo nicht/ so ist verhanden

Der bald an euch wird rächen sich/

Vnd machen euch zuschanden:

Wird sehen lassen seine macht/

Im zorn euch bald zerstören.

Diß ist gesagt/ es nehm' in acht/

Der Ohren hat zu hören. 


$$
\begin{gathered}
\text { VV. } \\
\text { I. } \\
\text { Z. } \\
\text { H. } \\
\text { B. } \\
\text { E. } \\
\text { B. } \\
\text { VV.I.Z.H.B.E.B.V.B.E.B.H.Z.I.VV. }
\end{gathered}
$$

B.

E.

B.

$\mathrm{H}$.

$\mathrm{Z}$.

I.

VV.

VVeil Ihr Zeit Habt Bekennt Ewer Boßheit/

73 Vnd Bessert Euch Bald/ Hohe Zeit Ists VVarlich.

\section{Peer/ Nielß sin Söhn tho Westerwyck/}

\section{Kam' dit tho handen gantz fründtlick}

Leve Peer Nielßon latet my weten/

Mög' gy so gern Blickhems Botter eten?

Wille gy hebben noch ein halff punt mehr/

So sendet den Linnen Büdel wedder her/

Edder tho Juwes Organisten Fruw/

Ick gaff er de Botter darin/ nich Juw:

Doch wiel jy so verleckert darup wehrn

Günne ich se Juw ock van herten gern.

Leet ist my dat dar nich ein gantz punt was.

Wo recht idel wol komt et Juw tho paß/

Dat gy so fry van uns möget halen/

Andern mött gy solck wahr betalen?

De Wedwen/ Weysen un Frembden dwingen/

Ehnen affnehmen/ nist wedder bringen/ 
Iß sulckes der Westerwycker wise?

So iß et ein arth de ick nich prise.

Gy hebben den Breef mit underschreven

Den my Hinrich Hanßen hefft gegeven/

Van wegen des wolgebarnen Herren/

Dat my nemand schall molesteren.

Ick kan bewisen mit Juw egen hant;

Wo gy wort holden/ dat iß Juw bekant.

Doch wat gy dhon/ dat moth syn wolgedahn;

Ick wilt ock nu so darby laten stahn.

Gott lath Juw de Botter wol bekamen/

Etet Brot tho/ denn dat hört thosamen.

Botter schlicken ohn Brot/ iß nicht gesunt/

Dat sach ick lest an minen olden Hunt;

De nam ock ein stück Botter van der banck/

Vnd fratt ohn Brot/ de arm schelm ward so kranck.

Wiel nu ein Hunt dit nicht kan verdragen/

De doch sonst hefft einen starcken magen/

Wat scholde denn ein Börger edder Buhr/

Alß gy/ de nich so starck iß van natur?

Dir hebb' ick willen thor warnung schriven/

Dat gy mögen in gesuntheit bliven.

Störve gy henn/ so trurd de gantze Stadt/

O welck ein jammer un schade wehr dat!

Darum wahrt Juw/ seht wol tho wat gy dhon/

Vp dat gy nehn Naruw kriget tho lohn.

Iß hir up Blickhem woll wat leckers mehr/

Dat gy begehren schicket einen her;

Lath halen dorch Johann Höen Juwen knecht

All' unse Eyer/ de hir sind gelecht.

Hir gahn kücken gröter alß ein Heister/

De recht sind vor sölcken Borgemeister.

Wenn wilt Gott kompt Herr Jurgen Guldenstern/

Wert sin gnad Juw den Wien dar tho vor ehrn/

Vnd bethalig vör de Botter halen.

Dissem Herren syt hirmit befahlen.

Den 10. 7bris an. 1633. 
A.O.H. 
Das Buch Ruth/ In Teutsche Reimen gestellet und ans Liecht

\section{gebracht}

Durch Annam Ovenam Hoyers.

Im Jahr nach Christi Geburt

LIeber Herr IesV koM zV Vns heVt/

HeLff Vns aVs nöten/ Denn es Ist zeIt.

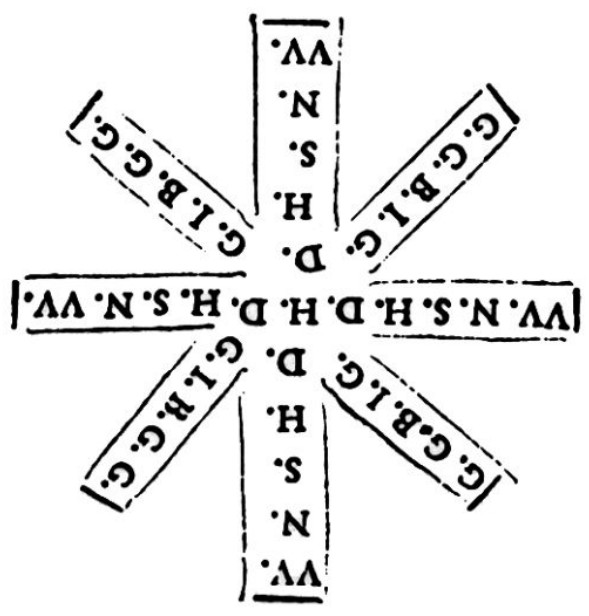

VVeinet Nicht Sondern Harret Der Hülff Des Herrn/

Seit Nicht VVanckelmütig/

Glaubet/ Geduldet/ Betet immer/ Gott Helfft Gern/

Ist Barmhertzig/ Gnedig/ Gütig.

A.

$\mathrm{T}$.

A.T.F.T.A.

$\mathrm{T}$.

A.

Auff Trawrigkeit Folgt Trost Allzeit/

Des frew ich mich in allem Leydt/

GOtt sey gelobt in Ewigkeit. 
N.H.

C.M.

A.C.

N.C.A.F.A.C.N.H.M.C.T.C.M.H.

A.C.

C.M.

N.H.

Nimbs Creutz Auff Folg Allzeit Christo Nach/

$L \mathrm{a}$ dich im guten Lauff nicht hindern Weltlich Sach.

Hilff Mein Creutz Tragen Christe Mein Herr/

Mit dir wil ichs wagen/ so wird mirs nicht zu schwer.

VV.
G.
VV.
VV.G.VV.S.VV.G.VV.
VV.
G.
VV.

VVen Gott VVill So VVirds Gut VVerden/

78 Bitt daß Sein Will gescheh auff Erden.

\section{[Widmung]}

Der Durchleuchtigsten/ Grosmächtigsten Fürstinnen und Frawen/ Frawen Mariae Eleonoræ, Der Schweden/ Gothen und Wenden Königin/ Groß-Fürstin in Finland/ Hertzogin zu Ehesten und Carelen/ Frawen zu Ingermanlandt/ Hochgebornen auß Churfürstlichem Stamm Brandenburg/ in Preussen/zu Gülich/ Cleve und Bergen/ auch zu Stättin Pommern/ der Cassuben und Wenden/ zu Crossen und Jägerndorff in Schlesien Hertzogin/ Burggräfin zu Nürnberg/ Fürstin zu Rügen/ Gräffin zu der Marck und Ravensburg/ Frawen zu Ravenstein/ etc. Witwen/

Meiner gnädigsten Königin. 
Dvrchleuchtigst/ Gnädig Königin/

Vnd Hochgeborne Groß-Fürstin/

Gott frist Ewr Maystät Leben/

Vnd bewar sie für allem Leidt/

Geb auch in ihrer Trawrigkeit

Gedult und trost darneben.

Diß wünsch und bitt demütigst ich/

Der fromme Gott erhöre mich/

Vnd nem mein Bitt an gnädig/

Stärck unser Gnädigst Königin/

Tröst aller Trawrig'n Hertz und Sinn/

Vnd mach's von sorgen ledig.

$\mathrm{O}$ wolte Gott wir möchten sehen

In allen dingen die geschehen

Allein auff seinen Willen/

Nach dem Er alles wol regirt/

Vnd uns zum besten ordinirt/

Diß würd den kummer stillen/

Vnd unser hertzen schmertzen lindern:

Aber wir gleichen sehr den Kindern

Die sich stellen unbändig/

Wenns nicht nach ihrem willen geht/

Gleich wie ein Kind das nichts versteht/

Meint doch es sey verständig/

Des Vatters thun für unnütz helt/

Sein eigen Weiß jhm wol gefelt/

Die acht es auch viel besser.

Es meint der Vater sey jhm feindt/

Weiß nicht daß ers so trewlich meynt

Wann er jhm nimbt das Messer.

Sieht's auch daß er die Blümelein

Abbricht/ zerstost und macht sie ein/

Es hat dran kein behagen/

Meint gäntzlich er verderb die Sachen/

Will man soll davon Kräntzlein machen/

Sie Hänslein lassen tragen.

Gedenckt der Vater sey verworn/

Verricht all diese ding' im zorn/ 
Es kan nicht anders glauben/

Dieweil es nicht kennt sein intent,

Auch kans nicht sehn zu welchem End

Er im Weinberg die Trauben

Abreist und in die Kelter trägt/

80 Es wird dadurch hertzlich bewegt/

Darüber sehr unwillig;

Greint/ weint und meynt es sey nicht fein/

Mit solchen schönen Weinbeerlein

$\mathrm{Zu}$ handeln so unbillig.

Der kleine Knab kans nicht verstehn/

Kein End-ursach im wercke sehn/

Warumb man diesen süssen

Vnd edlen Träublein also thut/

Ihn dünckt es sey ein ubermuht/

Sie tretten mit den Füssen/

Vnd springen so gar trotzig drauff/

Er will man soll sie heben auff/

Halten sie werth und lieber.

Der Vater lacht des Sons thorheit/

Spricht: Liebes Kind erwart der zeit/

Betrüb dich nicht hierüber/

Ob du wol itzt nicht weist warumb

Ich solches thu/ bist jung und thumb/

Vnd tadelst meine Wercke;

Wirst doch hernach anders sehn/

Vnd besser alle ding verstehn/

Darumb sey still und mercke:

Es steckt in diesem süssen safft

Verborgen ein sehr edle krafft/

Die viel Jahr gut kan bleiben/

Wenn man damit so procedirt,

Nichts guts sonst auß den trauben wird/

Drumb muß ich sie zerreiben.

Wenn nun das Kindlein kompt zu Jahrn/

Ist in den dingen mehr erfahrn/

So kan es erstlich mercken/

Worzu diß sey gewesen nütz/ 
Es erkent seines Vatern witz/

Preist ihn in seinen wercken.

Also wirds uns auch endlich gehn/

Wenn wir nur fest in hoffnung stehn/

Gott woll gedult verleyen.

Ist schon der Anfang wunderlich/

Wird doch am End/ des frew ich mich/

Alles sehr wol gedeyen.

Denn Gottes Will ist doch der best/

In dem vertrawen bleib ich fest.

Die Sonn wird wider scheinen/

Nach der duncklen betrübten zeit.

Auff trawren hat Gott frewd bereitt/

Drumb soll man nicht mehr weinen.

Sehr hertzlich gut Ers mit uns meynt/

Wenn Er sich gleich stelt wie ein Feindt/

Helt sein Natur verborgen;

So ist und bleibt Er doch die Liebe/

Will daß man in gedult sich übe/

Vnd laß ihn allein sorgen.

Wir glauben ja und ist auch wahr/

Ob wol Gott regiert wunderbahr/

So ist Er dennoch gütig:

Ja selbst das Allerhöchste Gut/

Auch ist gut alles was Er thut/

Solt das nicht machen mutig?

Ja freylich nimbts hin alles Leyd/

Erquickt das hertz/ bringt wider frewd/

Vnd tröstet sehr die Frommen/

So Gott allein gelassen seyn/

Vnd sprechen: Es ist sein/ nicht mein/

Das Er mir hat genommen.

Wol dem der mit dem Job einstimbt/

Spricht in gedult: Gott gibt/ Gott nimbt/

Sein Name sey geehret.

In allem will ich wie Gott will/

Stets seinem Willen halten still/

Nemen was er bescheret. 
Es thu mir gleich wol oder wehe/

82 Vnd geh mir wie es woll/ ich stehe

In Gottes Willn gelassen.

O Hochgeborne Königin/

Wie selig ist der solchen sinn

Durch Gottes Gnad kan fassen.

Daß nun Ewr hohe Majestät/

Für die ich täglich Gott anbet/

Auch den Trost möge haben

In aller Widerwertigkeit/

Bin Ewr Maystäten ich bereit

Mit der Schrifft zu begaben/

In unterthänigster Demuth/

Ja mit dem Edlen Büchlein Ruth/

In Teutsche Verß beschrieben/

Durch mich/ und ans Tag-liecht gebracht/

Wolln Ewr Maystäten geben acht/

Vnd sich im Lesen üben;

So werden Sie hier klärlich sehn/

Wie alle unser Sachen gehn/

Nach Gottes Wolgefallen/

Vnd daß Er alle ding der Welt

Vor hab ersehn und auch bestellt/

Wies seyn soll mit uns allen.

O Gnädigst Königin/ wie sehr

Erquickt und tröstet diese Lehr/

Mein Hertz springt auff für Frewden

Wenn ich des Herren Werck betracht/

Vnd auff sein Providentz geb acht/

Vergeß ich alles Leiden/

Auch daß ich arm und elend bin;

Denn all mein Reichthumb steht hirin/

Dafür ich Gott will preisen/

Der ein Beschützer und Ehman

Der Witwen ist und nimbt sich an

Aller Elenden Wäysen.

Es fällt von uns ohn Ihn kein Har/

83 Er hats gesagt/ Sein Wort ist war; 
Was Er vns hat versprochen

Das wird Er halten steiff und vest/

Wol dem der sich darauff verläst/

Sein Bund wird nicht zerbrochen.

Diesen Trost Gnädigst Königin/

Woll Gott in Ewr Maystäten Sinn

Selbst reden und einschreiben/

Vnd durch mein Büchlein schaffen nutz/

Ewr Maystät geb Ichß in schutz.

Sie wollen gnädigst bleiben/

I.K.M.

Vnterthänigsten demütigsten Dienerinnen

Herman Höyers Witwen

Annae Ovenae

\section{[Allen Guthertzign Boas Brüdern]}

I.

I.N.I.

I.

Allen Guthertzign Boas Brüdern/

Naemi Schwestern/ Christi Gliedern/

Nothleidenden Männern und Frawen/

Auch allen die Gott vest vertrawen

Offerir ich diß mein Büchlein;

$V$ iel trost bringts ein/ lasts euch lieb sein.

Erkennt daß Gott alles in allen/

Nach seinem guten Wolgefallen/

Also wie Ers von Ewigkeit

Hat versehn/ regiert in der zeit.

Offnet ewr Augen/ seht umbher/

Ihr habt kein Leiden ohn gefähr.

Ia/ wisset/ alles muß den Frommen/

Endlich zu ihrem besten kommen/ 
Rühmt Gott dafür wie sichs gebührt/ Sagt Danck dem/ der all Ding regiert.
A.
E.
G.
G.
A.

A.E.G.G.A.D.A.G.G.E.A.

A.

G.

G.

E.

A.

Alle Ehr Gebührt Gott Allein/

85 Denn Alles Gut Gibt Er Allein.

A.

I.

A.I.N.I.A.

I.

A.

Alles Im Namen Iesu Allein/ etc.

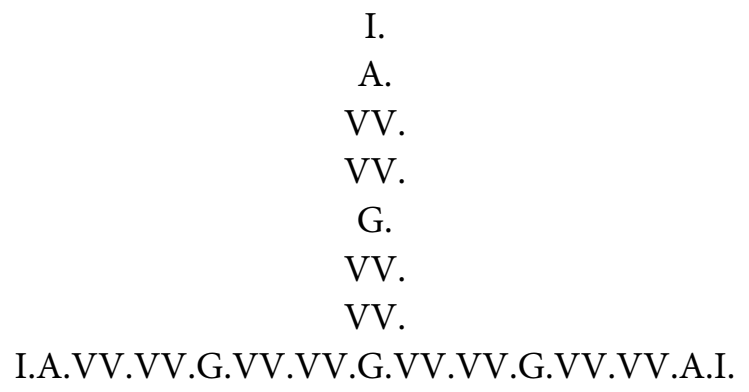


VV.

VV.

G.

VV.

VV.

A.

I.

In Allem VVilig/ VVie Gott VVill/ VVas Gott

VVill/ VVann Gott VVill/ VVill Auch Ich.

\section{Capvt 1}

ZV der Zeit oder in den Jarn/

Da die Richter regierten/

(Weil damals noch kein König warn/

Die das Regiment führten)

Ward mangel am täglichen Brot/

Bey den Israëlitern.

Wegen derselben Hungersnoth/

Zog zu den Moabitern/

Ein Bethlehemitischer Mann/

Eli Melech mit Namen/

Als ein Frembdling kam er da an/

Sein Söhn auch beyd zusamen

Folgten dem Vater ohn Verdrieß/

Es war ihn nicht zu wider;

Auch sein Weib das Naemi hieß/

Ließ sich bey ihm da nieder.

(Hie haben ein Exempel wir/

Gar schön/ daß gleicher massen

Einem ehrlichen Weib gebühr/

Ihrn Mann nicht zuverlassen.)

Wie sie nun meynten in der Ruh/

Ihr Nahrung zu erwerben/

Da sandte Gott ungluck herzu/

Vnd ließ den Mann hinsterben.

Naemi zu derselben zeit/ 
Blieb sitzen nach im Leide/

Im Witwenstandt voll trawrigkeit/

Mit ihren Sönen beyde/

Die Mahlon und Chilion genant/

Vnd ihnen liessen trawen

Zur Eh daselbst im frembden Land/

Zwo Moabitsche Frawen.

Arpa die ein mit namen hieß/

87 Ward dem Chilion gegeben/

Der Mahlon sich mit Ruth einließ/

Ehlich bey ihr zu leben.

Bey zehn jahr/ hört doch was geschach/

Wohnten die beyde Brüder/

Im Land Moab/ da kam hernach/

Von Gott das ungluck wider/

Die jungen Männer sturben hin/

Mahlon und Chilion beyde.

Naemi wust in jhrem Sinn/

Das mal von keiner Frewde/

Denn sehr groß war jhr hertzenleid/

Weil sie so gar verlassen/

Von jhren lieben Sönen beyd/

Vnd vom Mann gleicher massen.

Sie macht sich auff zog wider fort

Auß von den Moabitern/

Weil die Thewrung hatt auffgehort/

Bey den Israëlitern/

Vnd widerumb da war Getreid/

Davon sie kondten leben;

Drumb sie sich da zur selben zeit/

Wolt wider hin begeben.

Ihr zwo Sohns Frawen folgten ihr/

Vnd liebten sie mit Trewen/

Naemi sprach: Zieht nicht mit mir/

Hernach möchts euch gerewen:

Kehrt widerumb in ewer Stadt/

Der Herr woll euch beywohnen:

Die grosse liebe und Wolthat 
Euch wiederumb belohnen.

An den Todten vnd auch an mir/

Habt jhr viel guts geübet/

Gott geb jeder ein Mann dafür/

Von dem sie werd geliebet.

Also küsset Naemi sie:

Die beyde junge Frauwen

Gaben mit weinen Antwort/ wie?

Wolt ihr uns das zutrawen?

Vnser hertz ist zu euch gericht/

Wir wollen nicht umbkehren/

Seyt uns darinn zu wider nicht/

Wolt uns dasselb nicht wehren.

Sie antwort: Warumb wolt ihr doch

Gehn mit mir alten Weibe?

Werd ich denn auch itzt haben noch

Mehr Söhn in meinem Leibe/

Die ewer Männer möchten seyn?

O nicht! drumb zieht von hinnen/

Vnd last mich armes Weib allein/

Thut euch doch recht besinnen;

Wenn ich mir gleich die Hoffnung macht/

Mehr Kinder zu erlangen;

Ja wenn ich mich auch diese nacht

Ließ von einm Mann umbfangen;

Ja wenn ich auch schon allbereit

Itzt Söhne hett geboren/

So wern sie doch noch klein zur Zeit/

Ewr warten wer verloren.

Wiewol mir ubel ist zu muth/

Groß noth hat mich umbfangen;

Dieweil des Herren Hand und Ruth

Ist wider mich außgangen.

Weinend sie diese Wort außbracht/

Die zwo hatten mitleiden;

Die Arpa aber sich bedacht/

Küßt Sie im hinwegscheiden.

Ruth aber hatt ein andern Sinn/ 
Zu bleiben sie begehret/

Naemi sprach: Zeuch du auch hin/

Weil dein Schwägrin umbkehret

$\mathrm{Zu}$ ihrem Gott und Volck/ sie sprach/

89 Niemand wirds ubel deuten/

$\mathrm{Daß}$ du derselben folgest nach

Vnd gehst zu deinen Leuten.

Ruth gab darauff zur Antwort jhr:

Wie? solt ich gleicher massen

Auch kehren umb? Gott sey dafür/

$\mathrm{Daß}$ ich euch solt verlassen.

Darumb mir nicht zu wider seyt/

Ich bitt last es geschehen/

Sey wo es woll/ nah oder weit/

Will ich mit euch hingehen.

Denn also hab ich mich bedacht/

Laß mich davon nicht treiben/

Wo jhr werd bleiben über Nacht/

Da will ich auch mit bleiben.

Ewer Volck soll auch mein Volck seyn/

Ewr Gott mein Gott imgleichen.

Trewlich und gut ichs mit euch meyn/

Will nimmer von euch weichen.

An dem orth da jhr sterben werdt

Vnd ewer ruhe haben/

Da will ich in derselben Erd

Mich lassen auch begraben.

Der Herre thu mir das und diß

Laß ichs dazu nicht kommen/

Der Todt euch und mich scheiden müß/

Mein meynung habt vernommen.

Alß nun Naemi mercket/ was

Sich Ruth hat fürgesetzet;

Ihrs leides sie zum theil vergaß/

Der Antwort sich ergetzet/

Ließ ab mehr ein zu reden jhr/

Vnd gingen beid zusamen

So lange/ biß sie nach begier 
$\mathrm{Zu}$ Bethlehem einkamen.

Die gantze Stadt diß bald erfahrt/

Vbr ihnen sich erreget/

Die Weiber/ da es lautbar ward/

Worden auch sehr beweget/

Vnd sprachen zu ihr/ ist das die

Naemi/ so vor Jahren

Lang bey uns hat gewohnet hie?

Was ist ihr wiederfahren?

Sie sprach: heist nicht Naemi mich/

Weil sich mein lust geendet/

Sondern Mara heist mich/ bitt ich/

Gott hat mein Hertz gewendet/

Sehr bitter mir dasselb gemacht/

Vnd michs auffs höhst betrübet:

Leer hat er mich zu hauß gebracht/

Vnd der Mann/ den ich liebet/

Hat er von mir genommen hinn/

Beider Söhn mich beraubet;

Von hertzen ich drum trawrig bin/

Ja mehr denn man mir glaubet.

Darumb bitt ich daß jhr nicht mehr

Mich woll't Naemi nennen/

Denn wie mich hat betrübt der Herr/

Geb ich euch zu erkennen.

Es war aber zur selben zeit

Zeitig und reiff der Samen/

Daß jedermann im Feld arbeit

Da die beid wider kamen.

Die Gerstenernd ging eben an/

Hört wie Gott all's regieret:

Wer ist doch der außreden kan

Wie er die seinen führet?

\section{Capvt 2}

ES war ein Mann/ vernehmet recht/

Tapffer und reich von Güter/ 
Eli Melechs freund von geschlecht/

91 Auch ein Bethlehemiter.

Ein feiner Mann Boas genandt/

Der ließ auch Gersten schneiden;

Naemi war er wol bekandt/

Die mit Ruth saß in leiden/

Einsam/ und beyde nehrten sich

Durch das werck ihrer hände/

Wie arme Witwen kümmerlich/

Pflegen in ihrm Elende.

Es war gering ihr beyder sach/

Vormals besser gewesen/

Darumb Ruth zu Naemi sprach:

Last mich gehn und aufflesen

Ähern auffs feld dem nach/ für dem

Ich gnad und gunst itzt finde/

Vnd da ich seyn werd angenehm/

Im feld bey dem Gesinde.

Geh hin mein Tochter/ antwort sie/

Ich will es dir nicht wehren/

Bring was zu hauß daß wir uns hie

Mögen davon ernehren.

Sie ging hin/ merckt doch was geschicht/

Vnd kam auff Boas Acker/

Jedoch den Mann sie kante nicht/

Sie laß die ähern wacker

Den Schnittern nach. Boas der Mann

Von Bethlehem kam gangen/

Er sprach die Schnitter also an:

Was ihr habt angefangen/

Das geh in Gottes Namen fort/

Der sey mit euch im wercke.

Danck habt/ war wider jhr antwort/

Der Herr sey ewer stärcke.

Boas sah Ruth auch da im Feld/

Vnd sprach zu seinem Knaben

Der ubr die Schnitter war gestellt:

92 Was will die Dirne haben? 
Wes ist sie? Der Knab gab bescheit:

Sie ist/ hab ich vernommen/

Die von Moab vor wenig zeit

Ist mit Naemi kommen.

Ferner der Knab zu Boas sprach:

Sie ist hie heut gewesen

Bey uns im Feld den gantzen Tag.

Die ähern auffzulesen

Den schnittern nach; dieweil sie mich

Drumb bath ihr diß zu günnen/

Solch ihre bitt an mich hab ich

Ihr nicht abschlagen können.

Fleißig ist sie gewesen heut

Es geht ihr wol von handen/

Von morgen biß auff diese zeit

Ist sie bey uns gestanden.

Da ging Boas selbst hin zu ihr/

Sprach mit freundtlichen worten:

Meine Tochter gehorche mir

Vnd bleib an diesen Orten/

Es soll dir nichts zu leid geschehn/

Darumb geh' nicht von hinnen/

Mit meinen Dirnen soltu gehn/

Die dich anleiten können/

Da sie schneiden/ geh' jhnen nach/

Dem Volck hab ich gebotten

Daß keiner dich antast/ er sprach/

Oder sonst soll verspotten.

Vnd so dich durst/ geh hin zum krug/

Vnd trinck mit meinen Knaben/

Es wird für dir auch seyn genug/

Dein hertz damit zu laben.

Da fiel sie auff ihr angesicht/

Demütig sie ihn ehret/

Sprach: Ich hab je verdienet nicht

Das mir itzt widerfähret/

Ich weiß auch nicht in meinem sinn

Womit ich gnad bekommen/ 
Die ich doch hie ein Frembde bin.

Er sprach ich hab vernommen/

Daß du nach deines Mannes todt/

Hast wollen nicht verlassen

Dein Schwieger Mutter in der noth/

Sondern mit jhr die strassen

Gezogen bist im frembden Landt/

Hast ihr viel guts erzeiget;

Bey einem Volck dir unbekant

$\mathrm{Zu}$ bleiben bist geneiget.

Der Herr vergelt dir deine that/

Vnd mach dein lohn vollkommen:

Der zu dem Herren Zuflucht hat

Wird von jhm angenommen.

Israels Gott sey immer zu

Dein Hülff und Trost im leben;

Vnter des flügeln jtzund du

Dich hast zu wohnen geben.

Ruth sich der wort erfrewen thet/

Vnd antwort jhm demütig:

Wie freundlich hat mein Herr geredt/

Vnd ist mir doch so gütig.

Nun ich für ewren augen gunst

Vnd gnade hab gefunden/

Wird von mir nichts begehret sonst/

Mein Leid ist mir verschwunden.

Was solt ich doch begehren mehr

Denn ewer Gunst alleine?

Weil ich geringer bin/ mein Herr/

Als ewer Mägde eine.

Er sprach zu jhr: Wenns essen zeit

Ist/ solt dich auch hernahen/

Vnd bey dem Volck nach der arbeit/

94 Dein speise mit empfahen;

Ihrer freyheit dich mit gebrauch/

Vnd tuncke deinen bissen

In essig wie die andern auch/

So speiß einnehmen müssen. 
Sie nam diß an mit danckbarkeit/

Darüber sich ergetzte/

Vnd da es war zu essen zeit/

Sie sich mit nieder setzte.

Boas legt selbst zu essen für/

Sie $a ß /$ er ließ jhm langen

Gedörte ähern gab er jhr/

Die man sonst nennet Sangen:

Sie aß sich mit den andern satt/

Stund wieder auff zu lesen/

Von Sangen sie noch uber hatt/

Die zur mahlzeit gewesen.

Boas zu seinem knaben sprach:

Ihr solt sie nicht beschämen

Sondern lasset was bleiben nach/

Davon sie mög auffnemen;

Auch von dem hauffen ligen last/

Als ob jhr es nicht achtet;

Sie ist bey uns frembd wie ein Gast/

Ihr noth bey euch betrachtet.

Also lase sie fleissig auff/

Vnd war dasmal zum ersten/

So sie gesamlet hatt zu hauff/

Bey einem Epha gersten;

Da sie es hatt geschlagen auß/

Sie hub es auff zu tragen/

Kam damit in die Statt zu hauß:

Naemi sprach mit fragen/

Da sie diß all's gesehen hatt

Vnd von der Ruth empfangen

Das/ davon sie war g'worden satt/

Auch g'blieben nach von Sangen:

Mein Tochter wo bist g'wesen heut

Vnd wo bistu herkommen?

Es müssen g'wiß seyn gute Leut

Die dich hab'n angenommen.

Sie gab es zuerkennen ihr/

Sprach: da ich hab gelesen 
Vnd der diß all's hat geben mir

Ist der Boas gewesen.

Naemi sprach zu ihrer Schnur/

Der Mann ist mein bekanter/

Mein Tochter sey zu frieden nur/

Er ist meins Manns Verwanter/

Vnd Erb/ ein solcher frommer Mann/

Der nicht hat unterlassen

Sein Gütigkeit zu zeigen an

Thut unser sich anmassen.

An den Todten und Vns hat er

Barmhertzigkeit beweiset;

Geseg'n ihn dafür Gott der Herr/

Den er mit gutthat preiset.

Ruth wieder zu Naemi sprach/

Der Mann sagt mir imgleichen/

Ich solt sein'n Dirnen folgen nach/

Vnd nicht von ihnen weichen/

Biß alles Korn zu hauß gebracht/

Solt auch mit jhnen essen/

Solch wort hat er zu mir gesagt/

Die ich nicht kan vergessen.

Naemi sprach ja/ das ist gut/

$\mathrm{Da}$ du mit jhnen gehest;

Niemand dir da einreden thut/

Wie du diß wol verstehest.

Also die Ruth zu ihnen sich

Bald widerumb gesellte/

Vnd laß/ wie vor geredet ich/

96 Da ähren auff im Felde/

Bey Boas Volck: wolt zu der zeit

Auff ander Feld nicht gehen/

$\mathrm{Bi} ß \mathrm{da}$ an Gerst und Weitzen beid

Die Ernd da war geschehen.

Darnach sie zu Hauß wider kehrt/

Naemi zu ernehren/

Die sie als jhre Mutter ehrt/

Wolt nicht mehr auß begehren. 


\section{Capvt 3}

Naemi sprach einsmals zu ihr:

Solt ich nicht darnach sehen

Mein Tochter/ Ruh zu suchen dir

$\mathrm{Daß}$ es dir wol mög gehen?

Nun wolan/ merck was ich dir sag/

Der Mann bey dem du g'wesen/

Vnd bey des Dirnen diese tag

Du Korn hast auffgelesen/

Boas/ unser verwandter Freund

Des Nam'n du wol thust kennen/

Der wird sein Gersten worfflen heint

Diese nacht auf der Tennen.

So folg mir liebe Tochter nun/

Es soll dir seyn ohn schaden/

Was du zu dieser zeit solt thun:

Nemblich du solt dich baden/

Auch salben/ und ziehn an dein Kleid/

Vnd gehn hin auff die Tenne/

Doch merck wol die gelegenheit/

Auff daß dich niemand kenne/

Biß Boas wol getruncken hat/

So merck den Ort gar eben/

Dahin er sich zu Abends spat

$\mathrm{Zu}$ schlaffen thut begeben.

So kom alßdann und lege dich/

Sein Füß soltu auffdecken/

Wenn er denn wird besinnen sich/

In dem du jhn thust wecken/

So wird er wol anzeigen dir/

Was du solt ferner machen.

Gehorch mein liebe Tochter mir/

Vnd folg in dieser Sachen.

Die Ruth nam diß in guter acht/

Vnd wolt nicht widerstreben/

Sprach: was ihr itzt zu mir gesagt/

Dem will ich folgen eben. 
Also ging sie auffs best geschmückt

Hinab auff Boas Tennen/

Weils Abend war/ es ihr auch glückt/

Daß niemand sie thet kennen.

Vnd da Boas gelebt frölich

Getruncken hatt und gessen/

Wolt er zur ruh begeben sich/

Vnd legt sich nach dem essen

Hindr einen Mandl und Gersten hauff.

Ruth merckt den Ort mit fleisse:

Sie kam und deckt sein füsse auff/

Vnd legt sich zu ihm leise.

Da es nun kam zur mitter-nacht/

Ward Boas solches innen/

Als er von seinem schlaff erwacht/

Kont sich doch nicht besinnen.

Erschrack des ohne masse sehr/

Wandte sich hin und wider/

Vnd sieh/ ein Weib sah ligen er

Bey seinen Füssen nider.

Er sprach: Wer bist? Was machstu hie?

Gib dich mir zu erkennen.

Ich ewer Magt Ruth/ antwort sie/

Bin kommen in die Tennen.

Breit uber mich ewr Flügel nun/

$98 \mathrm{Daß}$ ich eur gunst erwerbe.

Von Rechts wegen solt ihr es thun/

Dieweil ihr seyt mein Erbe.

Er sprach zu ihr: Gesegnet seyst

Mein Tochter/ von dem Herren/

Grösser gutthat hast itzt beweist/

In dem du mich in Ehren

Begerst/ und zu mir kommen bist/

Gegn mich mit Lieb umbfangen/

Vnd keines wegs auß böser lust/

Den Jünglingn nachgegangen.

Darumb solt gar nicht fürchten dich/

Alles nach deinem willen/ 
Was du gesagt/ will trewlich ich

Verrichten und erfüllen.

Die gantze Stadt meins volckes weiß/

$\mathrm{Daß}$ du ein Weib auffrichtig

Vnd tugendsam bist/ das mit fleiß/

Sich stets verhalten züchtig.

Wahr ist/ ich bin der Erb/ wie du

Sagst/ doch solt du auch wissen/

Einer gehört dir näher zu/

Dem werd ichs kundt thun müssen.

Nimt er dich morgen/ so will ich

Hierinn nicht widerstreben:

Wo nicht/ so will ich nehmen dich/

So wahr der Herr thut leben.

Daran solt gar nicht zweiffeln du/

Schlaff nur ohn furcht und sorgen.

Sie legt sich nieder da zu ruh/

Vnd schlieff biß an den morgen.

Darnach eh es ward tag und liecht/

Sie auß dem schlaff erwachte/

Ehe einr den andern kennen mücht/

Sie sich vom Bett auffmachte.

Boas hatt sie geweckt so früh/

Gedacht/ ich möcht mich schemen/

Daß ein Weibs-bild gewesen hie/

Niemand soll diß vernehmen.

Er sprach: lang her dein Schürtztuch mir/

Das du hast umbgeschürtzet.

Sie hielt es ihm/ alßbald Er ihr

Drinn sechs maß Gersten stürtzet.

Legts auff sie/ ließ sie von ihm gehn/

Im tunckel und verborgen.

Sie kam da man noch nicht kont sehn

Zur Mutter früh am Morgen/

Die sprach zu jhr: wie stehts mit dir

Vnd wie bistu empfangen?

Das sag mein liebe Tochter mir

Wie ist es dir heint gangen? 
Ruth zeigt Naemi solches an/

Vnd sagt ihr alles eben/

Was ihr gethan Boas der Mann/

Vnd was er ihr hatt geben.

Sechs Maß Gersten/ sprach sie/ gab er

Mir/ die hab ich genommen/

Denn er sprach du sollt itzt nicht leer

$\mathrm{Zu}$ deiner Schwieger kommen.

Naemi sprach: sey du nur still/

Du wirst es bald erfahren

Wie sich der handel schicken will:

Kein fleiß wird Boas sparen

(Weis ich gewiß) und ruhen nicht/

$\mathrm{Biß}$ er noch heut am Tage

Diß alles hab glücklich verricht/

Dran ich kein zweiffel trage.

\section{Capvt 4}

Boas ging hin/ wie er geredt/

Den Handel zu verrichten/

Vnd sich ins Stadt Thor setzen thet

100 Da man all's pflag zu schlichten.

Vnd sieh' da kam gegangen der/

Von dem Meldung geschehen/

Boas sprach zu ihm: setz dich her

Woll'st nicht darüber gehen.

Zehn Männer in derselben Stadt/

Die zeugnus konten geben/

Boas bey ihm zu sitzen bath/

Die satzten sich darneben.

Zum Erben der nechst bey ihm saß

Fing Boas an zu sagen:

Ohn zweiffel wirstu wissen/ daß

Hie vor etlichen Tagen

Naemi widerkommen ist/

Vom Land der Moabiter/

Die beut zu kauff/ wie mir bewust/ 
Auß Armuth ihre Güter/

Ihrs Mannes unsers Freundes feld/

Das sein war bey seinm Leben/

Darumb hab ich dirs angemelt/

Wiltu dein Gelt nun geben/

Vnd alß ein Erb es kauffen dir/

So thu es hie zugegen/

Wo nicht/ so will ichs lösen mir

Vnd mein Gelt dafür legen:

Denn es ist sonst kein Erb/ denn du

Vnd ich/ ders kan erwerben:

Darumb antwort/ was sagst dazu?

Er sprach: Ich wills beerben.

Wolan/ es ist gut/ sprach Boas/

Doch soltu dabey wissen/

Welches tages du kauffest das/

Wirstu auch nemen müssen

Ruth des Verstorbnen Mahlons Weib/

Daß du ihm einen Namen

Der allzeit auff sein Erbtheil bleib/

Erweckst auß deinem Samen.

Da sprach der Erbe zu Boas:

Vielleicht möcht ich verderben

Mein Erbtheil/ drumb ich uberlaß

Dir; was ich kan beerben/

Behalte dir; ich hab genug/

Mag kein gelt daran wagen;

Vnd gab ihm damit seinen Schuch

Den er am Fuß getragen.

Es war aber solch gewohnheit

Herkommen von den Alten/

Vnd ward noch fest zur selben zeit

In Israel gehalten:

$\mathrm{Da} /$ der sein Erbgut oder Haab

Vberließ/ auch daneben

Den Schuch auß zog und mit hin gab/

Zum gezeugnüs merckt eben;

Damit der Käuffer alles möcht 
Betretten und besitzen/

Dürfft jemands einred fürchten nicht/

Könt mit dem pfand sich schützen.

Also nam auch Boas der Mann

In gegenwart der Zehen

Den Schuch von andern Erben an/

Vnd sprach: ihr habt gesehen

$\mathrm{Daß}$ ich mir heut auff diesen tag

Das Feld gekaufft zu eigen/

Ihr ältsten meines volcks (er sprach/)

Solt heut seyn meine Zeugen.

Dazu will ich auch nemen mir

Die Ruth in Gottes Namen/

Daß dem Verstorbnen ich auß ihr

Erwecke einen samen

Auff sein Erbtheil/ damit auff Erd

Seiner nicht werd vergessen/

Ihr Männer hie zugegen werd't

102 Seyn Zeugen alles dessen.

Alles Volck das im Thor war sprach:

Wir wollen zeugniß geben/

Der Herr das Weib deins Hauses mach

Fruchtbar in deinem leben/

Wie Rahel und Lea/ die beid

Israels hauß gebawet:

Also sey auch zu dieser zeit

Die dir itzt wird vertrawet.

Halt dapffer dich im Ephrata/

Wachs und mach einen Namen

In Bethlehem/ auff daß dir da

Durchs Weib von deinem Samen

Dein hauß erbawt werd immerdar

Wie Peretz Hauß gewesen/

Den Thamar dem Juda gebar/

Alß wir beym Mose lesen.

Solches wünschen von Hertzen wir/

Vnd bitten Gott darneben;

$\mathrm{Daß}$ er wolle viel samen dir 
Auß dieser Dirnen geben.

Also Boas zur selben zeit

Ließ ihm die Ruth bey legen/

Der Herr gab ihr die Fruchtbarkeit/

Daß sie durch seinen Segen

Dem Boas einen Sohn gebar.

Die Weiber alßbald kamen

$\mathrm{Zu} \mathrm{Naemi/} \mathrm{die} \mathrm{frölich} \mathrm{war/}$

Sprachen: Gott hat den Samen

In deinem Alter geben dir/

Auff daß du würdst erquicket/

Gelobet sey sein Nam dafür

Der diß so hat geschicket/

Denn dein Sohns Fraw/ die dich allzeit

So sehr lieb hat von Hertzen/

Die hat ihn dir geboren heut/

$\mathrm{Zu}$ lindern deinen Schmertzen.

Durch sie du hoch erfrewet bist/

Hettstu der Söhn auch Sieben;

Dennoch sie dir viel besser ist/

Billig thustu sie lieben.

Naemi nam das Kindlein hin/

Auff ihren Schoß es legte/

Vnd ward selbst seine Wärterin/

Seiner sie fleißig pflegte/

Vnd hatt daran ihr Wolgefall:

Der Sohn wer ihr geboren

Sagten die Nachtbarinnen all/

Denen diß kam zu Ohren.

Der Nam Obed ward ihm mit recht

Gegeben auch von ihnen/

Denn er solt seyn Naemi Knecht

Vnd ihr im Alter dienen.

Dieser Obed wie offenbar/

Ein Vater ist gewesen

Jesse/ der Davids Vater war/

Des Königs wie wir lesen.

Diese Nahmen hie an der zahl/ 
Sind von Peretz herkommen/

Die ich gar kürtzlich auff dißmal

Beschreib in einer summen:

Peretz zeugt Hetzron/ Hetzron Ram/

(Die Chronica nicht treuget)

Von Ram Aminadab herkam/

Der Nahasson gezeuget/

Der Salmah/ Salmah den Boas/

Von dem ist Obed kommen/

Wie ihr zuvor gehöret das

Vnd alles habt vernommen.

Den Jesse hat gezeuget er/

Dem ist David geboren/

Ein Man von Gott geliebet sehr/

104 Zum Königreich erkohren.

Hiemit diß Büchlein endet sich/

Kurtz doch deutlich beschrieben.

Gott geb uns allen Gnad/ wünsch ich/

Im guten uns zu üben/

Vnd die Lehren so hirin sind/

Mit fleiß wol zu betrachten.

Viel guts in diesem Buch man findt/

Drumb woll't es nicht verachten.

Zwo Haubtlehren insonderheit

Sollen wir hie wol mercken/

Die ein von Gott's Fürsichtigkeit

Vnd Wunderbaren Wercken.

Nemlich daß Gott der Höchste Herr

Regier der Menschen willen/

Ihr thun und lassen damit Er

Das jenig mög erfüllen/

Welches er hat von Ewigkeit

Beschlossen und fürsehen/

$\mathrm{Daß}$ es geschehn soll in der zeit:

Denn dahin müssen gehen

Alle Sachen in dieser Welt/

Zeigt an diese History/

Gott regiert all's wies ihm gefelt 
$\mathrm{Zu}$ seiner Ehr und Glory.

Merck hie/ die Ruth ein Heydin war/

Nun hatt es Gott beschlossen;

$\mathrm{Daß}$ sie auch in der Christen Schar

Solt seyn ein Mitgenossen

Vnd Gesellin im Gnaden reich/

Der Christus auch solt kommen;

Wie allen Glaubigen zu gleich

Zur Seelen Heil und Frommen.

Damit also der Herr an ihr

Vns möcht Anzeigung geben/

Daß auch die Heiden/ nemlich wir/

Gehörten mit zum Leben/

Vnd zu seiner bestimmten zeit

Solten beruffen werden/

Von allen Orten nah und weit

Auff dieser gantzen Erden.

Auff daß nun aber Gottes Wahl

Vnd sein Fürsatz fortginge/

Vnd Ruth würd Boas Ehgemahl

Von ihm Obed empfinge;

Auß welches stamm herkommen müst

Vnd werden solt geboren/

Nach der verheissung' Jesus Christ/

Durch den wir sind erkohren;

So hat Gott wunderbarer weiß

Die menschen umbgeführet/

Diß und Jenes zu thun mit fleiß/

Ihren willen regieret/

Dadurch zu letzt sein Rathschluß ist

Zum guten end gekommen/

Mit Boas Heyrath wie ihr wist

Vnd zuvor habt vernommen.

Denn erstlich/ damit Gott der Herr

Des Boas Bluts-verwanten

Eli Melech hinführt/ daß er

Von Freunden und Bekanten/

Mit seinem Weib und Söhnen beid/ 
Gen Moab sich begeben;

Vnd zwar an den Ort da zur zeit

Sich Ruth verhielt/ merck eben/

So lest er hunger und gebrech

Im Land Israel kommen/

Dadurch dann dem Eli Melech

Sein nahrung ward benommen/

Vnd er bewegt zur selben zeit/

Dem hunger zu entfliehen

Vnd nach besser gelegenheit/

106 Ins Land Moab zu ziehen.

Ferner hatt Gott beschlossen/ daß

Er in der Frembd solt sterben:

Damit gelegnheit und anlaß

Möchten sein beide Erben

Haben/ dazu befreyen sich

Mit zwo Heydnische Frawen:

Vnd zwar der ein/ Mahlon nemblich

Die Ruth ihm zu vertrawen/

Welches vielleicht sonst nimmermehr

Eli Melech dermassen/

Wenn er im Leben g'wesen wer'/

Wurd haben zugelassen.

Mahlon must aber/ merck mit fleiß

Nemen nach seinem Sinne/

Die Ruth/ das sie auff solche weiß

Wurd Boas Schwägerinne/

Vnd derselb darnach hätt das recht/

Naemi gut zulösen/

Weil er ihr Erb und vom Geschlecht

Eli Melechs gewesen/

Vnd also auß der ursach auch

Ruth nemen möcht zur Frawen/

Nach dem Gesetz und Lands Gebrauch

Seins Bruders Nam zu bawen.

$\mathrm{Zu}$ dem hat Gott nach weinig zeit

Beide Söhn ebner massen

Alß sie im Land Moab gefreyt/ 
Daselbst auch sterben lassen:

Auff daß den Witwen wider nun

Zufreyen macht würd geben/

Welchs sie nicht hetten durffen thun

Bey ihrer Männer leben.

Auch hats müssen darumb geschehn/

Daß Naemi begehren

Möcht/ nach dem Todt der beiden Söhn

Vnd ihres Lieben Herren/

Wid'rum zu ziehn in jhrem Land/

Zu ihren Bluts-verwanten/

Da sie mehr Hülff/ Trost und Beystandt

Bey Freunden und Bekanten

Kont haben/ denn im Land Moab/

Vnter den frembden Leuten.

Der Herr stärckt den Fürsatz und gab

Drumb eben zu den zeiten/

In Israel widrumb das Brot

Vnd Nahrung zu gewinnen/

Naemi must in ihrer Noth

Auch solches werden innen/

Auff daß sie/ wie zuvor gehort

Nach ihrem wunsch und willen/

Möcht widerkommn an ihren Ort

Ihr Hertzleit da zu stillen:

Weil bey den Freunden jederzeit

Viel besser ist zu leben/

Einer Witwen insonderheit/

Denn in der Frembd zu schweben.

Arpa und Ruth hattn anfänglich

Auch Willn von Gott bekommen

Auß Moab zu begeben sich/

Vnd ihnen fürgenommen

Von Naemi zu scheiden nicht.

Doch Arpa wird abwendig/

Ihrn weg widrumb gen Moab richt:

Ruth aber bleibt bestendig/

Will sich von ihr nichts/ ohn allein. 
Durch den Todt/ scheiden lassen:

Naemi Gott soll ihr Gott seyn/

Sie zeucht mit ihr die strassen.

Diß schickte also Gott der Herr/

Vnd regiert ihren willen/

Damit Naemi leiden schwer

108 Etlicher maß zu stillen:

Auch daß dadurch würd offenbar

Die ware furcht des Herren/

Mit welcher Ruth erfüllet war

Vnd sie durch die in ehren/

Beym Boas würd so hoch geacht/

Daß er sie ihm ließ trawen/

Vnd leichtlich ihr die Ehe zusagt/

Vnd sie ihm macht zur Frawen.

Daß aber solches alles möcht

Dest' eh zur endschafft kommen;

So hat es Gott also gericht/

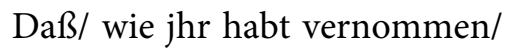

Naemi eben zu der zeit

Mit Ruth kam zu den ihren/

Da reiff im feld war das getreid/

Vnd sie beid mangel spühren

An leibes nahrung: drumb ging Ruth/

Die ähern auff zu lesen/

Den Acker sie antreffen thut

Da Boas Volck gewesen.

Diß ist geschehn alls ohngefehr/

Nemblich ohn ihr verhoffen;

Doch hats also regiert der Herr/

Das sies so hat getroffen.

Der Oberst Knecht viel von ihr helt

Vnd ihr viel guts erzeiget;

Dem Boas ihren fleiß vermeldt/

Macht sein hertz ihr geneiget;

Erzehlt weitleufftig ihm dabey/

Wie er es hat vernommen

$\mathrm{Daß}$ sie die Moabitin sey/ 
Die mit Naemi kommen:

Denn daß Naemi kommen war

Auß dem Land Moab wider

Vnd Ruth mit ihr/ war schon ruchtbar/

In der Stadt auff und nieder.

Auff daß nun Boas diß erführ

Vnd sie bekäm zu sehen/

Auch selbst würde bekant mit jhr/

Must diß also geschehen.

Boas kompt auch zu rechter zeit

Hinauß im Feldt und siehet

Vnter dem Volck in der arbeit

Wie sich die Ruth bemühet.

Da er vom Knecht auff seine frag

Bericht von jhr empfangen/

Sah auch ihrn fleiß am selben tag/

Bekam er ein verlangen

Mit jhr zu redn/ ging zu ihr/ und

Sprach sie an in der güte/

Macht ihr den guten willen kunt/

So er hatt im gemute.

Ruth frewt sich seiner freundligkeit

Vnd daß sie gunst bekommen;

Naemi sich mit jhr erfrewt/

Da sie es hatt vernommen/

Nunt daher ursach und anlaß

Ruth diesen rath zu geben;

Daß sie den Heyrath mit Boas

Solt suchn und darnach streben:

Hat auch die Ruth bewegt dahin/

Daß sie gab jhren willen/

Nach der Naemi rath und Sinn/

Den anschlag zu erfüllen.

Demnach begehrt sie von Boas

$\mathrm{Daß}$ er sie nehmen wolte

Zur Eh/ und sagt daneben/ daß

Er solches billig solte/

Vermög des Gebots so der Herr 
Von diesem Heyrath geben;

Drumb er wie ander schüldig wer/

110 Demselben nach zu leben.

Den guten rath nimt Boas an

Vnd ist in allem willig;

Thut auch alß ein ehrlicher Mann

Alßbald dazu was billig:

Bekümbt dadurch in seine hand/

Wie das Sein zu bebawen/

Der Naemi verkaufftes Land/

Vnd nimt ihm Ruth zur Frawen;

Die durch Gotts segen schwanger wird/

Vnd wie im Text wir lesen/

Ihm seinen Sohn Obed gebiert/

Des Sohns David g'wesen;

Auß welches stammen Jesus Christ/

Durch den wir selig werden/

Ein warer Mensch gebohren ist

(Vns alln zu trost) auf Erden.

Diß ist also die erste Lehr/

Darauß wir sollen mercken:

Wie wunderbar regier der Herr

In allen seinen wercken.

Sein Nahm und That ist wunderbahr/

Vnmöglich zu ergründen/

Täglich erfahrung zeigt es klar/

Diß Büchlein thuts verkünden.

Niemand ist der außreden kan

Die grossen werck des Herren/

Wer ihrer acht/ hat lust daran

Thut David uns erkleren.

Gott führt die seinen wunderlich/

Regiert jhr thun und lassen/

Deß soll ein jeder frewen sich/

Es wol zu hertzen fassen.

Denn wer wolt sich erfrewen nicht/

Der augenscheinlich spühret

Daß Gott der Menschen Händel richt 
Vnd ihm zum lob außführet/

Ihr wort und werck ihr gehn und stehn/

Vnd was man sonst mag nennen?

Hat ers doch alles vor ersehn/

Thut alle hertzen kennen:

Hat aller Menschen tag gezelt/

Eh jemand ward geboren;

Vnd auch die seinen vor der Welt

In Christo außerkoren:

Thut sie auch noch all stund und tag/

So Väterlich bewahren/

Daß ihnen ohn sein willen mag

Kein unglück widerfahren/

Die haar ihrs hauptes sind gezehlt/

Daß der keins auff die Erden

Ohn den willen des Herren felt

Oder gekrummt mag werden.

Der diß betracht zum offtermal

Wird sich erfrewen dessen/

In elend/ armut und trübsal

All's trawren bald vergessen.

Dieweil Gottes fürsichtigkeit

All schmertzen überwindet;

Besser artzney in noth und leit/

Als die man nirgend findet:

Denn was solt einen trösten mehr

In traurigkeit und schmertzen/

In creutz/ kranckheit und leiden schwer/

$\mathrm{Al} ß$ glauben diß von hertzen?

Daß alles was uns widerfehrt/

Von Gott sey ordiniret

Vnd werd auch/ wie die Schrifft uns lehrt/

Zum guten dirigiret?

Drumb diese Lehr euch nützlich macht/

Die euch zum trost beschrieben/

Das Paulus sagt/ nemt wol in acht/

Thut in der Schrifft euch üben/

Des Herren werck euch stets erfrewt/ 
Vnd macht sie euch nicht bitter/

Ewr Seligkeit zu ieder zeit/

Wircket mit forcht und zitter.

Bleibt in ewerm beruff und stand/

Vnd ernehret euch ehrlich;

Kompt euch creutz und armut zur hand/

Vnd wird es euch beschwerlich;

Sterben die liebsten Freunde hin/

Seyt gedültig im leiden/

Setzt vest auff Gott hertz/ muth und sinn/

Trawret nicht wie die Heiden:

Denn reichthumb/ armut/ glück und fall/

Der Todt und auch das leben/

Kompt uns von Gott her allzumal/

Er nimt/ kan wider geben.

Vnser fleiß thut es warlich nicht/

Wenn wir den segen haben/

Gott gibt üb'r unser zuversicht/

Reichthumb und seine gaben.

Es helffet nicht das früh auffstehn/

Drumb trawren oder weinen/

Oder auch spath zu bette gehn/

Gott gibts im schlaff den seinen.

Wem Gott wol will/ dem schad kein neit

Vnd hindern keine Feinde/

Wenn Er nicht gibt hilfft kein arbeit/

Hett man auch tausent Freunde.

Das best in allen dingen ist

Befehlen Gott die sachen;

In hoffnung/ daß zu rechter frist

Er alles wol werd machen.

Wer ist von Gott verlassen doch

Der ihm nur hat vertrawet?

Keiner wird hülffloß bleiben noch/

113 Der nur vest auff ihn bawet:

Dran sollen gar nicht zweiflen wir/

Die Exempel der Alten

Stellet die Schrifft zum trost uns für/ 
Dran sollen wir uns halten.

Von Gott ist alles gut gemeint/

Was uns hie widerfähret/

Ob es schon noch so übel scheint/

Solches die Schrifft uns lehret:

Drumb haltet Gott in allem still/

Befehlt jhm ewer sachen;

Denn das ist seyn befehl und will/

Er gibt nach trauren lachen/

Vnd helffet zu erwünschter zeit/

Allen die jhm vertrawen:

Gleich wie er hat errett auß leit

Die vorgemelte Frawen

Vnd jhr trübnüß in freud verkehrt

So will er auch vertreiben

Alls ubel so uns wiederfährt/

Wenn wir in g'dult nur bleiben.

Alles soll zu seins Namens Ehr

Vnd uns zum besten kommen/

Betrachtet fleissig diese Lehr/

Sie ist tröstlich den frommen.

Wol allen die dran halten sich/

Vnd damit sich erquicken/

In g'dult und hoffnung stets frölich/

Fein in der zeit sich schicken:

Wie der Apostel Paulus spricht/

Ihr hoffnung wird nicht feilen/

Der Herr wird sie verlassen nicht/

Ob sichs schon thut verweilen.

Harrt nur des Herrn/ er ist nicht fern/

Sein Ohren stehn euch offen/

Er ist bereit und helffet gern

Allen die auff jhn hoffen.

Die ander Haubt-lehr hierin ist/

So man soll mercken eben:

Wie sich ein jeder rechter Christ

Verhalten soll im leben:

Nemlich Gottförchtig/ Fromb/ Erbar/ 
Züchtig in wort und wercken;

Vnd freundlich gleich wie Boas war/

Diß woll' ein jeder mercken/

Sich üben in Gottseeligkeit/

Vnd in Christlicher liebe;

Arme und hochbetrübte Leut

Er ja nicht mehr betrübe;

Sondern nem' sich derselben an/

Vnd helff ihr wolfart bawen;

Gleich wie der Boas hat gethan/

Diesen betrübten Frawen/

Die trostlos warn in ihrer noth

Vnd hatten keine güter/

Denselben schafft er täglich brodt

Vnd erquickt ihr gemüter.

Seinem Exempel nach ein Christ/

Sich billig auch soll halten/

Alßdann für Gott er selig ist

Vnd wird in ehren alten.

Der sich des Nechsten noth annimmt/

Vnd helffet gern den Armen/

Segen vom Herrn wid'rumb bekömbt/

Gott will sich des erbarmen/

Erretten jhn zur bösen zeit/

Beym leben jhn bewahren/

Daß jhm in nöthen und kranckheit/

Kein leid soll widerfahren.

Es wird jhm wol und glücklich gehn/

Sein g'dechtnüß bleib im segen;

Der Herr wird jhm zur seiten stehn/

115 Auff allen seinen wegen/

Wird geben ihm glück und gewinn/

Nach seinem wunsch und willen/

All sein Anschläg nach seinem sinn/

Außführen und erfüllen.

O wol dem! sag ich noch einmal/

Der sich freundtlich erzeiget

Den armen leuten in trübsal 
Vnd ihnen ist geneiget/

Helfft wo er kan/ mit rath und that/

Gibt wenn er hat zu geben;

Solches der Herr befohlen hat/

Verheist auch lohn daneben/

Hie zeitlich und hernach wird er

Für allen außerwehlten/

Solch lieb und gutthat preisen sehr/

Vnd ewiglich vergelten.

Die Lieb ist des gesetzes end/

Drinn üben sich die Frommen:

Der Glaub wird durch die Lieb erkennt/

Ohn sie ist nichts vollkommen:

Ja/ das band der vollkommenheit

Thut sie Sanct Paulus nennen/

Daß jhr Kinder des Höchsten seyt/

Ist dabey zu erkennen.

Drumb strebet nach der Lieb allzeit/

Werd't reich an guten wercken/

Last ew'r wolthat und gutigkeit/

Ein'm jeden sehn und mercken;

Seyt freundtlich/ fromm/ sanfft und gelind/

Sonderlich gegn die armen

Die notturfftig und hülffloß sind;

Zieht an hertzlichs erbarmen.

Ihrs elends nemt euch also an

Alß wenn es wer' ewr eigen;

Gott der Herr wird mit gnad alß dann

Euch wider hülff erzeigen/

Gedey geben in ruh und still/

Eur Kinder gleicher massen

Wird er segnen reichlich mit füll/

Vmbsonst nicht suchen lassen.

So aber Gott nach seinem rath

Euch ließ in armut kommen/

Zweiffelt gar nicht an seiner gnad/

Es dient zu ewerm frommen.

Wol zu thun vergest darumb nicht/ 
Last es euch nicht gerewen/

Habt ihr wenig/ Tobias spricht/

So gebt es doch mit trewen;

Es wird reichlich bezahlt hernach/

Ewr glück wird wider wachen;

Dem Herrn ist es ein leichte sach/

Die armen reich zu machen.

Daß die Welt dem zuwider sagt/

Lasset euch nicht turbiren/

Der Gottloß nur dem geld nachjagt/

Thut dem Mammon hoffiren;

Er sicht nicht an des armen noth/

Hört nicht nach seinem schreyen/

Wenn er ihm helffen könt vom todt/

Mit geben oder leihen/

Thut doch nicht gern der geitzig das/

Er meynt es sey verlohren:

Solchs dich o Christ nicht irren laß/

Der du auß Gott geboren.

Hang dein hertz an kein zeitlich gut/

Es muß endtlich verschwinden/

Vnd wenn der Mensch absterben thut/

Lest ers dahinden/

Nichts davon bleibt ihm/ denn allein/

Was er den armen leuten

Hat geben/ das wird fruchtbar seyn/

117 In den zukunfftig'n zeiten.

Das du hie gibst wirst finden dort/

Bey Gott im andern leben/

Vberflüssig nach Christi Wort/

Wird man dir widergeben/

Heltstu nun diese wort für war/

Vnd trawst Christo dem Herren/

So mach den Glauben offenbar/

Vnd gib zu seinen ehren.

Trawt man doch wol eins Menschen Kindt/

Da doch all Menschen liegen/

Alß David sagt/ und man befindt 
Wie sie gar offt betriegen:

Dennoch gibt man sein gelt dahinn/

Daß mans wider bekommen

Mög/ und einsamlen mit gewinn/

$\mathrm{Zu}$ mehren seine Summen.

Solt man denn nun nicht billig mehr/

Den worten Jesu trawen/

Vnd folgen seiner guten Lehr?

Ist doch auff jhn gut bawen;

Man findet bey ihm kein betrug/

Er helt vest sein zusagen;

$\mathrm{Zu}$ b'zalen hat er auch genug

Vb'r ihn kan niemand klagen.

Wer nun begehrt zu haben g'winn/

Für sich und seine erben/

Der leg sein gelt an den orth hin/

Da ihm nichts kan verderben.

Sein tranck und speiß so er mit fleiß

Auch begehrt zu bewahren/

Kan er behalten gleicher weiß

Wolschmeckend auff viel Jaren.

Merck wol das Herr Spinoeus spricht:

Die allerbesten Schläuche/

Drinn speiß und tranck verdirbet nicht/

Sind armer leute Bäuche.

Was man in solche töpffen thut/

Das kan man lang behalten

Auff kindes kind/ bleibt frisch und gut/

Mag nimmermehr veralten.

Darumb beweiß hülff in der noth

Den elenden und armen/

Vnd Brich Dem Hungrigen Dein Brot

Auß hertzlichem erbarmen:

Von deinem fleisch dich nicht entzeuch/

Dem nackenden gib Kleider:

Bess'r ist wolthätig seyn denn Reich/

Das glauben wenig leider.

In dein hauß den elenden führ/ 
Vnd den der schwach ist stärcke;

Laß niemand trostlos von der thür/

Doch wol daneben mercke:

So diß auß liebe nicht geschicht/

Nutzen dir nicht die gaben:

Nach dem hertzen Gott sicht und richt/

Will die lieb allein haben.

Gebstu all deine güter hinn/

Vnd hettest nicht die liebe/

So brächt es dir doch kein gewinn/

Drumb in der lieb dich übe.

Folgestu hirinn meinem Rath/

Vnd machst dich loß von sünden/

Durch gerechtigkeit und wolthat/

So wirstu gnade finden/

Vnd zu der zeit barmhertzigkeit/

Vom lieben Gott erlangen/

Wenn du in noth und Hertzen leidt

Begehrst hülff zu empfangen.

Dein gebet wird nicht seyn umbsonst/

Dein schreyen nicht verlohren/

So du erzeigst dem armen gunst/

119 Vnd neigst zu ihm dein ohren.

Hüt aber dich für heucheley/

Gott lest nicht mit ihm schertzen;

Wiltu guts thun/ so thu es frey/

Vnd auß gutwillig'm hertzen.

Bistu ein Christ/ so weiß ich gwiß/

Man darff dirs nicht fürschreiben/

Dein hertz wird dir wol sagen diß/

Vnd dich zum guten treiben/

Denn womit man Gott dienen soll/

Vnd seinen Nahmen ehren/

Wissen die ware Christen wol/

Die Gottes lob vermehren.

Ja es bringt den Christhertzen frewd/

Mit gutthun Gott zu preisen/

Vnd die werck der barmhertzigkeit/ 
Den Nechsten zu beweisen.

Sie könnens unterlassen nicht/

Wenn man sie schon wolt zwingen/

Ist doch ihr hertz dahin gericht/

Sie müssen guts vollbringen.

Vnd da es heimlich kan geschehn/

Halten sies gern verschwiegen;

Auff Gottes willn allein sie sehn/

Lassen daran sich gnügen.

O weren heut viel solcher leut!

So hett der Arm gut leben/

Aber wenig zu dieser zeit

Findt man die willig geben/

Da doch jeder solt fleissig seyn/

Sich in der Lieb zu üben;

Denn das gantz gesetz steht allein

In dem wort: Du solt lieben/

Von gantzem hertzem Gott den Herrn/

Von g'müth und allein kräfften:

Vnd deinem Nechsten dienen gern/

Mit worten und geschäfften;

Ihn lieben alß dein eigen hertz.

O möcht diß seyn bey allen!

So wer kein list/ betrug noch schmertz/

Das würd Gott wolgefallen.

Aber leider/ Gott seys geklagt/

Die Lieb ist gar vertrieben;

Hertzlichs erbarmen ist verjagt/

Vnfreundtligkeit geblieben/

Deucalion und Pirra beid

Haben viel Steinen Hertzen

Gelassen nach zu dieser zeit/

Daher kömpt so viel schmertzen.

Boas ist aber längst dahinn/

Gestorben mit den seinen/

Ihm gleich an gemüth/ hertz und sinn/

Findt man itzt schwerlich einen.

Das Hertz ist kalt bey Jung und Alt/ 
Die Christlich Lieb erfroren;

Man klagt und sagt diß mannigfalt/

Ist aber alls verlohren.

Die Reichen Leut mit Vbermuth/

In jhren Gütern sitzen/

Fragen nicht was der Arme thut/

Der den Angstschweiß muß schwitzen.

Ach ihr Reichen bedencket heut/

Lernet bey zeit verstehen/

Wie schwer es sey daß Reiche Leut/

Ins Reich der Himmel gehen.

Alß Christus unser Heiland spricht:

Ach/ ach ihr arme Reichen/

Verstockt doch ewer Hertzen nicht/

Last es euch doch erweichen.

Zuviel nicht auff das Zeitlich seht/

Mittheilet solche gaben/

Suchet den Schatz der nicht vergeht/

121 Da die Dieb nicht nach graben/

Heut weil er noch zu finden ist/

Durch Gott last euch doch sagen/

Sonst jhrs gewißlich ewig müst

Mit ach und weh beklagen.

Wie wolt jhr alßdenn doch bestehn/

Für Christo unserm Herren/

Wenn jhr die Armen werdet sehn/

Bey ihm in grossen ehren/

Die euch hart werden klagen an?

Wie wolt jhr antwort geben/

Wenn gesagt wird daß ihr gethan/

Kein guts in ewerm Leben?

Wen der Herr wird verstossen euch/

Wie wolt ihrs doch denn machen?

Bedenckt wie in des Satans Reich/

So tewr wird seyn das Lachen/

Da jhr von Gottes Angesicht/

Ewig must seyn gescheiden.

O Gottes Zorn! O streng Gericht! 
O unerträglichs leiden!

Ein lange zeit Ist Ewigkeit/

O ihr Mammons Gesellen!

Stetwehrend pein Ohn end wird seyn

Beym Teuffel in der Hellen;

Da Gottes Gnad Ein ende hat.

Bedenckt diß ihr Geltgecken/

Vnd last die Welt Mit ihrem gelt/

Euch nicht mehr so wol schmecken:

Setzet den muth Auffs beste gut/

Das ewig bleibt bestendig.

All's ander man Euch nemen kan

Vnd wird sonst leicht abwendig.

Bessert doch heut/ Ihr geitzign Leut/

Ewr Leben/ weil ihr lebet.

Ewr geitzen last/ Das zeitlich hasst/

Die Seel umb gelt nicht gebet.

Kein Mensch euch kan Erretten dann/

Wann die Seel ist verlohren/

Vnd ihr hernach Schreyt weh und ach

Wer ich doch nie geboren.

Seht ein solch lohn Gibt der Mammon/

Was wolt ihr ihm denn trawen?

Ist doch reichthum Ein schat und blum/

Habt vielmehr dafür grawen.

Reichthum und gelt Den stich nicht helt/

Hilfft keinem vom verderben;

Wenn man muß fort Von diesem orth/

Nimt man nichts mit im sterben;

Das zeitlich hie So man mit müh

Erworben/ muß verschwinden/

Fleucht hin wie staub/ Felt ab wie laub/

Man lest es alles hinden.

\section{Vale Mammon}

Ade fahr hin/ Zeitlich gewinn/

Such Menschen die dich lieben. 
Nim ihr hertz ein Mit deinem schein/

Mich soltu nicht betrüben.

Nach dem Schatz tracht Ich tag und nacht/

Der nimmer kan verderben/

Auch mich im todt Nicht lest in noth/

Sondern errett vom sterben.

$O$ Herr mein Ruhm/ Schatz und Reichthum:

Mein Lust/ mein Frewd/ mein Leben:

Von dir kompt her Das ich begehr/

Wollst diesen Schatz mir geben;

Erhalte mich/ Bestendiglich/

Bey deinem Wort zu bleiben;

Nim von mir ab/ Was ich noch hab/

Das mich davon möcht treiben:

$A l ß$ denn werd ich/ Stets frewen mich/

123 Dir dancken und lobsingen.

HErr mich befreit/ Daß ich allzeit

Dir dien in allen dingen.

Öffne die thür/ Meins Hertzen mir/

Du weist daß ich mit sorgen/

Im selben schrein/ Die Weißheit rein

Such/ die da ligt verborgen.

Jesu mein Herr/ Zu deiner Ehr

Ich diß allein begehre:

Es ist für dir Was mangelt mir/

Mich meiner bitt gewehre:

Regier mein Sinn/ Nim vor mir hinn/

Mein missethat zusamen:

So werd ich seyn/ Schneeweiß und Rein/

Stets preisen deinen Namen/

Amen Herr Jesu Amen.

A.

G.

A.G.V.G.A.

$\mathrm{G}$.

A. 
T.

T.I.T.

$\mathrm{T}$.

\section{Trost In Trawren}

Gestelt durch Annam Ovenam Hoyers.

Mein Höchster Trost in Traurigkeit/

Ist Gottes Providentz allzeit.

L.

L.

A.

VV.

$\mathrm{S}$.

L.L.A.VV.S.G.S.VV.A.L.L.

S.

VV.

A.

L.

L.

Lernet Leiden Alles VVillig/ Seyt Gedüldig

So VVird Alles Leiden Leicht.

Folget Christo/ es ist billig/ wir sinds schüldig/

Wol dem der nicht von jhm weicht.

Ich bins gewiß daß Gott der Herr

Mich wird verlassen nimmermehr:

Hab auch zu jhm die zuversicht/

Er wird mir böß zu schicken nicht;

Sondern creutz/ trübsal und dergleichen/

Muß mir zum guten End gereichen/

Vnd muß daß/ was böß wird genennt/

Gut seyn/ weils kömpt zu guten End. 
Solches glaube ich vestiglich/

Hab auch des zu erfrewen mich/

Dafür dem/ der alles regiert/

Ewig lob/ preiß und danck gebührt.

G.

G.S.G.

G.

Gott Sey Gelobet.

So gut ist Gott/ das Glaube mir/

Er wird nichts böß zuschicken dir/

Alles zu seinem lob er richt/

Vnd dir zum nutz/ dran zweiffel nicht.

Tam bonus est Deus, ut nullo modo permittat malum, nisi inde noverit elicere bonum.

Augustinus.

Gott ist Gut/ Auch alles was er thut/

126 Das erfrewt meinen muth.

\section{Von der Fürsehung Gottes}

Die Göttliche Fürsichtigkeit

Mich trösten kan in allem leit;

Denn was mir widerfahren thut/

Heiß wie es woll/ böß oder gut/

Das alles regiert Gott allein:

Drumb kan ich allzeit frölich seyn.

Daß ein Göttlich Fürsehung sey/

Muß jederman bekennen frey/

Dieweils so hell und offenbar/

Auch in der heilgen Schrifft ist klar/

Durch welche alles wolgeziert/

Verordnet und regiret wird. 
Daß auch ohn die kein ding auff erd

Geschehen ist/ und noch seyn werd/

Wissen wir/ Gott sey lob und ehr/

Denn es ist nichts von anfang her/

Wird auch biß zum end nichts geschehn/

Das nicht zuvor von Gott ersehn.

Vnd wann wir ungezweiffelt diß

Glauben/ und halten für gewiß/

Daß gar nichts geschicht ohn gefehr/

Kan uns kein unglück seyn zu schwer;

Sondern wir können alß Gott will/

Gedüldig seyn und in der still/

Alles ertragen und außstehn/

Weil wir wissen es muß so gehn;

Denn was kan doch mehr frewd im leben

Alß die Fürsehung Gottes geben?

Wir wissen wie die Schrifft vermeldt/

Daß unser hare sind gezehlt/

Ein Sperling ohn Gotts willen nicht

Felt auff die Erde/ Christus spricht.

Wie solt nun dann uns Menschen doch/

Was grössers widerfahren noch/

Ohn Gottes Willen und Fürsehn?

Fürwar es kan je nicht geschehn.

Vnd wenn ich diß bey mir betracht/

Mein Hertz für tausend Frewden lacht;

Auch in der grösten Trawrigkeit/

Kan es seyn voller Lust und Frewd;

Dafür ich Gott lob/ preiß und Ehr/

Will sagen allzeit immermehr/

Das er durch seine Gnad und gunst/

Lauter/ ohn mein verdienst/ umb sonst/

$\mathrm{Zu}$ der Erkentnüß mich gebracht/

Lob/ Ehr und Danck/ sey jhm gesagt;

Er walle auch zu seinen Ehrn/

Den Trost und diß erkentnüs mehrn

In mein'm und aller menschen hertzen/

Dadurch auch lindern alle schmertzen/ 
Vmb Jesu Christ meins Herren willen/

Bitt ich woll Gott mein Wunsch erfüllen.

Amen Hanns Ovens Tochter spricht/

Gott erhört es/ sie zweiffelt nicht.

G.

$\mathrm{H}$.

G.H.V.H.G.

$\mathrm{H}$.

G.

Gott Hat Vnser Hare Gezehlt.

Gott Höret Vnd Heisset Gern.

All's was Gott thut/ Ist nütz und gut/

Vnd g'reicht zu seinen Ehren.

Nach sein'm Fursehn Muß alles gehn/

Niemand kan solches wehren.

Nichts kompt auch her/ Von ohngefehr/

Glück/ unglück/ todt und leben.

Alles regiert Gott/ wie man spührt/

128 Durch sein Fürsehn/ merck eben.

$O$ Frommer Christ/ Wie Selig ist/

Der in all seinen sachen

Von hertzen grundt $\mathrm{Zu}$ aller stundt

Ihm diß kan nutzlich machen.

Es mag kein leit Noch trawrigkeit

Sein Gemüth überwinden;

Nichts ist ihm schwer/ In dieser Lehr

Kan er bald lindrung finden.

All' Weltlich ding/ Helt er gering/

Für Eitel und Vergänglich;

Hat seinen sinn Gesetzet hinn

$\mathrm{Zu}$ dem das überschwencklich;

Ohn Gott er acht Kein pracht noch macht/

Weltfrewd kan er leicht meiden;

Ihm ist stets wol/ Denn was er soll/

Kan er gedultig leiden; 
Jst wie Gott will/ Friedlich und still/

Er hab viel oder wenig/

Es gilt ihm gleich: Denn er ist Reich/

In Gott/ mit dem er einig;

Richt sich allzeit/ In lieb und leit/

Nach Gottes wolgefallen;

Sehr danckbarlich Erzeigt er sich

Auch allzeit in den allen.

Man kan Gott so viel gutes nicht

Zutraw'n/ er ist noch besser.

Groß übelthat hab ich verricht/

Doch ist sein Gnad viel grösser.

So ich im Glauben nur nicht gleit/

Sondern steh' vest ohn wancken/

Bleibt wol vest sein Barmhertzigkeit/

Der ich will Ewig dancken.

G.

$\mathrm{R}$.

M.

G.R.M.H.M.R.G.

M.

$\mathrm{R}$.

G.

Gott Regier Mein Hertz/ Mach Reine Gedancken/

Laß mich in frewd und schmertz ja nicht von ihm wancken. 
H.

G.

G.

D.

D.

G.

V.

G.

B.

E.

M.

G.

H.G.G.D.D.G.V.G.B.E.M.G.G.G.M.E.B.G.V.G.D.D.G.G.H.

G.

M.

E.

B.

G.

V.

G.

D.

D.

G.

G.

$\mathrm{H}$.

Herr Gott Gedencke Doch Deiner Güte Vnd Grossen Barmhertzigkeit/ Erhör Mein Gebet Gnädig/ Gib Mir Ein Beständig/ Gehorsam/ Vnd Gedültig/ Demütig/ Dir Gantz Gelassen Hertz. 


C.
C.G.C.
C.

\title{
Christi Gülden Cron/ Trewer Kämpffer Lohn
}

Auffmuntrung zum Christlichen streit/

Hochnötig heut in dieser zeit;

An mein' drey Söhn und Töchter beid/

Auß Mütterlicher trew geschrieben/

Daß sie sich darin sollen üben/

Vnd unsers Könings Kreutzfahn lieben.

Im Jahr:

Da DIe WeLt Von KrIegen VoLL

AVCh an aLLen orten ToLL war/

IesVs ChristVs Vnser Herr heLffe Vns aVs gefahr.

\begin{abstract}
[Widmung]
Meinen Hertzlieben Kindern/ Söhnen und Töchtern: Casparo, Christiano vnd Friderico-Hermanno, auch Mariæ vnd Christinæ Hoyern Auß trewen hertzgen Mütterlich/ Hab’ diß zur Lehr geschrieben ich:
\end{abstract}

Anna Ovena Hoyers.

K.
M.
K.M.O.M.K.
M.
K.

Kempffet Männlich $O$ Mein Kinder

Seht daß euch niemand daran hinder/

So macht Gott euch zu Vberwinder. 


\title{
C.
}

C.R.C.

C.

\section{Christus Rex Crucis}

\author{
C. \\ D. \\ C.D.K.D.C. \\ D. \\ C.
}

Christus Der König Des Creutzes

Christus des Creutzes König ist/

Nach dem genennet wird ein Christ/

Wie ihr mein' Kinder allzusamen

Auch seyt genant nach seinem Namen/

Vnd in der Tauff darauff getaufft/

Mit seinem teuren blut erkaufft;

Daß ihr ihm sollt seyn unterthan.

Darumb Caspar und Christian,

Auch Friedrich-Hermann, komm't heran/

Seyt willig/ Gott wird helffen dann.

Maria und Christina beid/

Macht euch zu folgen mit bereit.

Gehorchet ewer Mutter Rath/

Begebt euch auff den engen pfath.

Führet würdig im Christenthum/

Den Edlen Namen Gott zum ruhm;

Lebet alß Christen und Christinnen

Vnd folget nicht mehr ewern sinnen

In eigen will'n/ nutz/ lieb und Ehr/

Wie von euch ist geschehn bißher:

Sondern geht unserm König nach/

133 Ohn zorn und rach/ durch schimpff und schmach/

In Lieb/ gedult/ zucht und demut:

So ihr das thut/ wird alles gut. 
Gebet auff ewer sachen acht/

Betet und wacht bey tag und nacht.

Lasst euch von freund/ Mann/ Weib und Kindern

An ewern guten Lauff nicht hindern;

Ew'r eigen Leib und Leben hasst/

Nemet auff euch des Creutzes last;

Sie ist leicht dem/ der sich drinn übet/

Ja sueß dem/ der den König liebet/

Der für uns alle hat gestritten/

Vmb unsernt willen viel gelitten:

Darumb seyt willig unterthan/

Vnd stanthafft unter seiner Fahn/

Alß tapffer Helden in dem streit/

Beweiset ewer Mannlicheit

Wieder die drey haubt-feind zu kempffen/

Satan/ Welt/ eigen fleisch zu dempffen/

Goliat/ Saul und Absolon/

Wie uns die Schrifft fürbildet schon.

Leset sie fleißig mit bedacht/

Klaubt auß den kern/ gebt darauff acht/

Bleibet nicht an den schalen hangen/

Es ist ein bessers zu erlangen.

Ich sag' es euch in rechter trew/

Das alte ist ein bilt auffs new:

Was dort außwendig ist geschehn/

Das muß inwendig dir angehn:

Kehrt umb die augen/ seht einwertz/

Gebt acht auff ewer eigen hertz/

Da wohnt der Schalk/ da helt er hauß/

Seyt fleißig/ treibt denselben auß/

So werdet ihr noch hir auff Erden/

Freyherrn und Freyherrinnen werden.

In die Rustkammer Pauli geht/

Die bey seinen Ephesern steht. ${ }^{1}$

Zieht an den harnisch/ nemt das Schwert/

Setzt auff den Helm/ thut was er lehrt/

1 Cap. 6. v. 11. 
Vnd seyt gestiefelt an den beinen/

Der rechten Krieger art lasst scheinen.

Trett frisch her an/ steht Mann bey Mann/

Greifft keck den Alten Adam an/

Der sich in euch täglich auffrichtt/

Wehrt tapffer euch/ schont seiner nicht/

Leidt und vertragt/ seyt unverzagt/

Bey ewerm Köning alles wagt/

Er ist ew'r schutz und Auffenthalt/

Wird helffen bald; drumb thut gewalt:

Fasst einen starcken helden muth/

Setzet daran leib/ gut und blut.

Gleich wie die Kriegs-leut in der Welt/

Nur umb vergänglich Ehr und gelt

Bey ihrem Haubtmann alles wagen/

Kein last ist ihnen schwer zu tragen/

Sie folgen willig an den orth/

Da Leib und Seel offt wird ermordt:

Solt dann nun nicht ein Christ viel mehr/

$\mathrm{Zu}$ erlangen die Ewig Ehr/

Von diesem Herrn sich lassen führen?

Ist doch bey ihm nichts zu verliehren/

Er gibt die allerbeste beut/

Ewig Reichtumb und Herzlichkeit/

Dazu ihr seyt geladen heut/

Nemet in acht die Gnaden zeit/

Vnd machet euch darin bereit.

$\mathrm{Zu}$ lohn ein Cron und Ehrenkleit/

Auch Ewigwehrend freud ohn leit

Werdt ihr empfangen nach dem streit.

Dafur sey Gott beid nah' und weit

Gelobt und hoch gebenedeit/

Von Ewigkeit zu Ewigkeit.

Christi Gülden Cron/

Vnd das Ehrenkleit/ 
Empfanget zu lohn/

In der Herzlichkeit/

Der in dieser zeit/

Vberwindt im streit.

M.

K.

S.

I.

M.K.S.I.G.I.S.K.M.

I.

S.

K.

M.

Meine Kinder Seyt Im Geist Immer Starck/

Kämpffet Männlich/

Das rathe ich ewere getrewe Mutter

Anna Ovena Hoyers.

H.

F.

I.

H.F.I.H.I.F.H.

I.

F.

$\mathrm{H}$.

Habt Freud Im Herrn

Ihr Fromme Hertzen:

Er lindert gern

All ewer schmertzen;

Will verkehrn/

In frölich schertzen. 


\section{[Freut euch im Herren allezeit]}

F.

F.D.F.

F.

Freude Der Frommen/

Muß von Gott kommen;

Wird nicht genommen.

Freut euch im Herren allezeit/

Lasst kunt sey ewer Lindigkeit.

Der Herr ist nah/ drumb sorget nicht;

Bittet nur so euch was geschicht;

Legt ab die Lügen/ redt Warheit;

Mit ewerm Nehsten friedlich seyt.

Gebet nicht raum dem Lästerer;

Wer g'stolen hat der stehl nicht mehr;

Sondern arbeite mit den händen

$\mathrm{Zu}$ nutz den dürfftig'n und Elenden.

Faul geschwätz/ schandbar wort und zorn

Lasst nicht auß ewerm munde horn;

Vnreinigkeit/ geitz/ Hurerey/

Vnd lästerung fern von euch sey.

Haltet Freundschafft mit Frommen hertzen/

Seit züchtig und Ehrbar im schertzen/

Vnd meidet allen bösen schein.

Lasst ewer Red' holdseelig seyn.

Meynt es mit allen menschen gut/

Vergebt dem der euch böses thut;

Gedenckt was Gott euch hat gethan.

Der Heil'gen notturfft nemt euch an/

Traget mitleiden mit den Armen;

Vnd ziehet an hertzlichs erbarmen/

Werdet an guten Wercken Reich/

Verweist alß Christi Diener euch.

Redet und thut zu jeder frist

137 Was nutz und gut zur bessrung ist.

In summa seyt erbawlich allen/ 
Sündiget niemand zu gefallen;

Seyt in all ewerm thun geflissen

$\mathrm{Zu}$ behalten ein guts gewissen.

Betrübet nicht den Heil'gen Geist/

Sondern Gott mit Danck-psalmen preist.

H.

D.

H.D.S.D.H.

D.

$\mathrm{H}$.

Hosianna Dem Sohn Des Höhsten/

Lobet den Herrn/ dienet dem Nehsten.

G.

G.

$\mathrm{G}$.

G.G.G.S.G.G.G.

$\mathrm{G}$.

$\mathrm{G}$.

G.

Gebt Gern Gehör So Gibt Gott Gnad/

Vnd steht Euch bey mit hülff und Rath/

Das sollt ihr spühren in der that.

Ihr lieben Kinder seyt bereit

$\mathrm{Zu}$ guten wercken allezeit;

Thut fleiß/ daß Gottes Herrligkeit

Durch tugend weit werd außgebreitt:

Habt lust zu seyn in niedrigkeit/

Welt hocheit werffet von euch weit.

Hocheit ist voll gefährlichkeit/

Hocheit bring't viel beschwerlichkeit:

Demut von schwerem fall befreyt/

Die Demut sich mit niemand zweyt/ 
Demut vertreibet Traurigkeit/

Darumb zu Gott nach Demut schreyt.

Fliehet Hoffart/ geitz/ unzucht/ neit/

Hasset den haß/ zorn/ zanck und streit/

Liebet die Lieb und frommigkeit.

Lobet den Herrn in Reinigkeit.

Lebet in fried und Einigkeit.

Thut allen gutes/ niemand leit/

Alßdann fur Gott und menschen beid/

Ihr heut und auch in Ewigkeit

Ruhm-würdig und recht selig seyt.

M.

F.

M.F.V.F.M.

$\mathrm{F}$.

M.

Mercket Fleißig Vnd Folget Mir/

Bittet Gott daß Er euch regier/

Vnd mit des Geistesgaben zier.

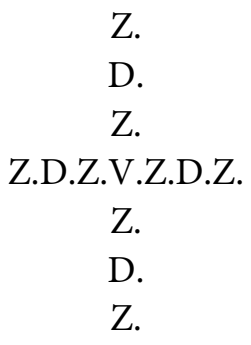

Zähmet Die Zung Vnd Zwingt Den Zorn/

Kein Lästerung lasst von euch hörn.

Zorn kombt auß Hoffart/ machet thorn/

139 Vnd pflegt viel gutes zuverstörn.

Lebet ohn Neit/

Hasset den streit;

Liebt Einigkeit 
In Reinigkeit;

Seyt fromb allzeit/

Thut niemand leit/

So gehts euch wol in Ewigkeit.

Amen.

Tugend Demut ist allen gut/

Ohn Demut niemand gutes thut.

Die Demut ist ein Edle tugend/

Steht wol dem Alter ziert die Jugend.

Demut auß Gottes lieb entspringt/

Demut durch Lieb zu Gott eindringt.

Demut Lieb wieder nieder bringt:

Selig ist/ der nach Demut ringt/

Demselben alles wol gelingt.

Betet Täglich/

So thu auch Ich/

Gott wird erhören Euch und Mich.

Herr/ der du Mir nah' bist/

Laß mich gnad erlangen/

Demut/ die dein Gab' ist/

Von dir zu empfangen.

Amen.

G.

VV.

G.

G.VV.G.K.G.VV.G.

G.

VV.

G.

Gott VVill/ Gott Kan/ Gott VVirt Geben

Allen die nach tugend streben/ 
Jesum lieben und ihm leben/

Was sie bitten/ mercket eben.

G.

G.G.G.

G.

Gottes Gnaden Gab'

Von oben herab.

G.

G.

G.G.G.G.G.

$\mathrm{G}$.

G.

Gott Gibt Gute Gaben Gern/

Bittet drumb und lobt den Herrn/

So wird Er sie euch beschern/

Euch bringen zu hohen Ehrn/

Vnd durch euch sein lob vermehrn.

Der Mensch wird billig hochgepreist/

Der allen Leuten guts beweist.

Der freundtlich/ fromb und friedsam ist.

Der nicht gebraucht betrug und list.

Der Gott in allen dingen traut.

141 Der seines Nehsten wolfart baut.

Der nicht das recht der Armen beugt:

Der nicht wieder die Warheit zeugt.

Der sich durch geitz nicht blenden lest.

Der beym freund steht in Nöten fest.

Der Glauben helt/ den Eydt nicht bricht.

Der der Elenden Sach außrichtt.

Der keinem leit noch schaden thut.

Der sich befleißigt der Demut.

Der sich in Reichtumb nicht erhebt/ 
Der in der Armut frölich lebt.

Der nicht begehrt was er nicht hat.

Der nicht folget der bösen rath.

Der sich in sünden nicht ergetzt/

Der sich nicht bey den Spöttern setzt.

Der Gottes geboth nimbt in acht/

Der vom Gesetz redt tag und nacht.

Der Gottes gaben wol bewahrt.

Der heimlichkeit nicht offenbahrt.

Der seines Nechsten feil bedeckt.

Der sich mit unzucht nicht befleckt.

Der niemands guten Namen schendt.

Der sein zeit Gott zum lob anwendt.

Der sich in guten Wercken übt;

Der alle tröst/ niemand betrübt.

Der Wäisen und Witwen versorgt.

Der willig ist/ gibt/ leiht/ und borgt/

Der mit dem schüld'ger hat gedult.

Der nachlesst und vergibt die schult.

Der sein brot theilt den Armen mit;

Der hülff beweist dem der ihn bitt.

Der böser Leut gesellschafft meidt.

Der gern recht thut/ das unrecht leidt.

Der in Sanftmuth kan tragen schmach/

Der nicht sucht noch begehret rach.

Der nicht schilt/ zörnet/ flucht noch schlegt;

Der sein Creutz auffnimbt/ willig tregt.

Der seiner sünd die straff zuschreibt;

Der in gedult und hoffnung bleibt.

Der fleißig im Gebeth anhelt.

Der wieder auffsteht wann er fellt;

Der nicht in seiner noth verzagt.

Der allezeit dem fried nachjagt.

Der mit danck nimbt was Gott beschert.

Der dem gehorcht der gutes lehrt/

Der alle ding zum besten kehrt.

Der Gottes Will'n zu thun begehrt/ 
Der Jesu Christi Lob vermehrt/

Der der ist werth daß man ihn Ehrt.

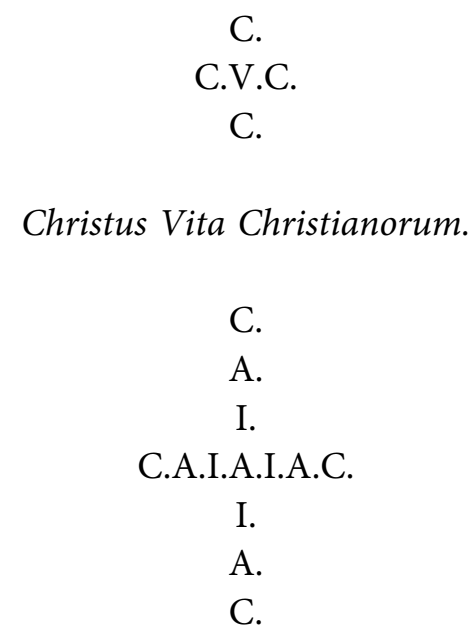

Christus Allein Ist Alles In Allen Christen.

A.

A.G.VV.G.A.

G.

A.

Alles Gut VVircket Gott Allein/

Wol dem der sein Werck-zeuch mag seyn/

Gibt ihm die Ehr/ achtt sich selbst klein/

Sein eigen werck auch für unrein

143 Wie gut sie seyn in ihrem schein.

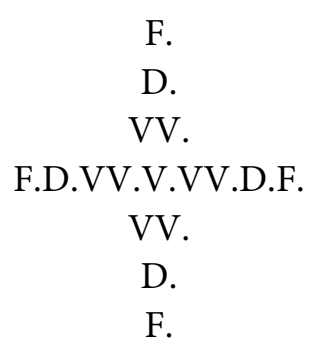


Fliehet Die VVelt Vnd VVollust Des Fleisches/

Bittet den Herrn umb ein reines/ keusches/

Ihm wolgefälligs/ Christliches Leben/

So wird Er es euch gewißlich geben;

Auch was sonst mehr nötig ist darneben.

Dominus sustentavit me,

Der Herr hat mich erhalten.

Sein gnädig hülff ich täglich seh:

Ihn will ich lassen walten.

In Ihn ich fest gegründet steh'/

Sein Reich zukomb/ sein wil gescheh/

In Jungen und in Alten.

G.

G.S.G.

G.

Gelobet Sey Gott/ von

A.O.H.

Hallelujah.

\section{Annæ Ovenæ Hoijers Rath/}

Den sie auß gutem hertzen hat

Allen Alten Wittwen gegeben/

Darnach zuleben;

Vber diese die widerstreben/

Wird unglück schweben/

Diß mercket eben.

Gestellt im Jahr:

ALte WeIber soLLen nICht HoChzeIt haLten/Tantzen oDer sprIngen/ sonDern In Ihrer ReInigkeIt/IVnge Frawen zVerbawen/ Ihre zeIt zV Gottes/ Lob/fröLICh In gVter rVhe zVbrIngen. 
Alte Bleib Allein/

Stell das Tantzen ein/

Laß die Männer seyn/

Hüte dich fürs Freyn/

So du wilt gedeyn.

Halt dich still und rein;

Acht den Rath nicht klein/

145 Gut mit dir ichs meyn.

Ihr Alten Weiber höret her;

Was ich euch rath/ nemt an die Lehr/

Begehret keine Männer mehr/

Sonst stürtzet ihr euch in beschwer/

Vnd wird euch endlich rewen sehr.

Ein Wittwe Alt von Jahren

Soll sich nicht wider pahren/

Vnd im Ehelichen leben/

Beym Mann mehr wider geben;

Sondern in Einsamkeit

Zubringen ihre zeit/

Vnd in der furcht des Herren/

Nach Sanct Pauli begehren/

Die Junge Frawen lehren/

Ihre Ehe-Männer ehren/

Kinder erziehn und nehren/

Des hauses wolfart mehren/

Desselben schaden wehren/

Alles zum besten kehren.

So wird Gott gnad bescheren.

Das wünsch trewlich/

Von hertzen ich 
Ihr Wittwen über funfftzig Jahr

Haltet euch still/ seyt fein Ehrbar/

Liebet das Einsam leben:

Bleibet alß Gott euch hat gesetzt/

In seiner Liebe euch ergetzt:

Das hertz sollt ihr ihm geben/

Vnd nicht mehr treten an den tantz/

Mit Heintz/ Kuntz/ Hannß/ Fritz oder Frantz.

Sie meynens nicht so trewlich

Wie manches Weib sich bildet ein/

Lieben nur ewer gelt allein;

Ohn das seyt ihr abschewlich.

Ich weiß es/ mercket was ich sag/

Ihr seyt den Männern nur ein plag/

Sie können euch nicht lieben.

Ob sie sich freundtlich stellen schon/

Ist doch das hertz sehr weit davon/

Sie müssen sich betrüben.

Mit seufftzen sie zu bette gehn/

In trauren widerumb auffstehn;

Sehn euch scheel an mit schmertzen.

Das Alte blut macht kalt den muth/

Nichts ist annehmlich was ihr thut/

Kein schertzen geht zu hertzen.

Trawt mir ich zeig die warheit an/

Ein altes Weib bey einem Mann

Kan nimmermehr gedeyen.

Exempel hab ich viel gesehn/

Wie wunderbar es pflegt zugehn/

Wann alte Frawen freyen.

Man hats erfahrn bey den Nachbarn/

Wie sie geschleppt sind bey den Harn/

In ihren Alten Tagen:

Daß ich gedacht: O armes Weib/

Wie wird tractirt dein Alter Leib/

Du magst von ungluck sagen/

Hast gethan einen bösen kauff/

Da du dir diesen schlag darauff/ 
Zum Ehmann hast genommen.

Wahrlich es kan nicht wol gedey'n/

Wann Alte Weiber wider frey'n;

Nachrewen pflegt zukommen.

Wie mancher Mann fällt in Ehbruch

Darüber in Gotts zorn und fluch/

Ins Richters hand darneben?

Liebe Fraw Alte saget doch/

Wo kompt diß her? man fraget noch:

Habt ihr kein ursach geben?

Ja freylich/ jhr seyt schüldig dran/

Daß euch der Mann nicht lieben kan:

Dann es ist nichts zufinden

An ewerm leib und Angesicht

Das jhn zur lieb bewegen mücht/

Er seh' vorn oder hinden;

Beym Alten Weib wird keiner frisch/

Es sey im Bett od'r an dem Tisch/

Bedencket diß jhr Alten.

Im Ehstand' ihr euch gar nicht schickt/

Kein Mann wird mehr durch euch erquickt/

Wer kan's mit Alten halten?

Sie sind der Männer Fegefeur/

Ihr gelt kaufft mancher viel zu theur/

Wer' gern davon frey wider:

Spricht: O daß ich ein' Junge hett/

Bey der ich möcht im Ehebett/

Außstrecken meine glieder.

Sehr thörlich hab' gehandelt ich/

Da ich ließ also binden mich/

$\mathrm{Vmbs}$ losen geldes willen.

O phuy der schand/ wer löst den band?

Ist dann niemand im gantzen land/

148 Der mir mein leit kan stillen?

Gott stürtz den Pfaffen in die Hell/

Der mich bandt an das Alte fell/

Er hat gehandelt trüglich:

Daß ihm ankomb die schwere seuch. 
Er sprach: Wachset und mehret euch/

Wust doch daß nicht war müglich.

Ach leider ach/ es ist geschehn/

Geschehn ding' nicht zu endern stehn/

Hin ist mein freud und lachen:

Zuseufftzen wird mein hertz beweg't/

So offt ich seh' daß sie sich reg't;

Ach/ ach/ wie soll ichs machen?

Wer hilffet mir? wer steht mir bey?

Wer mach't von ihr mich wieder frey?

Wer kan mein leiden enden?

Niemand ohn Gott; Er helff auß noth/

Ihn bitt' ich/ daß Er woll den todt

$\mathrm{Zu}$ meiner Alten senden.

Die Red' hört man/ und noch viel mehr/

O liebe Alt' so gehts daher/

Todt wunschet er euch täglich;

Verfluchet beid die stund und zeit/

In welcher er euch hat gefreyt/

Nichts ist an euch behäglich:

Vnd diß/ so noch das ärgste ist/

Das ihm benimbt all lieb und lust/

Er kan nicht Vater werden;

Bekombt von euch kein Kinderlein/

So lang ihr lebet/ muß er seyn

Ein Dürrer Baum auff Erden.

Ew'r Magnet hat sein krafft verlohrn/

Kein Kindt wird mehr auß euch geborn/

Das bringt dem hertzen schmertzen/

Vnd thut ihm weh/ wann er muß sehn

Ins Nachbarn hause Kinder gehn/

Die mit dem Vater schertzen:

Wann sie alß Pfläntzlein Jung und frisch/

Sich mit der Mutter an den Tisch

$\mathrm{Zu}$ seiner seiten setzen/

Sieht sie des Alten Weibes Mann/

Sehr traurig an/ und spricht alßdann:

Was soll doch mich ergetzen? 
Ich hab im Hauß kein zeitvertreib/

Muß einsam seyn beym Alten Weib/

Das mich nicht kan erfrewen!

O daß ich so verheyrath bin/

Wie geht mein Edle zeit dahin/

Mein tag wirds mich gerewen!

Also ihr Alten Weiber seht/

Was auß ewer beyrath entsteht/

Stellet doch ab diß klagen/

Bleibt ungefreyt in reinigkeit/

So macht ihr euch kein hertzenleit/

Den Männern auch kein plagen.

Wollt ihr daß es euch wol soll gehn/

So lasst das freyen nur anstehn/

Befehlt es Jungen Frawen;

Denn dar ist noch ja hoffnung an;

Ein Junge Fraw kan ihrem Mann

Die Welt noch helffen bawen.

Ein Altes Weib dient nirgends zu/

Dann fein zu sitzen in der ruh'/

Oder den Kindes-kindern

Auffwarten und behülfflich seyn/

Sie wiegen/ winden/ halten rein/

Vnd wischen ihren hindern:

Das thut weil Gott euch kräffte günnt/

Vnd was ihr sonst im hause könnt/

Mit Nehen oder Spinnen.

Trawt Gott und betet in der noth/

So werdet ihr wol ewer broth

150 Ohn einen Mann gewinnen.

Gott nimmt sich der Elenden an/

Ist aller frommen Wittwen Mann/

Ein Vatter ihrer Kinder:

Weiß was ein ieder nötig hat/

Gibt allen Notturfft und Vorrath/

Sein schatz wird nimmer minder.

Seht nur auff ihn/ sonst auff niemand/

Nem't alles an von seiner hand/ 
Seyt danckbar seiner gaben;

Vnd willig so gern Arm alß Reich/

Es sey euch gleich Gott speise euch

Durch Engel oder Raben.

Ist übrig/ theilt mit dem der bitt/

Nach aller frommen Christen sitt;

Habt ihr nicht viel/ gebt weinig.

Die Jungen Leute wollet lehrn/

Gott fürchten/ und die Alten ehrn/

Lebt mit den Nachbarn einig.

In Demut/ zucht und frommigkeit/

Der Jungen Frawen Spiegel seyt/

Geht ihnen vor in Tugend;

Lehret sie ihre Männer ehrn/

Das Hauß regiern/ die wolfart mehrn/

Vnd wol erziehn die Jugend.

Ein jeder lern sein Lection/

So steht im Hause alles schon/

Ist billig hoch zu preisen.

Darumb alß Wittwen auch gebührt/

Einen Christlichen wandel führt/

Mit Lehrn und Vnterweisen.

In der Armut gedültig seyt/

Frölich in widerwertigkeit/

Vnd lasset euch nicht grawen/

Hoffet das best/ und glaubet fest/

Daß Gott in noth nicht stecken lest

Die seiner zusag trawen.

So euch zufällt reichtumb und gelt/

Nach art der Welt euch dann nicht stellt/

Euch darin zuergetzen:

Sondern wie rechte Christen thut/

Die auff vergänglich/ irdisch gut

Hertz/ sinn und muth nicht setzen.

In Gottes freud die zeit vertreibt/

Leset und betet/ singt und schreibt;

Gebt gut Exempel allen:

Könnt ihr nicht lesen/ höret zu/ 
Vnd Meditiret in der ruh/

Daran hat Gott gefallen.

Sein lob wird dadurch außgebreitt

Vnd seines Namens herrlichkeit

Gebaw't an allen Orten;

Helffet dazu stets/ wo ihr künnt/

Vnd thut fleiß daß ihr viel gewinnt/

Mit Wercken und mit Worten.

Im guten leben wandelt fort/

Richtt ewer thun nach Gottes Wort/

Geht fleißig mit in Tempel;

Betrachtet was da wird geredt/

Vnd haltet euch stets am Gebeth/

Thut nach Hannoe Exempel:

Die ihr zeit in keuscheit zubracht/

Diente dem Herren tag und nacht/

Setzt auff ihn ihr vertrawen:

Drumb ward das heil ihr offenbart/

Diß ist der rechten Wittwen arth/

Gott wird ihr wolfart bawen/

Sie werden ihn anschawen/

Auff einer grünen Awen/

152 Selig sind solche Frawen.

Kurtz Bedencken von der Alten Weiber Heyrath,

Da Gott nichts mir zu schaffen hat.

Gestellt in Wästerwijck, im Julio, Anno 1643.

\author{
A. \\ VV. \\ A.VV.L.VV.A. \\ VV.
}

A.

Alte VVeiber Laßt VVohnen Allein/ 
Denn sie in der Ehe nicht tauglich seyn/

Ich schreibe euch hie die Warheit rein/

Gehorchet mir/ sehr gut ich es mein.

Diß mein Kurtz Bedencken/

Habe ich wolen schencken

Casparo, Christiano und Friederico-Hermanno Hoyern.

Meinen hertzlieben Söhnen/ und allein jungen Gesellen/ auch jungen und alten Männern/ die nach Ehren streben/ und im Ehe-leben sich wollen begeben/wünsch jhnen Gottes Gnad darneben.

Ein Mann der lust zu freyen hat/

Soll erstlich bitten Gott umb gnad:

Vnd darnach folgen mit der that

Annæ Ovenæ Hoijers Rath:

Ders nicht will thun, wird haben schad.

Abschewlich ist mir anzusehn

Ein altes Weib fürm Pfaffen stehn/

Beym Mann sich lassen trawen.

Kein lust/ frewd oder zeitvertreib

Kan seyn bey einem alten Weib/

Das Ansehn bringet grawen.

Was solt denn das anrühren nicht?

$\mathrm{O}$ armer Mann der sich verpflicht

Sein zeit so hin zu bringen

Ohn frucht/ frewd und ergetzligkeit/

Verlohren ist all sein arbeit/

Das heist nach unglück ringen.

Ist doch kein lieblichkeit daran!

Man schmück es auch so schön man kan/

Laß koltzen/ kosen/ kallen

Babst/ Bischoff/ Bader/ Herr und Knecht/

Wenn sie es hielten all für recht/

Wills mir doch nicht gefallen.

Ich halt der Alten Weiber Frey

Für ein Ehrbare Hurerey

Warheit höfflich zu sagen: 
Aber man wil sie hören nicht/

Sie findt kein Herberg/ wie man spricht/

Dennoch muß ich es wagen/

Vnd sagen: Es ist schand im Land

Daß man setzt solche im Ehestand

Die nicht mehr können taugen.

Betrachtet des Ehestands final.

Ich bitt euch alle noch einmal/

Seht doch mit eignen augen/

Wachset und mehrt euch/ spricht der Herr/

Kein altes Weib dient darzu mehr/

Ist dann solch Frey nicht grewlich?

O lieben Männer jung und alt/

Der Alten Weiber euch enthalt

Ich warn euch für sie trewlich:

Denn es ist doch bey ihrer frey/

Kein Gottes segen noch gedey.

Ein solch Heyrath gehöret

Zum grewel der Verwüstung mit/

Der Geist des Lebens wird verschüt/

Viel guts dadurch zerstöret/

Des Herren grimm und straff erweckt/

Vnd das Gewissen sehr befleckt/

Diß wollet wol bedencken:

Vnd ewer Adelich Freyheit/

Mannliche Krafft und Herrligkeit

Nicht Alten Weibern schencken.

Sonst daß man Alte Frawen ehrt

Ist billig/ weil die Schrifft es lehrt/

Wenn die sich ehrbar halten/

Lehren die Junge Frawen fein

Keusch/ unterthan und heußlich seyn.

Sind recht Ehrliche Alten/

155 Ihr Hoffnung ist gestelt zum Herrn/

Er ist der Mann den sie begehrn/

Vnd keinen mehr zu kennen/

Ihnen soll man im Wittwenstand

Gern reichen die Hülffliche hand 
Sie liebe Mutter nennen:

Aber Ehe-Weib das ist zuviel.

Vnd weit geschritten übers ziel;

Darumb laßt solche bleiben

In jhrer Ruh und Einigkeit/

So könnt ihr auch ohn rew und leit/

In Frewd die zeit vertreiben.

Ob schon ein Mann alt ist, noch dann

Er wachsen und sich mehren kan

Oder sein Hauß auffbawen/

Vnd setzen newe stützen drein/

Nemlich hertzliebe Kinderlein

Bey einer Jungen Frawen;

Aber ein Junger Mann im hauß

Beym alten Weib/ richt gar nichts auß/

Hopffn und Maltz ist verlohren/

Die Brüst sind leer/ drinn ist nichts mehr/

Der alte Leib steckt voll beschwer/

Nichts guts wird drauß geboren.

Darumb jhr Freyer rath ich euch/

Erwehlt ein Junge Tugend-reich/

So wird ewr Stamm-baum grünen;

Sie kan vermehren ewr Geschlecht/

Vnd euch mit Lieb auffwarten recht

In allen dingen dienen/

Die das thun/ O wol ihnen!

Laßt alte Weiber unberührt/

Vnmolestirt und unturbirt/

Ins Hauß ein Junge Jungfraw führt/

Vnd damit ewern Ehstandt ziert/

Wer diß nicht thut/ der ist vexiert/

Schimpff er zum schaden haben wird.

A.O.H. 
Judicium vber des in Gottseeligen Herrn Caspari Schvvenckfelds Buch vom Worte Gottes/ etc

Gestellt Im Julio, Anno 1642.

I.

A.

VV.

D.

I.A.VV.D.VV.D.VV.A.I.

D.

VV.

A.

I.

Im Anfang VVar Das VVort/

Das VVar Allein Iesus.

Sein krafft bringt altes fort/

157 Ist aller ding beschluß.

A.D.

I.A.

VV.VV.

A.I.VV.D.VV.I.A.D.A.VV.G.VV.A.D.

VV.VV.

I.A.

A.D.

Allein Iesus $V V$ ar

Das VVort Im Anfang/

Bleibet immerdar/

Ohn End und abgang.

Das Allmächtig VVort

Gibt VVesen Allen Dingen.

Hat Kraft immerfort/

Alles herfur zubringen. 
G.VV.

VV.G.

I.I.

G.VV.I.C.I.VV.G.VV.G.I.C.I.G.VV.

I.I.

VV.G.

G.VV.

Gottes VVort Ist Christus Iesus VVarer Gott.

Wird wie Töpff zerschmeissen die Gottlose Rott/

Vnd alle seine feinde machen zu spott.

VVarer Gott Iesus Christus Ist Gottes VVort.

War im anfang bey Gott und bleibt immerfort/

Sein Nahm sey gebenedeyet hie und dort.

I.

VV.

$\mathrm{S}$.

D.

I.

$\mathrm{S}$.

I.VV.S.D.I.S.VV.S.I.D.S.VV.I.

$\mathrm{S}$.

I.

D.

S.

VV.

I.

Ich VVerde Seyn Der Ich Seyn VVerde, Spricht Iesus Das Selbstendig VVort Iehovah. 


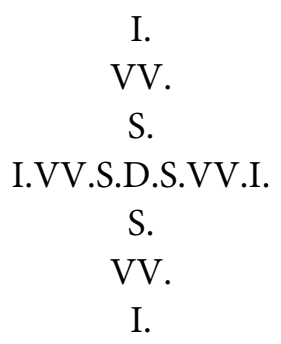

Ich VVerd Seyn

Der Seyn VVird Iesus.

Bin allein/

159 Anfang und Beschluß.

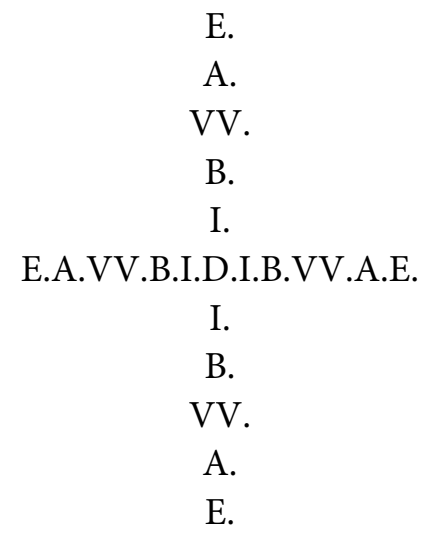

Ehe Abraham VVar Bin Ich/

Der Ich Bleiben VVerd Auch Ewig. ${ }^{1}$

1 Joh. 8. v. 58 
I.

VV.

$\mathrm{S}$.

D.

$\mathrm{H}$.

M.

G.

I.

E.

I.VV.S.D.H.M.G.I.E.V.E.I.G.M.H.D.S.VV.I.

E.

I.

G.

M.

$\mathrm{H}$.

D.

S.

VV.

I.

Ich VVerds Seyn/ Der Hat Mosen Gesandt

In Egypten/ Vnser Erlöser/ Israëlo Gott/

Mein Herr/ Das Sprechend VVort/ Iesus. ${ }^{2}$

2 Exod. 3. v. 14. 
I.

A.

VV.

D.

VV.

$\mathrm{G}$.

B.

G.

I.A.VV.D.VV.G.B.G.VV.G.B.G.VV.D.VV.A.I.

$\mathrm{G}$.

B.

G.

VV.

D.

VV.

A.

I.

Im Anfang VVar Das VVort Gottes Bey Gott/ VVar Gott/ Bleibet Gott/ VVelcher Da VVar/ Allein Iesus. ${ }^{3}$

C.

$\mathrm{S}$.

C.S.E.S.C.

$\mathrm{S}$.

C.

\section{Casparus Schvvenckfeldius est Sanctus Christianus}

Caspar Schwenckfeld Ein Seeliger Christ

Vnd Zeug der reinen Warheit ist/

Sein gedechtnüß bleibt jederfrist/

Wird nicht gedempfft durch Satans list.

3 Joh. 1. vers. 1. 
Der Frommen Lob breittet auß mit reden und schreiben/

Der Gerechten gedechtnüß wird im Segen bleiben, ${ }^{1}$

Kein Teuffel oder böser Mensch wird sie vertreiben.

Caspar Schvvenckfeld von Ossing ist

Der Warheit zeug, ein Frommer Christ;

Hat Gottes Wort bey seiner zeit

Durch red und schreiben außgebreitt/

Vnd umb deßwillen viel gelitten/

Weil Satan wieder ihn gestritten/

Vnd seine Hund' an ihn gehetzt/

Die ihm starck haben zugesetzt/

Vnd hätten ihn zerrissen gern:

Aber er war im schutz des Herrn/

Sie musten ihn passieren lassen

Frey unbeschädigt seine strassen.

Er hat gelebet Gott zum preiß/

Vnd ruhet itzt im Paradeys:

Sein Bücher gehn/ Satan zum trotz/

Durch Stät und Land/ sind vielen nütz/

Auch kommen Gott sey lob zu mir/

Viel gutes ich darinnen spühr/

Des waren Wortes Eigenschafft/

Sein lebendige würcklich krafft/

Sein wesen her von Ewigkeit/

Wird uns hirin klar angedeut.

Auch vom Buchstab der Heilig'n Schrifft/

Was sein Würckung und art betrifft/

Vnd daß er nur sey ein Figur/

Des Waren Worts contra-factur/

So für den eussern Menschen ist;

Aber Gottes Wort Jesus Christ/

Ist Geist und Leben/ redt inwendig/

Machet allein das hertz verständig/

Endert der Menschen sinn und muth/

Reicht weiter dann der Buchstab thut.

1 Prov. 10. vers. 7. 
Das Eußer nur die Ohren rührt/

163 Das Inner wort zum Geist einführt;

Bringt mit ihm lebens krafft und safft/

Ohn diß das Eußer weinig schafft/

Drumb soll man nach dem Innern trachten/

Das Eußer aber nicht verachten;

Sondern zum zeugnuß nemen an/

Weil es uns dazu dienen kan/

Vnd ist darumb gebracht ans Liecht/

$\mathrm{Daß}$ es uns sey zum unterricht/

Vns tröst/ lehr und vermahn mit fleiß ${ }^{2}$

Zuführ/ und auff das Inner weiß:

Kan sonst nichts mehr/ ist viel zu schlecht;

Der Geist ist Herr/ der Buchstab knecht.

So ich des Worts krafft soll geniessen

Muß der Herr selbst mein hertz auffschliessen.

Gleich wie der Purpur Krämerinnen/

Alß wir in Actis lesen künnen. ${ }^{3}$

Vmbsonst ist was man hört und list/

So nicht das Wort inwendig ist.

Paulus pflantzt/ Apollo begeust/

Vom Herren das gedeyen fleust, ${ }^{4}$

Das inner kan sein wirckung haben/

Ohn eußer mittel und Buchstaben:

Aber ohn krafft des innern liechts/

Wircken die eußern mittel nichts.

So uns soll nutz seyn hörn und lesen/

Muß wircken diß das ware wesen.

Das Wort das uns die Schrifft erklert/

Die Salbung die uns alles lehrt/

Ist die warheit die niemand treugt/

Ein Mund ohn falschheit/ der nicht leugt/

Der Schlüssel Davids der auffschleust/

Der Brunn darauß die Weißheit fleust/

2 Rom. 15. 4.

3 Cap. 16. vers. 14.

4 1. Cor. 3.v.6. 
Ein Liecht so das hertz illustrirt;

Der Weg so uns zum Vater führt.

Im Anfang war dieß Lebens Wort/

War bey Gott/ war Gott/ bleibt hinfort/

Bey Gott und Gott in Ewigkeit.

Vnd diß Wort ward Fleisch in der zeit/

Ist zu uns in die Welt gekommen/

Ward von der Welt nicht angenommen:

In der finsternuß scheint diß liecht/

Die finsternuß begreifft es nicht.

Druch diß Wort ist die Welt gemacht/

Vnd/ was man sicht/ ans liecht gebracht:

All' wachsende ding kommen fort

Noch täglich/ durch diß kräfftig Wort.

Diß Wort ist der Balsam in allen/

In Thieren/ Kräutern und Metallen.

Alles wird durch diß Wort bewegt/

In diesem Wort sich alles regt.

O blinder Menschen unverstandt/

Möcht euch diß Wort seyn recht bekant!

Ihr würdet ander sachen spühren/

Vnd viel ein bessers leben führen/

Aber wer ist der darnach fraget?

Man schreyt und schreibt/ man singt und saget/

Ist alles umbsonst und verlohren/

Verstockt und verstopfft sind die ohren.

Das mach't der böse will allein/

Keiner begehrt recht weiß zu seyn;

Jedermann meynet er sey klug/

Der Buchstab geb' ihm liechts genug.

Kompt einer her und sagt vom Geist/

Der wird sehr übel abgeweist/

Vnd alß ein Ketzer hart verklaget/

Incarcerirt oder verjaget/

Genant Schwenckfelder und Phantast/

Rosencreutzer/ Enthusiast/

Chiliast/ Weigelianist/

Davidianer/ Neutralist. 
Welche nicht mit dem grösten hauffen

165 Den breiten Welt-weg wollen lauffen:

Sondern nach Christi Lehr sich halten/

Die sind verhasst bey Jung'n und Alten.

Ja, alle die den innern grund/

Mit hand und mund recht machen kund/

Vnd vom Geist sagen oder schreiben/

Können nirgend mit frieden bleiben.

Der Dreyköpffige Hund der Hellen/

Kan's lassen nicht/ muß sie anbellen:

Ihr keiner vom Geist hören will.

Wilt haben fried/ schweig davon still; ${ }^{5}$

Das inner wort redt viel zu hart/

Wieder des alten Adams art.

Es ist dem fleisch ein schweres Creutz/

Keiner von den Welt-kindern leidts/

Weil sie zu weit sind außgefallen;

Der alte Wahn ist starck in allen.

Die breite Bahn ist leicht zu lauffen/

Man helt es mit dem grösten hauffen.

Welt gunst und freundtschafft hindert viel/

Daß man nicht kompt zum rechten Ziel.

Der Gelerten Authorität/

Vielen frommen im liecht auch steht/

$\mathrm{Daß}$ sie nicht wieder kehren ein/

$\mathrm{Zu}$ dem darauß sie kommen seyn.

Der Ketzer Name manchen schreckt/

Daß er den kern der Schrifft nicht schmeckt.

Keiner will sich gern schelten lassen/

Vnd sehn daß ihn die Freunde hassen.

Man liebet mehr Welt-freund' und Ehr/

Alß Gottes Wort und reine Lehr.

Darumb bleiben auch viel dahinden/

5 C.

C.L.C.

C.

Cerberus Lästert Chrillum. 
Werden die Weißheit nimmer finden.

Aber all' die sich hertzlich gern

Woll'n lassen lehrn vom Geist des Herrn/

Vnd nach dem schatz im Acker trachten/

Welt-kunst/ gunst und freundtschafft verachten/

Schmach/ schelt- und Läster-wort vertragen/

Nach Ehr und Ansehn nicht mehr fragen/

Die Welt und alle ding verlassen/

Ja, auch ihr eigen leben hassen/

Die sind durch Gottes gnad geschmückt/

Würdig gemacht und wolgeschickt/

Im innern Tempel einzugehn/

Des Herren Herrlicheit zusehn.

Oratio

O Wesen das all' ding beweg't/

In dem sich alles Wesen reg't/

O inner Kern/ O Morgenstern/

O glantz der Herrlicheit des Herrn/

O sprechendes Wort/ Gottes Sohn/

Sende herab von deinem Trohn

Deine Weißheit/ zu lehren mich/

O Gott von Gott, erbarme dich.

O Liecht von Liecht brich doch herein/

Vnd meiner Seelen grund beschein:

Mach auff das thor meins Hertzen weit/

Zeuch ein/ laß sehn dein Herrlicheit.

O du mein Leben, Lieb und Liecht/

Komb doch/ erleucht mein angesicht:

Laß mich nicht mehr im finstern gehn/

Weil meine augen auff dich sehn/

Wie auff die händ der Herrn und Frawen/

Der Knecht und Mägde augen schawen.

Vertreib die finsternuß inwändig/

Vnd mache mich doch recht verständig:

Mein unverstand ist dir bekant/

Helff mir davon/ sonst kan niemand. 
Kom Herz besuch dein eigen hauß/

Die Tauben-krämer treib darauß/

Stoß umb die bänck der Wechseler/

167 Daß sie darin nicht handlen mehr;

Dir geb ichs gantz/ befehl dirs gar/

Mach doch dein werck drinn offenbar/

Nach deinem guten wolgefallen;

Der du alles regierst in allen/

Schick alles zu deins Namens Ehr/

Diß und nichts mehr begehr ich Herr/

Dein Reich zukomb/ dein Herrlichkeit

Werd allenthalben außgebreitt/

Dein Nahm sey Hochgebenedeyt/

Heut und auch Ewig nach der zeit.

Amen.

$\mathrm{H}$.

I.

K.

L.

D.

H.I.K.L.D.S.D.L.K.I.H.

D.

L.

K.

I.

$\mathrm{H}$.

HErr Iesu Komb Laß Doch Scheinen

Deines Liechts Klarheit Im Hertzen.

Gib wiederumb nach dem weinen

168 Trost und Underung in schmertzen. 


\title{
Deutsche Wahrheit
}

Jesu dem Herrn/

Vnd allen die ihm folgen gern/

Auch fleiß ankehrn/

Sein Lob zu mehrn/

Gestellt zun Ehrn/

Durch Annam Ovenam Hoyers,

\author{
Im Jahr: \\ Gehet nVn aVs o Ihr I Vngfrawen/ \\ Vnsern König IesVm zV schawen/ \\ AVff Der grVnen Awen.
}

D.

$\mathrm{K}$.

D.K.VV.K.D.

$\mathrm{K}$.

D.

Du Klare VVarheit Komb Doch/

Mach den Lügener stumm doch/

Vnd den der böß ist/ fromb doch.

K.
L.
D.
VV.
K.L.D.VV.B.VV.D.L.K.
VV.
D.
L.
K.

Komb Liebe Deutsche VVarheit/

Bring VVieder Dein's Liechts Klarheit. 
Ihr Fromme hertzen in gemein

Lasst euch/ bitt ich/ diß klein Büchlein

Lieb umb der Warheit willen seyn.

Nemts an von mir/ so/ wie ichs hir

Euch prosentir und offerir:

Leset und judiciret recht/

Es wird darin gezeiget schlecht

Die art der klugen Letter-knecht.

Was Babels Bulen sind für leut

Welche die Welt regiren heut.

Fur ihrem thun gewarnet seyt;

Cavete vobis, spricht der Herr/

Gehorchet seiner trewen Lehr;

Liebet Warheit/ gebt Gott die Ehr/

Vnd lasst euch nicht verführen mehr;

Sonst werdet ihrs beklagen sehr/

Vnd wird die straff euch fallen schwer.

F.
H.
VV.
F.H.VV.H.VV.H.F.
VV.
H.
F.

Fromme Hertzen VVerden Heut

$V$ Varheit Herrlich Finden.

Kommet suchet lieben Leut/

Seyt nicht alß die blinden:

Lasset Warheit euch bey zeit

Reinigen von sunden;

Denn ihr gesicht bringt ein Liecht

170 Das nicht wird verschwinden:

Sie kompt nun bald/ mit gewalt/

Vnd wird überwinden

Die Lügener nah' und fern/

Sampt all' die euch schinden: 
Steht Warheit bey/ rühmt sie frey/

Lasst das Maul nicht binden:

Es hang' ihr an/ jedermann/

Keiner bleib dahinden.

Deutsche VVarheit bin ich genant.

Denn Frommen Hertzen wolbekant/

Von einer Frawen außgesant/

$\mathrm{Zu}$ suchen Herberg hie im Land:

Möcht ich sie finden bey jemand/

So wer' mein müh' wol angewandt;

Gott behüt' mich für spötters hand.

K.
D.
D.
L.
D.
VV.
K.D.D.L.D.VV.T.VV.D.L.D.D.K.
VV.
D.
L.
D.
D.
K.

Komb Doch Du Liebe Deutsche VVarheit/

Treib VVeg Die Lügen Durch Dein' Klarheit.

Dein heller Stern/

Jag von uns fern

Die Cantzel-herrn

So unrecht lehrn/

Die Schrifft verkehrn/

Das gute wehrn/

Vnd wieder dich

Aufflehnen sich/ 
Ihr, Macht zerbrich:

Erhöre mich/

Alßdenn preiß ich

Dich Ewiglich.

Amen.

Frombhertz und Deutsche Warheit/

Sprechen hir zusamen beid.

Frombhertz voll schmertz/ klagt/ fragt und sagt/

Weil man die Warheit hat verjagt:

\section{Frombhertz:}

Ach Gott was helt die Warheit auff?

Wer hindert sie in ihrem lauff?

Von hertzen verlangt uns nach ihr/

Will sie nicht wiederkommen schir?

Aber so viel ich kan ansehn

Vnd mit meiner vernunfft verstehn/

Merck ich daß ihr ist sonderlich

Das Pfaffenvolck sehr hinderlich:

Das hat ein ansehn in der Welt/

Mit dem der gröste hauff es helt.

Die Cantzel-herrn von Hohen-schulen/

Sind Babels allerliebste Vulen/

172 Die Titul-trager/ frommen plager/

Warheit verklager und verjager/

Geitzige blutsaugende Jgel/

Ligen fur die Warheit alß Riegel/

Regieren das gantz Römisch Reich/

An macht ist ihnen keiner gleich:

Sie fressen lecker/ schlaffen weich/

Vnd wollen gern man soll sie Ehrn.

Mit ihren lehren sie viel verkehrn.

SAL Diaboli hat sie gar

Gesaltzen/ das ist offenbar: 
Die Hoffart/ der Geitz/ die Vnzucht; ${ }^{1}$

Den baum kennt man bey seiner frucht/

Ihr hertzen sind voll böser list/

In ihnen ist der Anthichrist.

Ich wolt sie wol abmahlen nun/

Durfft ichs fur bösen leuten thun;

Aber die Warheit ist versteckt/

Vnd muß ein zeitlang seyn verdeckt:

Dieweil sie nichts denn haß erweckt/

Auch nicht gleich allen leuten schmeckt.

Der Sonnen glantz die Nacht-Eul schreckt;

Hört der Wolff daß ein Schäflein bleckt/

Bald er sein klawen herfur streckt/

Zerreist das fleisch/ das blut er leckt:

So pflegt es der Warheit zu gehn/

Wenn sie lesst ihre klarheit sehn;

Geht noch so all'n die ihr beystehn:

Solt mir imgleichen wolgeschehn.

Veritas parit odium/

Das erfähret man täglich/ drumb

Muß ich auch seyn alß wer' ich stumm.

$\mathrm{O}$ du Ewige Warheit komb/

Laß dich doch sehn bald wiederumb/

Mach klug das tumm/ das böse fromb/

Vnd bring zu recht was noch ist krumm/

Komb doch o liebe Warheit komb.

Veritas:

Harr noch ein weil/

Ich komm in eil

Zu rechter zeit/

Bin nicht mehr weit.

Kein Lügener

Soll, wie bißher

Offt ist geschehn/

1 Superbia. Avaritia. Luxuria. Hoffart. Geitz. Vnzucht. 
Mir wiederstehn/

Noch meinen lauff

Mehr halten auff.

Hab nur gedult

In Gottes huld/

Vnd wart' auff mich/

Alß denn will ich

Durch mein zukunfft erfrewen dich.

Frombhertz:

Liebe Warheit verzeuch nicht lang/

Mir ist sehr bang/ ich bin im zwang/

Möcht wissen gern obs lang soll wehrn.

Vnd frage noch/ bitt sage doch/

Warumb Gott in der Welt

Sich so lang zornig stellt

Vnd mit der straff anhelt/

Weil wie die Schrifft vermeldt/

Ihm guts zuthun gefellt?

Veritas:

Gott wolte euch gern guts thun alß seinen kindern/

Aber ewer sünde sind groß die das hindern.

Man findet unter euch Gottlose Gesellen/

Die fallen zurichten/ und den leuten stellen/

Sie zu fahen wie die Vögeler mit kloben!

174 Ew'r Richter und Priester/ die auch nicht zuloben/

Sind Reich/ fett/ satt und glatt/ haben kein erbarmen/

Helffen nicht zurecht Wittwen/ Wäisen und Armen.

Gleich wie ein Vogelbaw'r sind voll ihre Häuser:

Also habt ihrs gern und begehrt keine Weiser.

Was solt doch diß wol fur ein ende gewinnen?

Meynt ihr Gott werds also lenger leiden können?

Trawts nicht, glaubt frey/ Er wird ewer thun verfluchen;

Euch mit mehr plagen im zorn grewlich heimsuchen/

So ihr euch nicht in der zeit werdet bekehren/ 
Buße thun und ihn mit ewerm leben ehren.

Aber was hilfft es daß man viel davon saget?

Wer wills hören? und wer ist der darnach fraget?

Die große boßheit/ Tyranney/ sünd und schande/

Nimpt täglich zu und wächst in ewern Lande/

Ja, fleust über wie ein Brunn sein Wasser quillet/

Darumb kan Gottes zorn nicht werden gestillet.

Ein Lew kompt auß dem Walde der grewlich brüllet/

Diß sagt die Schrifft/ die noch muß werden erfüllet. ${ }^{2}$

Darin such antwort auff dein fragen/

Warumb sich enden nicht die plagen/

Vnd was sich künfftig wird zutragen.

Darff einer wetten ich wills wagen/

Was gilt's? man wird in kurtzen tagen

Baby ons fall hören beklagen/

Vnd einen zu dem andern sagen:

Frage:

Wo ist Babel die grosse Statt

$\mathrm{Zu}$ der ein ieder zuflucht hatt?

Antw.:

Sie ist zerstört durch Gottes hand/

Sein grimmig'r zorn hat sie verbrant.

Frage:

Wo ist doch ihr Reichthum hinkommen?

Antw.:

Von den Kriegs-leuten weg genommen.

Frage:

2 Jerem. 5. vers. 25. cap. 6. vers. 7. etc. etc. 
Wo sind die Krämer und Kauff-leut?

Antw.:

Sie werden nicht mehr holen Beut.

Frage:

Wo sind die Räth und Cantzeler?

Antw.:

Man gedenckt nicht derselben mehr.

Frage:

Wo sind die Junckern doch geblieben?

Antw.:

Die sind auch all' mit auffgerieben.

Frage:

Wo ist das schöne Frawenzimmer?

Antw.:

Hinweg/ man wird es finden nimmer.

Ihr gassen gehn und einher schwäntzen

In Sammten Schuh' und Perlenkräntzen/

Sieht man nicht wie geschehn bißher/

Ihr eigen stät kennt sie nicht mehr.

Frage:

Wo sind itzt all' ihr' Lediggänger/

Schalcks-narren/ Spielleut und die Sänger? 
Auch mit hin über einen hauffen/

Etlich' erschlagen/viel entlauffen/

Man sieht keinen mehr frölich springen/

Hört niemand spielen oder singen.

Frage:

Was thun die Bürger und die Bawren?

Antw.:

Man hört bey ihnen nichts denn trawren/

Acker und Weinberg sind verdorben/

Viel leut in Hungers-noth gestorben.

\section{Frage:}

Was haben itzo doch zuschaffen

Die Cantzelherrn/ Bischöff und Pfaffen/

Von Hohen-schuln die Titul-trager/

Warheit-verjager/ frommen-plager/

Die Reichen Thum-Herrn und Prælaten?

\section{Antw.:}

Ihr anschläg' sind nicht wol gerathen.

Sie haben kein Intraden mehr/

Beklagen ihren schaden sehr;

Ihr herrlichkeit und großer pracht

Ist schlecht gemacht/ nichts mehr geachtt/

Vnd gar stumpff ihr scharffschneidend Swerd/

Ihr Bann nicht mehr drey heller werth.

Ihr große Häuser/ hohe Fest/

Sind geworden der Eulen nest/

Darin die Wilden Thier und Raben/

Ihre Herberg und Wohnung haben. 
Der grosse muth ist klein bey allen/

Der breite Huet vom haupt gefallen.

Es geht wie beym Propheten steht/

Der Herr mach't/ wie Er hat geredt/

$\mathrm{Zu}$ nicht/ zu nicht/ zu nicht die Cron/

Es ist gantz auß mit Babylon/

Man hört nicht reden mehr davon/

Darumb sey frölich O Zion/

Sing Deinem Breutgam Davids Sohn/

Dem Herrn der Ehrn ein Liedlein schon/

Hosianna in süssem thon/

Gelobt sey Gott im höchsten Tron.

Hallelujah, Hallelujah/

Die hulff ist nah'.

Hallelujah.

Deo Triuni Gloria.

Amen.

1.

Komb/ Davids Sohn/

Stürtz Babylon/

Wirff ihren stuel danieder:

Erheb Zion/

Gib ihr die Cron/

Vnd mach sie frölich wieder.

2.

Ein lange zeit

Ist sie in leit

Vnd traurigkeit gesessen/

Alß wenn sie wer

Von dir bißher

177 Gewesen gantz vergessen.

3.

Aber O nein/

Es kan nicht seyn/ 
Dein gnad ist ungemessen/

Es hat kein noth/

Sie wird ihr broth

Nicht mehr so traurig essen.

4.

Sie ist die Braut

Die dir vertraut/

Vnd geben gantz zu eigen;

Drumb wirstu ihr/

Das glauben wir/

Barmhertzigkeit erzeigen.

5.

Ja/ Mütterlich

Beweisen dich/

Der sünd nicht mehr gedencken/

Sondern auß gnad

Ihr missethat

Ins tieffe Meer versencken.

6.

Dein Wort ist war/

Sagt offenbar/

Du wilt nicht ewig hassen/

Must springen bey/

Vns machen frey/

Kanst dein volck nicht verlassen.

7.

Nach der zusag

Wend unser plag/

Bleib mit der hülff nicht lange/

Stell dich bald ein/

Vnd laß uns seyn

Nicht mehr so hertzlich bange. 
Es komb dein Reich

Vns allen gleich/

Dann wollen wir Psallieren/

In der gemein/

Dir danckbar seyn/

Mit Cymbein Musiciren.

9.

Erbarme dich

Doch Väterlich

Vber all die gefallen;

Helff ihnen auff/

Sterck sie im lauff/

Dein Will' gescheh' in allen.

10.

Mach klug das tumm/

Das böse fromb/

Daß all die Rebelliern/

Vnd wieder dich

Aufflehnen sich/

Nicht mehr Tyrannisiern.

11.

Brich ihren muth/

Mach alles gut/

Laß alle Völker werden

Dir unterthan/

Löß ab die fahn/

Gib wieder fried auff Erden.

12.

So können wir

Von hertzen dir

Danck und Lob-opfer bringen

In stiller ruh: 
Herr helff dazu/

O Herr laß wol gelingen.

13.

Daß auch Anna

Hosianna

Mit möge frölich singen/

Dir Davids Sohn

In süßem thon/

Ihr Laut auch lassen klingen.

14.

O Herr ich bitt/

Hilff daß auch mit/

Ihr Kinder mögen kommen

Im Freuden Sahl/

Zum Abendmahl/

In die zahl aller frommen.

15.

Da wir sämptlich

Dann werden dich

Mit newen Liedern loben/

Ohn unterlaß/

O Herr gib das/

Hie und auch Ewig droben.

16.

Deine Warheit

Werd außgebreitt/

Dein nahm glorificiret/

Gebenedeyt dein Herrlichkeit/

Die Ewig Guberniret.

A.O.H. 
Posaunenschall/ Vom Abendmahl Ins Königs Sahl/ Nach Babels fall.

Auffmunterung und Einladung zur Hochzeit des Lambs/ auff der Burg Zion/ am tage Allerheiligen. An alle/ die Gott fest vertrawen und auff seine Verheißung bawen.

Gestellt durch Annam Ovenam Hoyers,

Im Jahr: Des HerrLIchen Lang gewVnsChten EInzVgs Vnsers ALLerLIebsten KönIgs/ EInIgen ErLösers/ Vnd Herrn aLLer Herrn Herrn IesV/ aVff ZIons BVrg.

K.

B.

D.

K.B.D.B.D.B.K.

D.

B.

K.

Kommet Bereitet Die Bahn/

181 Der Breutigamb Kompt.

K.

I.

K.I.V.I.K.

I.

$\mathrm{K}$.

Köning Iesus Vnser Immanuel Kompt. 
S.

A.

$S$.

S.A.S.V.S.A.S.

$\mathrm{S}$.

A.

S.

Steht Auff Singet Vnd Spielt Auff Seiten;

Der König lest fur uns bereiten

Einen Tisch unser Seel zu weiden/

Will uns zum frischen Wasser leiten;

So wir nur außgehn/ und bey zeiten

Vom Babylonschen wesen scheiden/

Das gute thun und böses meiden.

Kommet heut

Zur Hochzeit/

Lieben Leut/

Denn alles ist schon zubereitt;

Das groß und klein Mast-Vieh geschlachtet.

O weh dem der diß Mahl verachtet/

Vnd nicht des Königs Lieb betrachtet! 
K.

$\mathrm{H}$.

S.

B.

S.

D.

S.

F.

D.

Z.

$\mathrm{K}$.

K.H.S.B.S.D.S.F.D.Z.K.I.K.Z.D.F.S.D.S.B.S.H.K.

$\mathrm{K}$.

$\mathrm{Z}$.

D.

F.

S.

D.

S.

B.

S.

H.

K.

Komb Her Schöne Braut Schmücke Dich Schon/ Frew

Dich Zion/ König Iesus Kompt Zu Dir Frolocke

183 Sehr; Denn Seine Botten Sind Heut Kommen. 

S.
D.
K.
$\mathrm{L}$.
K.
E.
$\mathrm{D}$.

S.D.K.L.K.E.D.H.D.E.K.L.K.D.S.

D.

E.

K.

L.

$\mathrm{K}$.

$\mathrm{D}$.

S.

Sehet Den König/ Lieben Kinder/

Empfanget Den Herren Der Ehrn:

Kommet/ Lasset Klingen Die Seiten.

Freund und Freundinnen auch nicht minder/

Kommet all' von nah' und fern/

Helffet des Königs lob außbreiten.

Frew dich Zion/

Vnd schaw wie schon

Kompt David Sohn/

In seiner Cron/

$\mathrm{Zu}$ dir einreiten/

Mit seinen Leuten. 
$\mathrm{K}$.

\section{I.K.K.I.K.VV.K.I.K.VV.K.I.K.K.I.}

$\mathrm{K}$.

VV.

$\mathrm{K}$.

I.

$\mathrm{K}$.

$\mathrm{K}$.

I.

Israëls König Kompt/ Ist Kommen/ VVird Kommen/ Ia Kommend/ VVird Kommen In Krafft König Iesus.

Gott will Himmel und Erde bewegen/ Vnd die Stühle der Königreich umbkehrn/

Allen stoltz und hochmuth nieder legen/

Durch seinen zorn alles böse verzehrn/

Er sitzet seine Tenne zufegen/

Also steht geschrieben im Wort des Herrn. ${ }^{1}$

185 Richtet Euch Auff $\mathrm{hr}$ Menschen/ Ach Kommet Schawet/ Fliehet Babels VVesen Bald/ Sehet/ Sie Fällt. VVeinet Doch Ihr Studenten In Den Schulen/ Vnser Keiner Bringet Nun Mehr Prosenten. Babels Bulen/ Babst/ Pfaffen/ Münche/ Nonnen Brüder/ Klagen Vnd Schreyen. Denn Ihre Sachen In Der VVelt Furwar Sind Schlecht Bestellt/ VVeil Babel Fällt/ Sie Kommen Alle Mit $\mathrm{hr}$ An Einen Reyen.

Hört Wunder/ hört/

Nun wird zerstört

Vnd gantz zu grunde fallen:

1 Hag. 2. vers. 22. Matth. 3. v. 12. Luc. 3. vers. 17. 
Die Große Statt/

Da Satan hatt/

Das Regiment in allen.

Man nimbt die Cron

Von Babylon/

Ihr letster tag ist kommen;

Wir sind nun frey

Der Tyranney;

Dancket dem Herrn ihr Frommen.

Zions Elend;

Hat nun ein end/

Sie wird bald herrlich werden

Im Ehrenkrantz/

Vnd hellen glantz/

Fur allen Volck auff Erden.

Heran/ heran/

Beid Fraw und Mann/

Ihr freuden fest zuzieren;

Macht euch bereit/

Man wird sie heut/

Ihrem Breut' gamb zuführen;

Sie ist geschmückt/

Ihr kleid gestickt/

Mit Gold und reiner Seiden;

Drumb soll man gern/

Auch ihr zun Ehrn/

Sich schön und köstlich kleiden/

Vnd mit außgehn/

Die pracht zusehn/

Des Königs Sohn empfangen:

Der Breutigamb/

Auß Davids stamb/

Zeucht ein mit großem prangen/

Will seiner Braut/

Die ihm vertrawt/

Reichs Cron und Scepter bringen:

Dazu dann wir/

Von hertzen ihr 
Glückwünschen mit lobsingen.

Sie ist die zart/

Von Edler art/

Auffs schönst geziert inwändig/

Keusch/ fromb, gerecht/

Demütig, schlecht/

Vnd in der Lieb beständig.

Wird nun nicht mehr

Seyn/ wie bißher/

Im Elend alß verlassen:

All' die sie ehrn/

Sind lieb dem Herrn/

Weh' denen die sie hassen.

Wolauff ihr Gäst/

$\mathrm{Zu}$ diesem fest/

Breutgamb und Braut zun ehren:

Brautlieder singt/

Spielt/ hüpfft und springt/

Thut fleiß die freud zu mehren.

Die Spiel-leut all/

Mit Lautem-schall

Blasen schon die Trompetten;

Heut, heut ist zeit/

Werfft von euch weit/

Spieß/ Degen und Mußquetten/

Vnd legt beyseyt/

Das blütig kleid/

Helfft nicht mehr Stät zerstören;

Nun werden wir/

Das glaubet mir/

188 Von andern dingen hören.

Ein starcker held/

Hat in der Weld/

Sich eingestellt zustraffen:

Wird steuren bald/

Ewrer gewalt/

Abschaffen die Kriegs-waffen.

Helt nun Gericht/ 
Schertzt warlich nicht/

Diß mercket ihr boßwill' gen/

Sein starcke hand

Wird alles Land/

Drinn boßheit wohnt/ vertill' gen .

Die zeit ist da/

Wir sehn es ja/

Sein Schwerd ist scharff gewetzet:

Weh' dem/ sag ich/

Der sich bößlich/

Seiner Macht wiedersetzet!

Seht seine stärck/

Vnd Wunder-werck:

Geht hinauß in den Wälden/

Wie brennt das feur

So ungeheur/

Wie fallen die Kriegshelden!

Viel Fursten blut/

Ist in der glut/

Auch mit hinweg geflossen.

Der siedend topff/ ${ }^{2}$

Wird übern topff

Des Keysers außgegossen.

Babst/ Cardinal/

Abt/ Bischöff all/

Auch Münchesche dreckpatzen/

Werden fur leid/

In traurigkeit/

Die Haer und Ohren kratzen/

Denn ihr gewinn

Ist schon dahin/

Ihr hoffnung ligt in bronnen;

Keiner ist der

Nun tröstet mehr/

Die hochbetrübte Nonnen.

O Pfaffenvolck!

2 Jerem. 1. 
Ein dunckel wolck/

Von Donner und Feurstralen/

Bringt dir unglück/

Wird deine tück/

Vnd bubenstück bezahlen.

Du Baals hauff/

Steh eilend auff/

Vnd lauff/ du must doch weichen;

Die zeit ist hir/

Es gilt dem Thier/

Auch dir und deines gleichen.

Ihr habt zuvorn

Gemacht verwohrn

Den Armen und Elenden;

Diß kan der Herr/

Nicht leiden mehr/

Er muß bezahlung senden

In voller maß;

Ja eben das/

Was ihr beweist den frommen

Mit ewerm thun/

Wird wieder nun

$\mathrm{Zu}$ ewern thüren kommen.

Der streit im Reich

Ist erst von euch/

$\mathrm{Al}$ eine seuch/ außgangen;

Nun wird der stanck

Von ewerm zanck

190 Wieder an euch gelangen.

Der Wind braust sehr

Auß Norden her/

Wird hohe Stühl umbkehren;

Mittag gib acht/

In Mitternacht

Sind/ die dich demut lehren.

Merckt was ich sag/

Heut sind die tag/

Euch gilt es ihr Nacht-Eulen: 
Jtzt werdet ihr/

Nichts hilfft dafür/

Alß Hunde müssen heulen.

Chor-Rock und Capp

Auch legen $\mathrm{ab} /$

Weil sie nunmehr nicht taugen.

Ein scharffer rauch ${ }^{3}$

Kompt daher auch/

Stost euch hart unter augen.

Es ist gewagt/

Ich habs gesagt/

Ders hören will/ mag hören;

Der Herr wird beid/

Soldaten streit/

Auch Pfaffen neid zerstören/

Er macht zu spott

Der Spötter Rott;

Der frommen blut zu rächen

Wird er in eil/

Durch seine pfeil/

Schwert/ Spieß und Bogen brechen.

Ein jedermann

Wird sprechen dann:

Der Herr sey hochgeehret/

Sein ist der sieg/

Er hat den Krieg

Gesteurt und fried bescheret;

Es geht nicht mehr

So scharff daher/

Denn Pax ist nun geboren;

Die Charitas

Vertreibt den haß/

Der Kriegs-mann hat verlohren.

Im Regiment

Gehts Excellent/

Concordia floriret;

3 Jes. 14. v. 31. 


\section{Justitia/}

Ist wieder da/

Pietas Gubernieret.

In unser Grentz

Wohnet Scientz;

Wolstehts in allen Landen.

Fides und Spes

Frewen sich des/

Sind worden nicht zuschanden.

Veritas ist

$\mathrm{Zu}$ dieser frist

Wieder ans tag-licht kommen/

Thut auff den mund

Vnd macht sie kund;

Sprecht nun frey auß ihr stummen/

Sie steht euch bey/

Wird machen frey

Die auß Gott sind geboren;

Vnd in der zeit

Zur Herrlichkeit

Erwählt und außerkoren.

Solch Red' wird gehn/

Vnd man wird sehn/

Was wir nach wunsch begehren;

Denn wunderlich

Wird alles sich

192 In aller Welt verkehren.

Ein Newes Jahr

Wird offenbar/

Wie die Propheten deuten:

Ein zeit ohn streit/

Da Lieb ohn Neid

Seyn wird bey allen Leuten

Beständig trew;

Das Alte New/

Vnd alles restauriret.

O Freuden-tag/

Drinn niemand klag 
Mehr führet oder spühret!

Der Newe Bund

Wird allen kund/

Vnd in der Newen Erden/

Die Creatur

Auch schon und pur

Vom eiteln dienst frey werden.

Solch Herrlichkeit

Ist Propheceyt;

Wol dem der in den tagen

Mit leben mag/

Der wird ohn klag/

Frölich mit Warheit sagen:

Das mein ist dein/

Dein wieder mein/

Nichts wir für eigen haben/

Kein eigen nütz

Hat bey uns sitz/

Gemein sind Gottes gaben.

Das Wild ist zahm/

Man sicht das Lam

Bey Wölf und Bähren weiden.

Der Löw frisst Hew/

Das Vieh ohn schew

Geht frey dabey ohn leiden. ${ }^{4}$

Das Adam hat

Durch Satans rath

Im sünden fall verlohren/

Hat wiederbracht

Vnd gut gemacht

Der ohn sünd ist gebohren.

O Gülden zeit

Voll frölichkeit/

O Tag gemacht vom Herren!

Ohn End wird seyn

Dein heller schein/

$4 \quad$ Jes. 11. vers. 7. 
Vnd biß ins Ewig wehren.

Jungling/ Jungfraw'n/

Kommt her zuschaw'n/

Ihr Kinder mit den Alten:

Beid Arm und Reich/

Ach last doch euch

Nichts von der freud' abhalten;

Geht eilend fort/

Macht auff die pfort

Dem Herren der Heerscharen.

Der starcke Held/

Wird aller Weld

Sich Herrlich offenbaren

In seinem Volck;

Vnd wie ein Wolck

Außgeust fruchtbaren Regen

Auff Laub und Graß/

Auch gleicher maß

Außgießen seinen Segen.

Zum Abendmahl

Im freuden Sahl

Hat Er von allen gassen/

Durch seine knecht

Menschlich geschlecht

194 Fleißig einladen lassen:

Schickt heut noch auß/

Von Hauß zu Hauß/

Sein Lieb ist unverdrossen:

Nimbt jedermann

Gern willig an/

Niemand ist außgeschlossen.

Erkennt die trew/

Habt sünden rew/

Last euch Bußfertig finden:

Verseumet nicht

Das Gnaden-liecht/

Ew'r keiner bleib dahinden.

Schwach/ kranck und krumm/ 
Blindt/ taub und stumm/

Rath ist für euch zusamen/

Kommt alle gleich/

Last helffen euch/

Ihr krüppel mit den Lamen;

Erkennt den Mann

Der heilen kan

All' wunden und gebrechen/

Er kompt mit krafft/

Ist auch warhafft/

Vnd helt fest sein versprechen;

Hat wolgefall'n

$\mathrm{Zu}$ helffen all'n/

Lest sein Heilbrünnlein fließen:

Darumb geht frey

Nur bald herbey/

Ehr man die thür wird schließen.

Türck/ Jud' und Heid/

Weil ihr auch seyd

Zum großen Mahl geladen/

Stellt euch mit ein

Frölich zu seyn/

Erkennt die zeit der Gnaden.

In Christenthum/

Dem Herrn zum ruhm/

Wollet euch nun begeben/

Wie Schäflein all/

In einem stall/

Friedlich bey uns zu leben.

Die zeit ist hir/

In welcher wir

Sollen versamlet werden:

Denn es wird seyn

Noch ein gemein/

Ein hirt/ ein heerd auff Erden:

Voll ist die zahl/

Seyd frölich all/

Jauchzet und klopfft in händen; 
Auff Seiten spiel

Macht freuden viel/

Frolocket ihr Elenden:

Weint nun nicht mehr/

Jtzt kompt der Herr

Die tränen abzuwischen;

Hallelujah/

Sein hülff ist nah'

Die müden zuerfrischen;

Will reinen Wein

Vns schencken ein

Mit Freuden-öhl uns salben; ${ }^{5}$

Barmhertzigkeit

Vns guts allzeit

Wird folgen allenthalben.

Hie findet rath

Der hunger hat/

Hie kan man sich ergetzen/

Wer nur beyzeit

Sich macht bereit

196 Mit an den Tisch zusetzen/

O Gnadenbronn

Voll freud und wonn/

Du machst die hertzen mütig!

O lebens quell/

Immanuel/

Wie bistu doch so gütig!

Wo du einfleust/

Das hertz begeust

Vnd scheust der liebe funcken/

Da fangt man an/

Vnd wird alß wann

Man wer' von liebe truncken!

Schmeckt doch und seht/

Wie freundlich geht

Der Herr umb mit den seinen!

5 Psalm. 23. vers. 5, 6. 
Wie fromb ist $\mathrm{Er} /$

Sagt mir doch/ wer

Kan und will nunmehr weinen?

O lieben leut/

Legt weit beyseyt/

All traurigkeit und schmertzen.

Den Herrn erhebt/

So lang ihr lebt/

Mit wort/ werck/ händ und hertzen

$\mathrm{Zu}$ loben ihn/

Auch daß man dien

Mit hülff und rath dem nächsten/

Sind wir gestellt/

Hei in der Weld/

Vom Herrn dem Allerhöchsten.

Wolan steht auff

Vnd kommt zu hauff/

Erzeigt euch hiezu willig:

Thut ware buß

Fallt Gott zu fuß/

Gebt ihm die Ehr wie billig/

Was sich bewegt/

Den odem regt/

Das komm von den vier Winden;

Bring mit ihm her/

Das volck vom Meer/

Vnd laß sich danckbar finden.

Der sich auff helt

Am end der Weld/

Soll frölich jubiliren;

Mit Lobgesang/

Vnd Harpffen-klang

Das Fest der freuden zieren.

Freut euch im Herrn/

Beid nah' und fern/

Was leben hat/ ihn preise;

Hertz und gemüth/

Danck seiner güth/ 
Der allem fleisch gibt speise.

Mein' Kinder seyd

Auch frölich heut/

Singet lieblich zusamen;

Stimmet darein

Die seiten rein/

Zum Lob des Herren Namen.

Caspar mein Sohn/

Mach süssen thon/

Spiel lieblich auff der Geigen:

Veneris schertz

Werff hinder weitz/

Gib dich Gott gantz zu eigen/

Vnd halt dich rein;

Laß ander seyn

Vnd bleiben/ wie sie wollen;

Sich du auff dich

Das rathe ich/

198 Lebe nicht wie die tollen

Vnd losen leut/

Die jederzeit

Den breiten Welt-weg lauffen:

O mein Sohn weich

Vnd stell' dich gleich

Nicht dem Gottlosen hauffen.

Böß gesellschafft

Hat große krafft/

Frombhertzen zu verleiten;

Schand ist ihr lohn/

Drumb bleib davon/

Fleuch ihr freundtschafft bey zeiten.

Wieder wollust

Dich Männlich rust/

Merck wo dein zaun am schwächsten;

Ach bet' und wach/

Denn deine sach

Steht warlich hie am schlechtsten.

Richt dein gesicht 
$\mathrm{Daß}$ es sich nicht

Vmbwend nach schönen Frawen:

Acht auch nicht/ daß

Der Wein im glaß

Lieblich ist anzuschawen.

Weiber und Wein

Dir schädlich seyn;

Fur lieblich augen-wincken/

O mein Casparl

Dein hertz bewahr/

Meid auch das Truncken-trincken.

Berew in leid/

Was dein thorheit

Offt heimlich hat begangen/

Alßdann wirstu

Gott helff dazu/

Ins Königs Sahl mit prangen.

Dich/ Christian/

Ich auch ermahn/

Fürcht Gott/ lieb fried/ leb' züchtig;

Nach Christenbrauch/

Bet' fleißig auch/

$\mathrm{Daß}$ du mögst werden tüchtig;

Zur freud des Herrn/

Sein lob zumehrn

Laß dich gutwillig finden:

Thu deinen fleiß

$\mathrm{Zu}$ seinem preiß/

Lunam zu überwinden.

Sie ist schädlich/

Darumb raht ich/

Wieder sie scharff zukämpffen;

Gott geb dir krafft/

Mach dich Sieghafft/

Die Böse Arth zu dämpffen.

Friedrich-Hermann/

Tritt mit heran/

Leg' allen unmuth nieder: 
Nun kompt die zeit

Der Herrlichkeit/

Vnd bringet friede wieder:

Danck-psalmen sing/

Sey guter ding/

Vnd spring mit an den Reyen:

Lob Gott mit mir/

Vnd Musicir

Auff Pfeiffen und Schallmeyen.

Dein Vater hat

Auß reiffem rath/

Gewünschet dir den segen;

Den wünsch auch ich

Dir Mütterlich/

200 Auff allen deinen wegen;

Gott geb dir stärck;

Er hat sein werck

Schon in dir angefangen;

Fahr du nur fort/

Nach seinem Wort/

So wirst mehr gnad erlangen.

Was hindern mag

Bald von dir jag/

Laß dich nicht machen wändig

Von Mann noch Weib;

Dein fürsatz bleib

Zum guten stets beständig.

Im fried/ Friedrich-

Hermann, halt dich

Alß ein'm Ehrn-Mann gebühret;

Gedenck hiran

Mein Sohn/ alßdann

Wird dein Nam recht geführet.

Friedfertig' leut/

Werden zur beut/

Die Newe Erd' besitzen.

Werd nur nicht treg/

Auff gutem weg/ 
Wenn dich Creutz-dornen ritzen.

Gib fleißig acht/

Auff Satans macht/

Damit er wird zusetzen

Duch Leibes-freund/

Der Seelen feind/

Will er dich gern verletzen;

Die füllerey

Dir bringen bey/

Die guten Fürsatz hindert/

Den leib beschwert/

Die Seel versehrt

Vnd alle tugend mindert. ${ }^{6}$

Viel hertzenleid

Bringt Trunckenheit/

Führt manche Seel in zweiffel;

Hüt' dich rath ich/

O Sohn/ daß dich

Damit nicht fang der Teuffel:

Bleib ein Herr Mann

Deins muts fortan/

Friedsam und fromb ohn wancken/

Erkenn die gnad

Die Gott dir hat

Gegeben/ lern ihm dancken.

Daneben wiß

Mein Sohn/ auch diß/

$\mathrm{Daß}$ du auff eignen beinen

Nicht fest kanst stehn/

Auff Gott must sehn/

Er laß sein gnad dir scheinen.

$\mathrm{Zu}$ leben keusch

Bezwing dein fleisch/

Machs dem Geist unterthänig;

Halt dich auffs best/

Im Ehren-fest

6 NB. 
Werd Gott nicht wiederspänig.

Viel hindernüß

Weiß ich gewiß/

Wird Satan dir furwerffen/

Dawieder must

Du seyn gerust/

Dein gebeths pfeilen scherffen:

Arbeit dabey/

Vnd fleißig sey/

In Gott-gefellig'n wercken;

Theil davon mit

Dem der dich bitt/

202 So wird der Herr dich stercken/

Vnd dir dein brot

In hungers noth

Reichlich wied'rumb bescheren;

Also daß du/

In fried und ruh'/

Wirst kommen durch mit Ehren.

Gott helffe dir/

Sein Geist regier

Dich und all' meine Kinder/

Kinds-kinder mit

Nehm an mein bitt/

Mach euch zu überwinder.

Maria sey

Du auch hierbey/

Schlag frölich die Claviren;

Laß deinen sinn

Nicht/ wie vorhinn/

Vom Scorpion regieren;

Folg gehorsam

Dem Breutigamb/

Sey wie das Lamb/ sanfftmütig.

Fur Satans arth/

Zorn und Hochfart/

Auch eignen willen/ hüt dich.

Du hast bißher/ 
Geliebet Ehr/

Dich allzeit keusch gehalten;

Des bin ich froh/

Bleib ferner so/

Dann wirst in ehren alten.

Das wunsche ich/

Gott stercke dich/

Er hat viel gnad dir geben:

Du hast verstandt/

Dir ist bekant/

Wie man soll Christlich leben.

Nichts dir gebricht/

Ohn daß dich sticht

Bißweilen Iroe Angel.

Tochter/ hirinn

Zwing deinen sinn/

So hastu keinen mangel.

Ich bath für dich

Fleißig/ ehe ich

Dich hab zur Welt geboren/

Thu auch noch diß/

Vnd hoff gewiß/

Es werd nicht seyn verlohren.

Solarisch arth/

Ist etwas hart/

Jächzörnig und hochmüthig;

Wann Solis kindt

Die demuth findt/

Dann wird es fromb und gütig.

Ach lieb demuth/

Demuth ist gut/

Ihr folgen alle tugend;

Demuth gibt rath/

Erlanget gnad/

Dem Alter und der Jugend.

Humilitas

Kan allen haß/

Vnd zorn/ leicht überwinden. 
Neid treibt sie weit/

Geitz/ hochmuth/ streit/

Lest sie nicht bey ihr finden.

Halt demuth werth;

Denn demuth lehrt

Gott und die Menschen ehren:

Wer demuth hat

Der findet gnad

204 Vnd rath allzeit beym Herren.

Demuth geht vor

Durchs Königs thor

Mit den klugen Jungfrawen;

Mach' dich bereit

In solchem kleid

Zions schönheit zuschawen.

Stell dich mit ein

Danckbar zu seyn/

Christina, helff lobsingen.

Werff Martis stern

Auch von dir fern/

Lern dein Affecten zwingen.

Leg ab den Geitz/

Geitz ist dein Creutz/

Verzehrt das marck in beinen.

Geitz und Welt-Ehr/

Sind voll beschwer

Machen offt heimlich weinen.

O Gelt/ o Welt/

Wer euch nachstellt

Der ist der ärmst auff Erden/

Vnd immerzu

Voller unruh/

Man siehts an den geberden:

Die augen beid

Seh'n auß von neid/

Zornmütig und hochfertig.

Ach/ ach Christinn

Leg hin den sinn: 
Such in der Schrifft/ sie lehrt dich/

Was geitz außricht/

Du weist es nicht/

Sonst wurd dich dafür grawen:

Wer gelt und Welt

Nach stellt/ der fellt

Vnd kan Gott nicht vertrawen.

Wann man einmal

Von diesem thal

Soll durch den todt abscheiden:

Die noth wird groß/

Die Seel steht bloß

Hülffloß in angst und leiden:

Wer ist alßdann

Der helffen kan

Vnd auß der noth erretten?

Warlich es thut

Kein irdisch gut

Wann wirs schon alles hätten. ${ }^{7}$

Betracht doch diß

Vnd fleißig liß

Mit andacht in der Bibel:

Beth auch dabey/

So wirstu frey

Vom geitz und allem übel.

Zorn wird nicht mehr

Wie offt bißher

Gesehn ist/ dich turbiren;

Wirst auch hinfort

Kein stoltze wort

In deinem mund mehr führen.

Gehorsamkeit

Ein schones kleid

Zeuch an/ das wird dich schmücken/

Den frechen muth

Ja fleisch und blut

$7 \quad$ NB. 
Auch gar bald niedertrücken.

Hir helffet $\mathrm{zu} /$

Bringt fried und ruh'/

Demuth von Gott erkohren/

Zucht/ gehorsam

Sanfftmuth und scham/

206 Werden auß ihr geboren.

Wie auß hochfart

(Des Teuffels arth)

Alle boßheit entspringet:

Also Demuth

(Auß Christi blut)

Die frommigkeit fortbringet.

Hirinn Christinn

Ligt groß gewinn/

Daran hab ein gefallen:

Das beste guth

Steckt in demuth/

Demuth ist nötig allen.

Gott schmück/ wunsch ich/

Doch damit dich

Auch dein Brüder und Schwester;

Auff daß sein Reich

Werde in euch

Von tag zu tagen fester.

Bittet hirumb

Vnd werdet fromb/

So wird euch Gott erhören/

Sich zu euch kehrn/

Das gute mehrn/

Vnd alles böß zerstören.

$\mathrm{Zu}$ g'horchen mir

Seyd schüldig ihr/

Die Schrifft hats euch gebotten/

Nach der euch richtt/

Der Herr will nicht

Daß ihr sollt meiner spotten.

Mit euch meyn ich 
Es Mütterlich/

Wolt daß ihrs möchtet wissen;

Dann würdet ihr

Ohn zweiffel mir

Zufolgen seyn geflissen/

Vnd nicht hinfort

Stoltz bitter wort

Mehr wieder mich außgiessen/

So ihr das Mahl

Im Freuden Sahl

Begehrt mit zu geniessen.

Mein' Kinder all'

Fünff an der zahl/

So lang ihr seyt im leben/

Thut ewern fleiß

Mit ruhm und preiß

Den Herrn hoch zuerheben/

Außbreitet weit

Sein Herrlichkeit;

Macht kund den Kindes Kindern/

Was er gethan/

Last euch daran

Von keinem menschen hindern.

Ich kan und will

Nicht schweigen still/

Ihm auch Ehr zu beweisen;

Was an mir ist

Soll jeder frist

Sein' große gnade preisen/

Durch die Er hat

Nach seinem rath

In allen meinen wercken/

Sehr wunderlich

Geführet mich/

Das hab ich können mercken.

Von Jugend auff

In meinen lauff

Hat Er mir beygewohnet 
Mit viel gedult;

Vnd meiner schuld

208 Verschont und nicht belohnet:

Denn Er ist gut/

Vnd ob sein ruth

Auch wol offt machet schmertzen;

Erkenn ich doch

Daß Er mich noch

Nie hat gestrafft von hertzen.

Frero mich darob

Vnd ihm zum lob

Will ich die warheit sagen/

Er hat gelind

Mich/ wie ein kind/

Auff seine händ' getragen.

Der Menschen freund

Ist niemand feind/

Wann Er sich schon stellt grewlich/

Alß trüg er haß/

Weiß ich doch/ daß

Ers meynt von hertzen trewlich/

Vnd gutes schafft

In dem Er strafft/

Lehret uns seine strassen.

Drumb sollen wir/

Dir Herr dafür/

Danckbar seyn bester massen.

Willig bin ich/

$\mathrm{Zu}$ loben dich/

Mein mund fleust davon über.

Dir ist ja kund

Meins hertzen grund/

Du weist ich thu nichts lieber.

All mein begehrn/

Ist dich zu ehrn/

O Herr laß wolgelingen.

Gib du erst mir/

So kan ich dir/ 
Das rechte opffer bringen/

Vnd deiner trew/

Mit Liedern new/

Für allem volck lobsingen.

Ihr lieben Leut/

Zur danckbarkeit/

Last Laut und Harpffen klingen.

Wort sind zuslecht/

Man kan nicht recht/

All sein' wolthat erzehlen.

Doch zeig ich an/

So viel ich kan/

Will sein trew nicht verhelen.

Er offenbart/

Sein Vaters art/

Beweist sich wie ein Mutter.

Versorget mich/

Mit speiß täglich/

Gibt allem vieh' sein Futter;

Kehrt nicht abwertz

Sein Vater hertz/

Auch von den jungen Raben.

Wie solten wir

Dann nicht dafür

Ihn wiederumb liebhaben?

Vnd alles nun

Auß liebe thun

Alß fromme Kinder willig/

Die hertzlich gern

Den Vater ehrn?

Ja freylich! das ist billig.

Herr halt mich fest/

Daß ich auffs best/

Dir allzeit mög vertrawen;

Vnd laß mich seyn

In der gemein/

Der Außerwehlten Frawen;

Die dir zum ruhm/ 
Das Christenthum

Mit fleißig helffen bawen/

Vnd in der zeit/

Die herrlichkeit

Deines liechts sollen schawen.

Von welchem liecht/

Das schon anbricht/

Wird alles hell auff Erden/

Vnd Gott zum preiß/

Der gantze kreyß/

Voller erkentnuß werden/

Der frommen leid

Vnd traurigkeit

Wird sich in freud verkehren;

Vnd man wird sehn

In klarheit stehn

Das heilig volck des Herren/

In welches händ

Das Regiment

Kompt unterm gantzen Himmel:

Alßdenn wird seyn

Die Welt gantz rein/

Von des Satans getümmel.

Man wird nicht mehr

Von Kriegs-beschwer/

Vnd von todtschlagen sagen.

Nach laut der Schrifft/

Wird Satans gifft

Die frommen nicht mehr plagen:

Denn Gottes Lamb

Der Breutigamb

Kompt nun zu überwinden;

Wird (gebet acht)

Durch seine macht/

211 Den alten Drachen binden.

Wann das geschehn/

Dann wird angehn

Ein Paradeysisch leben/ 
In welchem wir

Recht nach gebühr/

Gott werden hoch erheben.

Der nun lust hat

$\mathrm{Zu}$ dieser gnad/

Vnd nach der freud verlangen/

Muß unsern Gott

Herrn Zebaoth

$\mathrm{Zu}$ loben hie anfangen;

In dieser zeit/

Weils noch heist heut/

Sonst wird er nimmer kommen/

Da man den Herrn

Wird Ewig Ehrn/

Diß nehmt in acht ihr frommen.

Lobet ihn all

Mit hohem schall/

Vnd unsern Gott erhebet

Mit werck und wort/

An welchem orth

Ihr seyt/ so lang ihr lebet.

Die gläubig Schar

Soll immerdar

Mit reverentz kniebeugen/

Vnd frey ohn zwang

Ihr leben lang

Ihm alle Ehr erzeigen.

Er ist der Herr/

Sonst keiner mehr/

Dem Ehr allein gebühret.

Sein Macht erhelt

Die gantze Welt/

Vnd was darin florieret.

Den Erdenkreyß/

$\mathrm{Zu}$ seinem preiß/

Hat Er kunst-reich gezieret.

Den Menschen mild

$\mathrm{Zu}$ seinem bild 
Herrlich und schon formieret/

Beid Fraw und Mann;

Daran man dann

Sein große weißheit spühret.

Sein güt' und trew

Wird täglich new/

Sein lieb das hertz mutiret/

Vnd uns umbsonst/

Durch Ihre gunst/

Auß allen nöthen führet.

Darumb mit Schall'

Ihr Volcker all'

Frolocket und Psalliret/

Hallelujah

Das heil ist nah'

Das rechte Recht regieret/

Die gantz' Gemein

Soll frölich seyn/

Im Herrn/ der Gubernieret.

Hallelujah.

E.

D.

E.D.K.D.E.

D.

E.

Empfanget Den König Der Ehren/

Vnd lobet den Herrn aller Herrn/

213 Er kompt nun bald/ ist nicht mehr fern. 


$$
\begin{gathered}
\text { VV. } \\
\text { N. } \\
\text { I. } \\
\text { VV.N.I.V.I.N.VV. } \\
\text { I. } \\
\text { N. } \\
\text { VV. }
\end{gathered}
$$

VVarlich Nun Ist Vnser Iesus Nicht VVeit.

Gelobet sey hie in der zeit/

Auch Ewig/ seine Herrlichkeit.

Amen.

G.G.

S.S.

D.G.

G.S.D.H.D.S.G.G.S.G.I.G.S.G.

D.G.

S.S.

G.G.

Gelobet Sey Der Herr Der Starcke Gott/

Mächtig und groß ist der Herr Zebaoth.

Wie Töpffe zerschmeist Er die lose Rott/

Vnd lest/ die da halten seine geboth/

Nimmer in der hoffnung werden zu spott.

Gelobet Sey Gott/ Ia Gott Sey Gelobet/

Er machet zu spott

Die Gottlose Rott/

Daß sie nicht mehr Tobet.

G.

$\mathrm{S}$.

G.S.D.S.G.

$S$.

G. 
Gelobet Sey Der Starcke Gott.

S.

V.

$S$.

S.V.S.A.S.V.S.

$\mathrm{S}$.

V.

S.

Singet Vnd Spielet Auff Seiten/

Vnserm Salvatori.

Er kompt sehr Herrlich einreiten

Voller krafft und Glori.

Kommt singet all/

Ins Königs Sahl/

Mit wolgefall

Beym freuden mahl/

Daß es erschall

Durch Berg und Thal/

Hallelujah.

Mit A.O.H.

215 Seyd frölich all.

1.

Avff/ auff Zion/

Vnd schmück dich schon/

Singe das Hosiannal

Frölich Psallier/

Es singt mit dir/

Hanns Ovens Tochter Anna.

2.

Nun kompt das Lamb

Auß Davids stamb/

Singe das Hosiannal

Will trösten dich/ 
Des frewet sich/

Hanns Ovens Tochter Anna.

3.

Nah' ist die zeit

Der Herrlichkeit/

Singe das Hosianna;

An diesem heil/

Hat mit ihr theil/

Hanns Ovens Tochter Anna.

4.

Auff, auff Jungfraw'n

Geht auß zuschaw'n/

Singet das Hosianna;

Der Breut' gamb kümmt/

Ihr seiten stimmt/

Hanns Ovens Tochter Anna.

5.

O Ihr Jüngling/

Seyd guter ding/

Singet das Hosiannal

Ihr Alten mit/

Weil euch drumb bitt

Hanns Ovens Tochter Anna.

6.

Von hertzen grund/

Auß vollem mund/

Singet das Hosianna:

Beid Arm und Reich/

Es singt mit euch/

Hanns Ovens Tochter Anna.

7.

Es frewe sich/

Vnd sey willig 
Zu sing'n das Hosiannal

Was leb't auff Erd/

Denn das begehrt

Hanns Ovens Tochter Anna.

8.

Nemet die Laut/

Erfreut die Braut/

Singet das Hosianna;

Ihr traurigkeit

Setzt weit beyseyt/

Hanns Ovens Tochter Anna.

9.

Alles unglück

Weich nun zurück/

Singet das Hosianna;

Der Fried floriert/

Frölich Psalliert/

Hanns Ovens Tochter Anna.

10.

Hallelujah/

Die hülff ist nah'/

Singet das Hosianna:

Frölich im Herrn

Ist immer gern

217 Hanns Ovens Tochter Anna.

11.

O scheinend' Sonn/

Voll freud und Wonn/

Singe das Hosiannal

An diesem tag/

Führt nicht mehr klag

Hanns Ovens Tochter Anna. 
Ihr mein drey Söhn

Macht laut gethön/

Singet das Hosianna:

Ihr Töchter beid/

Auch frölich seyd/

Mit ewrer Mutter Anna.

13.

Jesu des Herrn

Lob zu vermehrn/

Singet das Hosianna:

Auff Seiten spiel/

Macht freuden viel/

Mit ewrer Mutter Anna.

14.

Ew'r hertz bewegt/

Ew'r lippen regt/

Singet das Hosiannal

Frölich Psalliert/

Vnd Intonirt/

Mit ewrer Mutter Anna.

15.

Rühmet den Herrn/

Stets nah' und fern/

Singet das Hosianna;

In frölichkeit

Sein lob außbreitt

Hanns Ovens Tochter Anna.

16.

Sie Musicirt/

Sie jubilirt/

Sie sing't das Hosiannal

Den Herrn erhebt/ 
So lang sie lebt/

Hanns Ovens Tochter Anna.

Hallelujah.

Amen.

1.

Vnter den Dornen Rosen stehn/

Also auch unterm Creutz hergehn

Die Christen/ Christi Brüder/

Die nun bald werden Triumphirn.

Ihr Rosen die im Creutz floriern/

Seh' ich schon kommen wieder.

Gott sey gelobt in Ewigkeit/

Heut ist die angenehme zeit/

Der tag des Heils angangen.

Winter und Sommer scheiden sich/

Nun bricht herfür das/ darauff ich

Gewartt hab mit verlangen.

Alles was in den Lüfften schwebt/

Im Meer und auff der Erden lebt/

Soll sich zur freude schicken;

Gott will sein gnad uns machen kund/

Auffrichten einen Newen Bund/

All sein geschöpff erquicken.

4.

Freut euch ihr kinder Israël/

Nun kompt unser Immanuel/

219 Messias ist verhanden;

Ihr Weit zerstrewten macht euch auff/

Versammelt euch wiedrumb zu hauff/

Kommt her auß allen Landen. 
Zur Newen Statt Jerusalem:

Der Ertz-Hertzog von Bethlehem/

Wird nun sein Hochzeit halten:

Zieht an beyzeit das Ehrenkleid/

Macht euch bereit alß Hochzeit-leut/

Ihr Jungen mit den Alten.

6.

Kommt her zur Außerwehlten Zahl/

Ihr werdet eingeladen all/

Der Freud mit zugenießen:

Heut ist die zeit/ diß nehmt in acht/

Geht ein eh man die thür zumacht/

Sonst wird man euch außschließen.

7.

Schaw't doch wie schon tritt her Zion/

Zuempfangen des Könings Sohn/

Ihr'n Allerliebsten Herren?

Wie Schön ist sie im hellen glantz/

Geschmücket mit dem Rosen Crantz/

Ihrem Breut' gamb zun Ehren?

8.

Das Frawenzimmer folget ihr

In schöner zier fein nach-gebühr/

Den König zu empfangen:

O freud und wonn/ o große schön!

Ihr lieben kommt doch her zu sehn

Wie die Jungfrawen prangen.

9.

Ihr Jüngling schmückt das Fest mit Mey'n/

Tretet mit frölich an den Rey'n/

Jauchzet und Jubiliret;

Wünschet der Braut im Gülden-stück/ 
Viel Segen/ Wolfart/ Heil und Glück/

Frolocket und psallieret.

10.

Last hören der Posaunenthon/

Freut euch mit unser Braut Zion;

Was stimm hat/ soll nicht schweigen;

Lobsinget frölich/ groß und klein/

Wer spielen kan, der spiel darein

Auff Zitharn/ Harffen/ Geygen.

11.

Die hohen Berg und tieffen Thal/

Die Bäum und Kräuter allzumal/

$\mathrm{Al} ß$ wenn sie stimmen hetten/

Sollen frölich antworten all

Mit einen hellen wiederschall/

Den Trommlen und Trompetten.

12.

Die Thierlein werden springen dan/

Die Vogel haben freud daran/

Ihr stimm mit lassen schallen:

Die wilden Thier/ zahm' wie ein Lamb/

$\mathrm{Zu}$ ehren unserm Breutigamb/

In demuth niederfallen.

13.

Nun wolauff alle die ihr seyt

Vbergeblieben nach dem streit/

Versammelt euch zusamen;

Ihr krüppel steht nun auffgericht/

Ihr blinden kommet/ seht das Liecht/

Springt frölich auff ihr Lamen.

14.

Ihr tauben hört/ ihr stummen sprecht/

Ihr thoren last euch lehren recht/ 
Ihr Todten nehmt das Leben/

Es wird euch nun gebotten an/

Des soll sich frewen jedermann

Vnd unsern Gott erheben.

15.

Der uns erquicket nach dem leid/

Vnd lest uns sehn die Gülden zeit/

Die wir gewünschet haben.

Itzt scheinet uns die helle Sonn/

Er öffnet ist der Weißheit bronn/

Die dürstigen zu laben.

16.

Kommt alle her last schencken ein/

Nach Ewern willen/ Milch und Wein:

Die Weißheit lest fürsetzen

Alles voll auff/ sie hat zu kauff

Vmbsonst/ und lest uns tragen auff/

Von jhren reichen schätzen.

Das Ewig' Euangelium

Verkündigt den Fried wiederumb/

Nun hat ein end das klagen:

Die Warheit wird weit außgebreitt/

Man hört von Lieb und Einigkeit

Vnd nichts vom streit mehr sagen.

18.

Wer wolte sich nun frewen nicht/

Vnd wandeln in dem hellen Liecht

Das uns so Herrlich scheinet?

Erwehlet doch das beste theil/

Ihr lieben merckt/ zu ewerm heil/

Wie gut der Herr es meynet. 
19.

Das Paradeyß ist auffgemacht/

Der Segen wiederumb gebracht/

Der Fluch hinweg gekommen:

222 Das boß hat nicht mehr überhand/

Gerechtigkeit regiert im Land;

Drumb frewet euch ihr Frommen/

20.

Vnd singet mit Hallelujah/

Der Heyland kömpt/ die hülff ist nah'/

Hosianna dem Herren;

Lob/ Ehr und preiß/ sey Gottes Lamb/

Vnserm König und Breutigamb/

Er ist würdig der Ehren.

21.

Die feinde Er zuboden schlegt/

Vnd jhren hochmuth niederlegt/

Ein ende hat das trotzen.

Danck sey dem Herren Zebaoth/

Gelobet sey der starcke Gott/

Er kömpt sein Volck zu schutzen.

G.

G.S.G.

G.

Gelobet Sey Gott, von A.O.H.

Hallelujah.

1.

Avff/ auff es ist nun zeit/

Alle ding sind bereitt

Zum Großen Abendmahl/

Im Königlichen Sahl:

Der Breutigamb kömpt/ 
Der Breutigamb kömpt/

In großer Krafft und Macht/

Gebt acht und wacht/

Es ist schon über Mitternacht.

2.

Nun frew dich o Zion/

Setz auff die Ehren-Cron/

Zeuch an das Freuden-kleid/

Leg' hin dein Traurigkeit;

Der Breutigamb kömpt/

Der Breutigamb kömpt

In seiner schönen zier/

Zu dir/ glaub mir;

Sehr gute bottschafft bringen wir.

3.

Nun wolauff, stellt euch ein/

Mit uns frölich zu seyn/

Die ihr erwehlet seyd

$\mathrm{Zu}$ dieser Herrlichkeit;

Der Breutigamb kömpt!

Der Breutigamb kömpt/

Geht auß empfangt den Herrn

Der Ehrn/ helfft gern

Vnd willig sein lob mit vermehrn.

4.

Auff/ auff/ seyd guter ding/

Ihr Jungfraw'n und Jungling/

Tretet her an den tantz/

Mit ewrem Rosen-Crantz;

Der Breutigamb kömpt/

Der Breutigamb kömpt/

Schmückt euch auffs allerbest/

Alß Gäst/ zum Fest

Darauff Er Euch einladen lest. 
O wie anmuthig schon

Ist der Posaunen thon/

Man hört der Paucken hall/

224 Vnd der Trompetten schall;

Der Breutigamb kömpt/

Der Breutigamb kömpt/

Ist herrlich coroniert/

Geziert/ und wird

$\mathrm{Zu}$ seiner Hochzeit eingeführt.

6.

Vor ihm gehn die Spiel-leut/

Alles Volck nah' und weit

Freut sich und schreyet laut/

Saget Zion der Braut:

Der Breutigamb kömpt/

Der Breutigamb kömpt/

Er trägt ein Gülden Cron/

Zion/ wie schon

Zeucht zu dir ein des Königs Sohn?

7.

Es frew sich was da lebt/

Vnd unterm Himmel schwebt/

Ihr Berg und Bäum im Wald/

Vnd Kräuter mannigfalt;

Der Breutigamb kömpt;

Der Breutigamb kömpt/

Ihr Thier und Fisch im Meer/

Kommt her/ gebt Ehr

Diesem König und freut euch sehr.

8.

Nun wird der Newe Bund

Aller Welt werden kund;

Die Erd' gebenedeyt/

Vom fluch wiedrumb befreyt; 
Der Breutigamb kömpt/

Der Breutigamb kömpt/

Herrlich Er Triumphirt/

Regiert/ es wird

Nun alles werden Reformiert.

9.

Alle Welt lob den Herren/

Er ist werth aller Ehrn;

Die ihr seyd weit und nah'/

Kommt singt Hallelujah/

Der Breutigamb kömpt/

Der Breutigamb kömpt;

Macht richtig seinen steig/

Freut euch zugleich/

Er kompt zu nehmen ein das Reich.

10.

Hosianna dem Sohn

Des Herren, im höchsten Tron/

Der allem Volck bereitt

Ein große Herrlichkeit;

Der Breutigamb kömpt/

Der Breutigamb kömpt;

Lobsinget groß und klein/

Kommt ein/ last seyn

Ew'r Hochzeit Kleid sauber und rein.

11.

O große freud und wonn!

O Immerscheinend' Sonn!

Du bringest uns den Tag

Drinn man frolocken mag;

Der Breutigamb kömpt/

Der Breutigamb kömpt;

Der unser feinde zwingt;

Drumb singt und springt/

Er ist der uns den Fried mitbringt. 
Ihr/ die ihr seyd bißher

Gesessen in beschwer/

Von aller Weld verlacht/

226 Vnd gar zum spott gemacht/

Der Breutigamb kömpt/

Der Breutigamb kömpt/

Freut euch Er kömpt zur Rach/

Ew'r sach/ und schmach/

Herrlich zuführen auß hernach.

13.

Jauchtz frölich/ O Juda/

Messias ist gar nah'/

Vnser Immanuel!

Frew dich o Israël/

Der Breutigamb kömpt/

Der Breutigamb kömpt!

Frolocket lieben leut/

Vnd seyd bereit

Mit einzugehn zur Herrlichkeit.

14.

Ew'r leiden hat ein end/

Drumb klopffet in die händ;

Die Statt der schönen Braut

Wird nun wiedrumb gebawt;

Der Breutigamb kömpt/

Der Breutigamb kömpt/

Freut euch Er guberniert/

Floriert und führt

Den Reichs-scepter/ wie sichs gebührt.

15.

Recht Richtet unser Held/

Drumb hat jhn Gott bestellt/

Zurichten den Erd-kreyß;

Singet jhm lob und preiß/ 
Der Breutigamb kömpt/

Der Breutigamb kömpt/

Der Fried-Fürst hochgelehrt/

Es werd' auff Erd

Von allem Volck sein lob vermehrt.

16.

Singet mit süßem thon/

Der schönen Braut Zion

$\mathrm{Zu}$ ehrn/ ein new Gesang/

Last hörn der Harffen klang;

Der Breutigamb kömpt/

Der Breutigamb kömpt;

Sein Nahm gebenedeyt/

Sey weit und breit/

Gelobt in zeit und Ewigkeit.

Amen.

S.

$\mathrm{V}$.

S.V.P.V.S.

$\mathrm{V}$.

S.

Angel Vnd Psallieret Vnserm Salvatori;

Ihm allein gebühret

Alle Ehr und Glori.

1.

O Du geliebte Christenheit

Außerwehlt von dem Herren/

Gesessen bistu lange zeit

In schimpff/ spott und unehren/

Steh' auff/ frew dich und tritt herfür/

Dein König kömpt und will bey dir

Mit seiner hülff einkehren. 
Viel hastu/ das ist wahr/ verschuldt/

Drumb auch viel außgestanden/

Trägst aber alles in geduld/

228 Was dir mag gehn zuhanden;

Sey ferner still und Gott vertraw/

Auff sein' verheißung nur fest baw/

So wirstu nicht zuschanden.

Er, der lang hat geschwiegen still/

Alß wer' Er eingeschlaffen/

Lest sich sehn daß Er helffen will/

Vnd kömpt/ die Feind' zustraffen;

Hat seinen Bogen schon gespannt/

Nimbt seine scharffe Pfeil zur hand/

Die boßheit abzuschaffen.

4.

Nimb wahr, du wirst bald wunder sehn/

Wo die feind' werden bleiben;

Wie grewlich wirds den Spöttern gehn?

Der Herr wird sie vertreiben.

Die dich haben in noth gebracht/

Geplagt/ verjagt/ verachtt/ verlacht/

Wird Er im zorn auffreiben.

Alßdann wird die lieb außgebreitt/

Die Warheit herfür blitzen;

Frombhertzig' und friedfertig' Leut/

Werden das Land besitzen:

Des frewen wir uns im gemüth/

Gelobet sey der Sohn David/

Er kömpt/ sein Volck zuschützen. 
$\mathrm{H}$.

D.

H.D.S.D.H.

D.

$\mathrm{H}$.

Hosianna Dem Sohn Des Höchsten.

E.

S.

G.

I.

D.

$\mathrm{H}$.

F.

A.

E.S.G.I.D.H.F.A.E.A.F.H.D.I.G.S.E.
A.
F.
$\mathrm{H}$.
D.
I.
G.
S.
E.

Ehre Sey Gott In Der Höhe/ Friede Auff Erden/ Allen Frommen Hertzen/ Die In Gott Sich Ergetzen.

Woll allen die ihr vertrawen auff den Herren setzen/

Vnd seine Liebe für ihren höchsten Reichthumb schätzen.

Herr Du Frommer Gott/ Ach Gib Doch Fried/ Gedencke Deiner Barmhertzigkeit/ Erhör Doch Vnser Gebeth/ Herr Gott Zebaoth/ Du König Zion/ Komb Doch Zum Gericht/ Hilff Gnädig Unß Deinen Elenden; Brich Das Gefengnuß/ Führe Deine Gefangen Auß/ Gib Freyheit Deinen Heiligen. 
Schreiben von J.O.T.A. an die Gemeyn im Land Holstein In Den Heiligen Ostertagen/ Anno 1642.

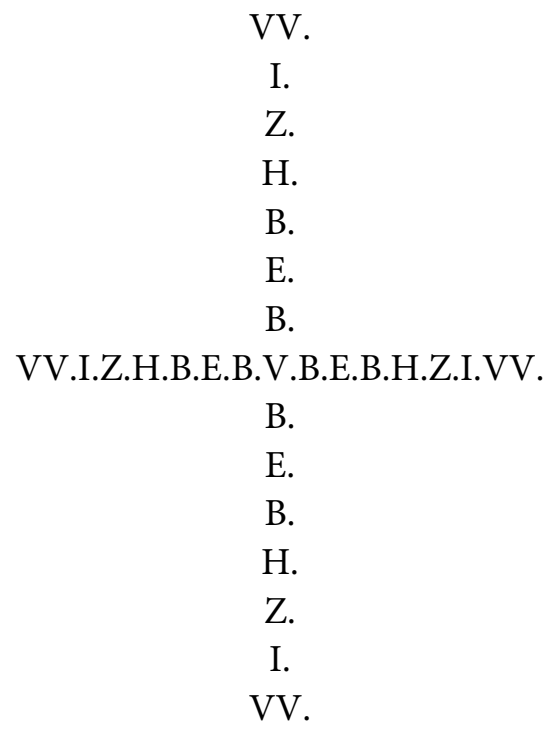

VVeit Ihr Zeit Habt Bekennet Ewer Boßheit/

231 Vnd Bessert Euch Bald/ Hohe Zeit Ists VVarlich.

S.

VV.

VV. 


$$
\begin{aligned}
& \text { V. } \\
& \text { B. } \\
& \text { D. } \\
& \text { S. } \\
& \text { I. }
\end{aligned}
$$

S.VV.VV.V.B.D.S.I.L.I.S.D.B.V.VV.VV.S.

I.

S.

D.

B.

V.

VV.

VV.

$\mathrm{S}$.

Seyt VVacker VVachet Vnd Betet;

Denn Satan Ist Loß In Seinen Dienern/

Brüllet Vnd VVütet VVarlich Sehr.

Durchs Gebeth sein Macht zertretet/

Denn wie ein Habicht fleucht nach den Hünern/

Also fleucht er auch umb euch her/

Darumb last beten seyn ew'r währ.

Herr Jesu unser Auffenthalt/

Komm bald und steur der Feind gewalt;

Sey unser Helffer/ steh' uns bey/

Mach uns frey von der Tyranney.

Alle die deiner Botten spotten

Wollestu gantz im grund außrotten/

Vnd der Gottlosen nahm vertilgen/

Die übels thun deinen gutwill'gen:

Allen betrübten und Elenden/

Gnad/ hülff/ trost und erquickung senden.

O Ewigs Liecht erleucht die blinden/

Vnd laß sie dein erkenntnuß finden.

Die einen guten vorsatz haben/

Wollestu mit verstandt begaben.

Breit auß dein Warheit nah' und weit/ 
Mach kund dein große Herrlichkeit.

Send deinen Geist herab von oben/

So wird die gantze Welt dich Loben.

Erhör doch das Gebeth der Frommen/

Laß deinen Fried auff Erden kommen/

Vnd bring dein Volck frölich zusamen/

$\mathrm{Zu}$ preisen deinen hohen Nahmen/

Komm bald Lieber Herr Jesu/ Amen.

Es spricht der solches zeuget

Vnd nicht leugt oder treuget:

Sieh ich komme bald/

233 Was du hast das halt. ${ }^{1}$

Ihr Vnterthanen groß und klein/

Der Gnädig'n Herrschafft in Holstein/

Sehr gut ichs mit Euch allen meyn/

Vnd bitt/ redet dem Fürsten ein/

Daß Er wolle gewarnet seyn/

Vnd nicht mehr der Warheit zuwieder/

Vertreiben Jesu Christi Brüder/

Vnd seiner Kirchen ware glieder/

Wie Er vor diesem hat gethan/

Seligen Teting und Lohmann/

Durch sein Fürstlich gestreng Mandaten/

Auff falsch angeben der Prælaten/

Husumer und Schleßwiger Pfaffen/

Die mit klaffen viel boses schaffen:

Wie auch nun thun die Cantzel-herrn

In Eydersteth/ die viel verkehrn/

Vnd alß die Phariseer pflegen/

Das Volck bewegen/ streit erregen/

Versammlen ihren rath zuhauff/

Lehnen sich wieder Christum auff.

Satans Wag' geht in vollem lauff;

Der Teuffel aller boßheit voll/

1 Apoc. 3. vers. 11. 
Ist in den Pfaffen rasend toll/

Vnd macht sie tobend wie die Heiden/

Daß sie Fried-liebend Leut nicht leiden/

Vnd im fried sitzen laßen künnen/

Noch ihnen ihre wolfart günnen.

Der friedsam Furst darff sie nicht schützen/

Die doch sind seines Landes stützen/

Vnd haben durch fleißig gebeth/

Bißher erhalten Eydersteth.

Itzt müssen sie von Hoff und Hauß/

Der Pfaffen-Teuffel treibt sie auß

Er lest nicht ab zu suppliciren/

Der Fürst soll/ wie er will/ regieren.

Ist Er dann nicht dazu geneigt/

So wird die straff ihm angezeigt/

Vnd muß Er sich bald von den schwätzern/

Auffs gräwlichst laßen mit verkätzern.

Das machet allen Leuten bang/

Helt Herrn und Fürsten auch im zwang:

Denn es erschrecket jedermann/

Fur Pfaffen zorn und ihrem Bann/

Vnd meynet/ Gott werd die nicht lassen

Gedeyen/ die die Pfaffen hassen.

$\mathrm{O}$ armes Volck/ o blinde Welt/

Wie übel ist die sach bestellt!

Seht einmal auff/ seyt nicht mehr blindt/

Wer hat doch das feur angezündt/

Das so sehr brennt im Römschen Reich?

Wisst ihrs? Sagt mirs/ ich frage euch/

Hats nicht gethan der Pfaffen-Teuffel?

Ja freylich/ daran ist kein zweiffel/

Er hat so lang das spiel regiert/

Die Herrn im streit zusamm'n geführt/

Daß so viel Stät sind destruirt/

Dörffer und Länder ruinirt/

Wie man üb'r all in Deutschland spührt;

Vnd nimmt der streit und die unruh'

Von tag zu tagen/ immer zu/ 
Wird auch wol nimmer haben end/

Bey diesem Pfaffen Regiement.

So lang die Baaliten wüten/

Werden noch viel Leut müssen blüten.

Gott woll' die seinen doch behüten!

Zuschanden machen Babels-bulen/

Die Titul-herrn von Hohen-Schulen/

Die im Land solche boßheit üben/

Vnd so viel fromme Leut betrüben.

Denn durch sie wird das Landt geschändet/

Das volck vom guten Weg gewendet/

235 Der großen Herrn gesicht verblendet/

Vnd die Göttlich Weißheit verdambt/

In ihrem Priesterlichen Ampt:

Die Welt-witz aber fürgezogen/

Dadurch sind bißher viel betrogen.

Der Pfaff will haben recht allein/

Vnd was er setzet das muß seyn/

Dazu sagt ja/ die gantz' Gemein;

So wird verführet Groß und Klein!

O lieben Leut seht auff beyzeit/

Ihr Fürsten liebt Gerechtigkeit/

Schaffet ab allen zanck und streit/

Im urtheil'n unparteylich seyt.

In gnaden neigt die ohren beid/

Mit fleiß auffmerckend/ ohn verstören/

Des gegentheils wort auch zuhören.

Ob es wol hat der Pfaff nicht gern/

Sondern ist fleißig das zuwehrn/

Wollet euch doch daran nicht kehrn/

Denn diß gereichet Gott zun Ehrn/

Vnd euch in ewerm Christenthum/

$\mathrm{Zu}$ unendlichem lob und ruhm.

Bittet den Herrn umb recht erkenntnuß/

So wird Er auffthun das verständnuß/

Vnd euch die Warheit lassen finden/

Dann wird der alte wahn verschwinden/

Da so viel Leut in allen Landen/ 
Ein lange zeit sind ingestanden.

Discordia wird sich verliehren/

Pax mit Concordia floriren/

Die Weißheit alle Völcker zieren/

Justita das Fähnlein führen/

Charitas über all regieren.

Dann wird man schöne sachen spüren/

Alles wird lieblich Concordiren/

Wann diese werden Guberniren,

Da die Gerechtigkeit im Land/

Vnd in der Statt/ hat überhand/

Steht's Excellent im Regiment/

Ist fried und freud wo man sich wendt/

Da scheint Warheit hell wie ein blitz:

Vnd wo die Witz hat ihren sitz/

Da haben auch die Frommen schutz

Wieder der bosen menschen trotz:

Wo aber die Gottlosen kommen

Zum Regiment über die frommen/

Da wird der Warheit lauff gewehrt/

Das Edle Recht in Gall verkehrt;

Die sünd nimbt zu/ straff wird gemehrt/

Alles gut verheert und verzehrt/

Wie die täglich erfahrung lehrt. ${ }^{2}$

Ein Frommes hertz in trauren lebt/

Da Gottloß wesen oben schwebt/

Vnd man der Warheit wiederstrebt/

Auch solche lose leut erhebt/

Die eigen Ehr und nutz vielmehr

Suchen/ alß Christi Ehr und Lehr/

Denn da kommt alles unglück her.

Die Frommen meng' ich nicht hirin/

Darumb ich wol entschüldigt bin:

Denn alle die nach Christi sinn/

Einen Christlichen wandel führen/

2 Pfal. 12. vers. 9 
Die Lehr mit ihrem leben zieren/

Vnd die Schrifft nach dem Geist erklären/

Selbst darnach leben wie sie lehren/

Achte ich würdig aller Ehren;

Wolt Gott daß viel derselben wären!

Aber ach daß die Fürsten wüsten/

Wie weinig Apostolsche Christen/

Oder rechte Evangelisten/

Man unterm Pfaffen-volcke findt/

Viel kenn ich die sehr Weltlich sind/

237 Vnd in Geistlichen sachen blind.

Wolcken ohn Wasser/ voll von windt/

Wie all ihr thun diß bringt am tage;

Trawt mir daß ich die warheit sage: ${ }^{3}$

Denn was ich wol beweisen kan/

Das zeig ich an für jedermann.

Eins muß ich hir noch setzen her/

Darüber ich mich wunder sehr.

In Husum habe ich gesehn/

Pfaffen Waffen im Fenster stehn/

Vnd auff ihren Schild einen Helm/

Seht/ ist der Teuffel nicht ein Schelm?

Kan er die Pfaffen so regieren/

$\mathrm{Daß}$ sie ihr Waffen damit zieren?

Ey hinauß/ auch die fahn zuführen/

Oder das Trommel-fell zu rühren.

Kriegs-art lest sich hir sehn und spühren.

Das alte Sprich-wort sagt gar recht:

Satan frisst Pfaffen/ scheist Lantz-knecht.

Mich dunckt die sachen stehn sehr schlecht/

Wann ein Geistlicher führt Kriegs-zeichen/

Die Priester den Welt-leuten gleichen/

Vnd auß der nachfolg Christi weichen.

Soll man die noch Frieds-botten nennen?

Ich kan es nicht für recht erkennen/

Die des Frieds spotten/ mag man sagen/

3 Jud. v. 12 2. Petr. 2. vers. 17 
Ein Wolfes hertz im Bußem tragen;

Vnd das Friedliebend Volck verjagen/

Wie können diese Gott behagen?

O ihr Häubter und Potentaten/

Last solche Leut nicht länger rathen/

Die so viel straffen auff euch laden/

Gewarnet seyd für ewern schaden/

Erkennet doch die zeit der Gnaden/

Vnd leget ewer Waffen nieder/

Frieden-statt helffet bawen wieder/

Zereisset nicht mehr Christi glieder.

Ihr Christlich' Fürsten trett zusamen/

Seyt geflissen nach ewerm Namen

In gnaden friedlich zu beschützen/

Alle die gern im friede sitzen:

Das wird dem Lande bringen nützen.

Regiert ewer Volck mit verschonen/

Lasset die Frommen bey euch wohnen/

Denn sie sind ein zierrath der Cronen.

Beschirmet die Frawen und Männer/

Welche sind der Warheit bekenner/

Die sich in guten Wercken üben/

Vnd aller Menschen wolfart lieben/

Niemand betriegen noch betrüben:

Das bose/ so viel möglich/ meiden/

Gern recht thun und das unrecht leiden/

Vnd sich von den Gottlosen scheiden/

In stillem wandel friedsam leben/

Mit wort und wercken auch darneben

Jedermann gut' exempel geben/

Sich über ander nicht erheben/

Der Obrigkeit nicht wiederstreben;

Sondern die Herrn gebührlich Ehrn/

Womit sie können/ hertzlich gern/

Derselben nutz und wolfart mehrn/

Vnd nach vermögen/ schaden wehrn.

Diese zuschützen euch gebührt/

Weil ihr der Götter Namen führt/ 
Vnd dazu seyt von Gott vocirt,

So hochgesetzt und ordinirt,

Mit vielen gaben illustrirt:

Seht nur zu daß ihr wol regirt/

Seyt ihr in ewerm Ambt geflissen/

Lasset Gott richten die gewissen.

Jeder wird selbst antworten müssen/

Vnd wie das Sprichwort pflegt zu sagen:

239 Sein eigen Säck zur Mühlen tragen/

An dem tag wann der Herr wird kommen/

Zurichten über böß und frommen.

Er ist übers gewissen Herr/

Gibt keinem andern diese Ehr.

Das Schwert Er euch befohlen hat/

Zustraffen eußer übelthat:

Er judicirt das innerlich:

Dafür ein Mensch soll hüten sich;

Ihm greiffen nicht ins Ambt noch Schwert/

$\mathrm{Da}$ er nicht werd dadurch verzehrt;

Es ist zweyschneidig/ geht hinein/

Scheidet Seel und Geist/ marck und bein.

Darumb ihr Herrn/ nach Gottes willen/

Thut fleiß den Pfaffen-streit zu stillen/

Helffet Christi gesätz erfüllen:

Seht nicht mehr durch der Priester brillen.

Satan hat sie erweckt zum streit/

Nimbt in acht sein gelegenheit/

Weiß er hat nunmehr weinig zeit:

Darumb er auch zu guter letzt/

Sie an die kinder Gottes hetzt/

Die hefftig werden zugesetzt.

Der Wolff hat seine zähn gewetzt/

Es forchten Schaf und Lämmer sich/

Darumb wirds hergehn jämmerlich/

Ja warlich gebt acht/ wunderlich

Wirds gehn den Spöttern sonderlich.

Gedenckt meiner/ ich habs gesagt/

Seht daß ihrs nicht zu späth beklagt. 
Daß schreib ich an die gantz Gemein/

Es geb darauff acht groß und klein.

Nemt es mit an ihr Canzelherrn/

Es gilt euch meist/ die ihr zu lehrn

Ansehnlich steht/ für Jung'n und Alten/

Im langen Rock mit großen falten/

Vnd eines Meisters namen tragt, ${ }^{4}$

Vngeachtt was der Meister sagt.

Das spiel ist von euch angefangen/

Der streit erst von euch außgegangen/

Wird auch an euch sein End erlangen/

Vb'r euch wird gehn ein scharff gericht/

Wann Gott wird durch ein heller liecht

Den Fürsten öffnen ihr gesicht.

Diß wird die ganze Welt erfahren/

Denn Jesus wird sich offenbaren/

Nach seinem Geist/ in großen scharen/

Mit krafft/ und anders alß viel meynen/

Herrlich erscheinen in den seinen.

Last euch die zeit nicht werden lang/

Er kömpt/ dem Teuffel ist schon bang/

Es krümmet sich die alte Schlang/

Stellt sich zur wehr/ will sich nicht legen/

So lang sie ihren schwantz kan regen:

Ihr macht soll aber bald verschwinden/

Ein Engel wird sich lassen finden/

Mit einer Ketten/ sie zu binden/

Der hat den Schlüssel zum Abgrund:

Die offenbarung macht es kund, ${ }^{5}$

Diß buch ist auß dem Geist geflossen/

Wird auch durch den Geist auffgeschlossen/

Vnd nun bald sein erfüllung haben/

Im Geist/ wie auch nach dem buchstaben.

Leset und hütet euch dabey/

Fur menschen witz und deuteley:

4 Matt. 2.3. v. 10.

5 Cap. 20 
Thut nichts dazu auch nichts davon/

Sonst folget darauff bösen lohn. ${ }^{6}$

Nemet die eigen Witz gefangen

So werdet ihr klugheit erlangen.

Wer willig mit Paulo begehrt

Ein Narr zu seyn/ der wird gelehrt/

Vnd von Gott endlich hochgeehrt. ${ }^{7}$

241 Folget ihm/ thut nach seinem Rath/

Steht ab von ewrer bösen that.

Fahrt nicht nach Wolfes art so fort/

Mit beißen/ reissen/ streit und Mord/

Sondern gehorchet Christi Wort/

Das unkraut last beym Weitzen stehn, ${ }^{8}$

Ihr könnt nicht in die hertzen sehn/

Was unkraut oder Weitzen ist;

Welches nur allein Jesu Christ/

Dem Nieren-prüfer/ ist bewüst:

Darumb ihr euch wol hüten müst.

Seine Engel hat Er bestellt/

Wird senden sie/ wanns ihm gefellt/

$\mathrm{Zu}$ rechter zeit es außzureissen;

Euch aber hat Er's nicht geheißen/

Sondern verbotten/ außzurotten:

Darumb steht ab von ewrem spotten/

Getrewe Warnung nem't zu hertzen/

Warlich Gott lest nicht mit ihm schertzen/

Oder an sein Aug-apffel rühren:

Denn die sein liebes Volck turbieren/

Incarcerieren/ tribulieren/

Verieren/ und in schaden führen/

Verklagen/ plagen/ jagen/ hassen/

Wird Er nicht ungestraffet lassen:

Sondern ihnen voll wieder messen/

Gleich wie Er hat gethan in Hessen/

6 Cap. 22 v. $18,19$.

7 I. Cor. 3. v. 18. Cap. 4. v. 10.

8 Matt. 13, vers. 30 
Vor weinig Jahrn/ noch unvergessen:

Wie außführlich ist kund gemacht/

Vnd durch den Druck ans liecht gebracht/

Davon ich weinig melden muß/

Bitt freundtlich/ hört es ohn verdruß:

Philipp-Henrich Homagius,

Vnd Georgius Zimmer-mann/

Zeigten die reine Warheit an/

$\mathrm{Zu}$ Marpurg auff der Hohen Schulen/

Den Titul-tragern/ Babels Bulen/

Vnd Letter-weisen/ Wolgelerten/

Ihr Red' sie mit der Schrifft bewehrten/

Wolten auch damit so fortfahren/

Vnd der Welt thorheit offenbaren:

Aber sie worden abgeweiset/

Mit angst und Tränenbrot gespeiset/

Vnd beid in Carcerem geführt/

So unbarmhertzig da tractirt,

Daß der Zimmer-mann revocirt.

Die Straff ward täglich immer strenger/

Er konte sie nicht leiden länger/

Vnd solche plagen mehr ertragen/

Bath Gnad und blieb so ungeschlagen/

Ward doch zum Lande außgejagt/

Hat seinen fall sehr offt beklagt/

Ja/ auch mit tränen bey dem Essen/

Da er an meinen Tisch gesessen.

Aber Homagius, mit krafft

Von Gott begnadet/ blieb standhafft/

Vnd wolt nicht von der Warheit weichen/

Ließ sich am Pranger blütig streichen.

Sagt zum Landgraffen unverholen/

Vnd dem Volck/ wie ihm war befohlen/

Daß der/ der ihn ließ streichen auß

Selbst weichen solt von Land und Hauß.

Er macht' dem Fürsten deutlich kund/

Die künfftig straff/ mit hand und mund/

Da er ihn sah am Fenster stehn/ 
Diese kurtzweil mit anzusehn:

In dem er solt vom Pranger gehn/

Rieff er gar laut mit hellen worten/

Daß es Ihr Fürstlich Gnaden horten:

Du Landgraff hast mich lassen streichen/

Du solt auch selbst zum Land außweichen:

Richt dich darnach/ du wirst nicht bleiben/

243 Denn man wird dich wiedrumb vertreiben;

Wann du drauß bist/ will ich eingehn

Vnd mich frey lassen wieder sehn.

Das alles ist auch so geschehn.

Die den Brey hatten angerührt/

Vnd ihren Herrn ins spiel geführt/

Sind mit ihr'm eignen fett geschmiert:

Worden darnach selbst Exulanien/

Musten außgehn von den Bekanten/

In frembden Landen alß Vaganten

Herumb spatzieren/ laboriren/

Authorität und gut verliehren/

Vnd in ihrem peregriniren/

Schmertzlich parlirn und lamentiren;

Also kan Gott das werck regieren!

Er lohnet beides/ boß und gut/

Gleich wie man seinen freunden thut:

Gibt immer gern das ein umbs ander/

Het loon na't doen, sagt der Hollander.

Dergleichen mehr/ hat man vernommen;

Darumb verjaget nicht die Frommen/

Sonst werden bosen wieder kommen/

Vnd euch so angst und bange machen/

$\mathrm{Da}$ euch vergehn wird ewer lachen.

Seelig ist der zu jederfrist/

Dem ander schad ein warnung ist.

Wann des Nachbarn hauß steht in brand/

Ist das feur nah' an unser wand/

Leschet/ ehe es nimbt überhand.

Ihr wisst was euch vor ist geschehn/

Meynt ihr die sach werd besser stehn? 
Warlich werdet ihr nicht zusehn/

Es wird euch noch viel ärger gehn.

Ehe die fluth kam/ wards euch gesagt/

Aber ihr habt/ Gott sey's geklagt/

Die Leut geplagt/ endlich verjagt/

Nach ihrer warnung nichts gefragt/

Sondern sie spöttlich außgelacht/

Vnd Zech-liedlein davon gemacht;

Seyt fortgefahrn in ewerm pracht.

Da nun die fluth kam in der nacht/

Vnd ewer etlich' mit umbbracht/

Sagt ihr darnach: wer hätts gedacht?

Itzt warnet man euch noch einmal;

Hört so ihr wollt/ ihr habt die wahl/

Erwehlt das beste/ ist mein rath/

Weil man noch zeit zu wählen hat.

Gott weiß ich meyn es herzlich gut/

Gehorchet mir/ fasst bessern muth.

O Ewig wol euch/ so ihrs thut!

Wo nicht/ so wird es kosten bluth.

Vber euch hang't ein scharffe ruth/

Der Nachbarn Häuser stehn in gluth/

Ich werd getrieben/ muß es sagen/

Habs ehe geschrieben/ wills mehr wagen/

Solt es auch kosten kopff und kragen.

Wolt Gott ihr könnt Warheit vertragen/

Vnd möchtt nach ihrer Lehre fragen/

Daß ihrs hernach nicht dürfft beklagen.

Wol an/ ich hoff es wird ohn brommen/

Gutwillig werden angenommen/

Vnd auch dem Fürsten seyn willkommen/

Was ich zu ewer aller frommen/

Geschrieben habe unverholen.

Hiemit seyt alle Gott befohlen/

Er Regier euch durch seinen Geist/

Also/ daß sein Nahm werd gepreist/

Hie in der zeit/ auch Ewiglich/

Von euch und allen/ auch durch mich/ 
Das wünsch von grund meins hertzen ich:

E.

D.

V.

$\mathrm{H}$.

E.D.V.H.V.H.D.E.

$\mathrm{H}$.

V.

D.

E.

Erbarme Dich Vnser Herr/

Vnd Helff Vnß Deinen Elenden;

Vnser Feinde wüten sehr/

Wo wir uns kehren und wenden;

Stärcken sie sich mehr und mehr/

Durch dein Macht ihr list abkehr;

Ihr furnehmen steur und wehr:

Du kanst all ihr anschläg schänden/

Sie in ihrer Weißheit blenden/

Vnser leiden frölich enden;

Hast alles in deinen händen.

Verzeuch nicht uns hülff zusenden.

Amen.

\section{De Denische Dörp-Pape}

Im korten Züge op Dütsch utstaffeert/ Schlecht un Recht van J.O.T.A.

Den 10 Julii am dage Saturni, do menn schreeff: Ein M. ein D. dre X. ein C.

In Puredof bym Poggenpohl/

Ein grot halff miel vam Predigstohl. 


\section{$S$.}

S.G.S.

S.

Simile Gaudet Simili,

Glieck freut sich sines gliecken/

Dat sehn in allen dingen wy.

By Armen un by Riecken.

Wat nicht glieckt/ dat mot wiecken/

Dat Klein vor't Grote striecken.

Im olden Sprichwort secht menn recht,

Alß de Herr $i ß /$ so $i ß$ de Knecht/

Alß de Werth $\mathrm{i} ß /$ so iß de Gast/

Alß de Mann iß/ so iß de Quast/

Alß de Herder iß/ sind de Schape/

De Tohörer iß alß sin Pape;

De hoet schicket sich na den mont/

De Scho iß schneden na den font.

Ein schön Huß hefft ein Hüpschen Gevel/

Ein wacker Spect ein sinen Knevel.

De Schede moet syn na dat Mest/

Denn glieck bym gliecken/ schickt sich best,

Dat süht menn hir ock/ gevet acht/

Vnbelacht leset mit bedacht/

Im lesen alles wolbetrachtt.

Hir mit wünschet Juw gude nacht.

Herr Hanns iß lustig im Beerhuse/

Springt mit der Maget umb bym Ruse,

Herr Hack kömpt ock/ wert dit gewahr/

Seit mit in und iß lustig dar.

Gvden dach min leve Herr Hannß/

Schall ick Juw finden hir im Danß? 
Ick meend' men schold' studeren/

Dewiel idt morgen Sonndach iß;

Wol schall denn vör juw holden Miß

Vnd Juw Thohörers Lehren?

\section{H. Hanns:}

Willkam/ kamt in/ leve Herr Hack/

Wy hebben hir recht gut gemack/

Sorget doch nicht vör morgen/

In minem kopp hebb' ick idt all

Wat ick morgen herschwatzen schall/

Dar darff ick nicht vör sorgen.

H. Hack:

Dat iß gut Herr Hannß ick gah' in/

Wiel ick ock gern mit frölich bin/

Ein Ehrloß Schelm mach truren/

Ick bin lang nicht by Juw gewest.

Wat sint dar binnen doch vör Gäst?

H. Hanns:

Idt sint min egen Buhren.

H. Hack:

Ick wunsch Juw all'n ein guden dach.

De Buhren:

Danck hebbt/ willkam in unse g'lach/

Wy sehn Juw hertlich geren.

Kam't neger her/ leve Herr Hack/

Verlehnt uns ock doch juwen schnack.

Sittet by unsem Heren/

Vnd drincket lustig mit umher/ 
Id iß recht gut und leefflich Beer/

Lett sich ock sehr wol drincken.

H. Hack:

Dat will ick dhon up juwe bede/

Lever gut Beer alß schlimme Mede/

Ick hap' idt schall wol sincken.

Drincket her/ mak't nicht mehr verwohr.

\section{Buhren:}

Darup gelt idt juw/ Herr Pastor.

\section{H. Hack:}

My alleen van juw beiden?

Dat iß my kruwen altho veel/

Ick krieg' idt nümmer dörch de keel/

Doch moet ick my bereiden/

Vnd sehn efft ick idt kan bestahn.

Ick bringt juw Herr Hannß min Compan/

Bringt idt dem Naber wedder.

H. Hanns:

Min Naber hefft all so veel Beer/

Dat he van avent drinckt nicht mehr.

He schlöpt/ legg't ehn doch neder/

Vn dhot ehm nu doch iho nehn leet.

Oleff dhot gy vor ehm bescheet/

Sett Juw in sine stede.

Oleff Buhr:

Ja gern Herr Hannß/ drinckt my menn tho.

Süh' Naber wat ick vör dy dho/

Vp Herr Hannß sine bede. 


\section{H. Hanns:}

Oleff dat Juw Gott geve glück/

Gy dhon ein recht truw Nabers stuck/

Ick moet juw darin römen:

Gy nemen juw Bentt siner an

Alß ein fram/ ehrlich/gut Dannmann/

So will ick juw ock nömen.

\section{H. Hack:}

Herr Hannß mak't doch nicht so veel wort/ Gude Frundt Oleff/ drincket fort/ Latht Trüwloß ock wat kriegen.

\section{H. Hanns:}

Dat's recht Herr Hack/ gevet mit acht/

Trüwloß ehm iß lang' nehn gebracht/

He plecht so nich tho schwiegen.

Trüwloß wo ißt? wo steit de mout?

\section{Trüwloss Buhr:}

Gott loff/ Herr Hannß/ idt iß all gout/

Ick hebb' min dehl bald kregen.

Idt iß my gahn/ so alß idt plecht/

Ick hebb' wat unnern disch gelecht/

Dat moet de Magt wechfegen/

Edder gy krieg'n de Neeß all voll.

\section{H. Hanns:}

$250 \mathrm{Ho} / \mathrm{ho} /$ Trüwloß/ wo? sy gy doll?

Warumb kond' gy nicht spreken?

Trüwl. Buhr: 
Idt quam ehr ickt vermoden was/

Ick dranck menn ein drunck över paß/

De wold' my't hert tho breken.

\section{H. Hack:}

Fuy Düvel/ nu rück ick den funt/

Trüwloß gy sint vörwahr nich sunt/

Idt rückt alß hädd gy’t scheten.

Trüwl. Buhr:

O leve Herr Hack schwiegt still/

Idt schüth wedder min egen will/

Iß my ock offt verweten/

Seit mennigmal henn/ ehr menn't föhlt.

H. Hack:

Trüwloß hebb' gy den munt ock spöhlt?

Dencket doch wo gy stincken.

Trüwl. Buhr:

Ho/ ho/ wat schall ick spöhlen veel?

Ick will spöhlen min munt un kehl/

Wenn gy my eins tho drincken.

H. Hack:

De Störttensueck drinck mehr mit juw.

H. Hanns:

Herr Hack/ hebb' gy vör ehm ein gruw?

Wat schall doch dat bedüden?

Dar kehr ick my vörwahr nich an/

Drinck glieckwol mit ehm uth de Kann; 
Dat wedderfahrt mehr Lüden:

Idt lett sich ja lichtlich versehn/

Iß my ock sulfest offt geschehn/

Im Bedd' by miner Fruwen;

Drincket menn mit/ denck't nicht daran/

He iß gewiß ein reinlich Mann;

Latht juw nicht vör ehm gruwen.

H. Hack:

Iß dit juw ernst? segg't my/ Herr Hannß?

Schold ick drincken mit sölcke Manns?

Sint se doch alß de Sögen.

Ick drünck lever im Jahr neen Beer:

My wundert idt van juw recht sehr/

Dat gy idt so dhon mögen.

H. Hanns:

$\mathrm{Ha} / \mathrm{ha} /$ dat schadet nicht ein har/

251 He iß ja nu innwändig klar.

Trüwloß/ latht menn her weyen/

Gy hebben juw vam unflath fryt

Oleff Buhr:

Holt Bror/ du heffst den bart bespy't/

Lath my't dy erst uthkleyen/

So kanstu Herr Hannß drincken tho.

Trüwl. Buhr:

Ja Oleff leve Bror/ dat dho/

Herr Hack secht/ dat wy stincken/

Oleff Buhr:

$\mathrm{Nu}$ Bror/ drinck nu/ nu bistu fry. 
Herr Hack/ dit geit juw Neeß verby/

Ick will't Herr Hannß tho drincken.

Herr Hannß ick bring't juw allthomal.

Dit hir iß unse Vagetsschahl/

Dar will wy ehn mit ehren/

H. Hanns:

Danck hebb't Trüwloß/ min gode fründt/

Ein Schelm iß de ehm övel günnt/

Ick drinck sin schal recht geren.

Dat lestmal do ick by ehm was/

Spöhld he my so tho uth sin glaß/

Dat ick sülfest nicht wüste

Efft ick ein Wieff was edd'r ein Mann.

Gy weten wo he supen kan/

Ick dranck mehr alß my lüste.

Herr Peter/ Herr Christen und Herr Cnuth/

Kregen ock datmal voll de Huth:

Wy wehren alß veer blinden/

Konden up unse föth nicht stahn.

Do ick wedder tho huß wold gahn/

Kond ick de Dhör nicht finden.

Wy bleeven dar ahn unsen danck/

Leden unß all' veer up de Banck.

Ick weet nicht wat he dachte/

Dat he uns maeckd so voll und doll.

Oleff Buhr:

O leve Herr/ dat weth gy wol/

Wenn't so tho geit/ so lacht he.

H. Hack: 
Ja he deit na der olden wiese/

Iß nehn hunt över dranck und spiese/

Ick hebb' ock by ehm seten/

Weet wol wo he sin Gäst tracteert,

He iß utbündig gut thon werth/

Drinckt gern/ mach ock wol eten.

Oleff Buhr:

Ja/ dat iß wahr/ leve Herr Prest/

He iß ein Werth vör gode Gäst/

Dat weten all de Buhren/

Iß jümmr blied/ süht nümmer suhr/

Wol dar kömpt/ Börger edder Buhr/

He will nicht dat se truren.

H. Hanns:

O dat iß recht ein gode arth/

Wat hefft menn mehr thor hennefart

Nödig/ alß solcken Namen?

Wy nehmen nichts mit uth de Welt/

Laten hir unse guth und gelt/

Salich sint alle Framen.

Herr Hack will gy mit buten gahn?

Ick moth min Water eins affschlan.

Oleff Buhr:

Kamt doch bald wedder binnen/

H. Hanns:

Ja/ ja/ Oleff wy dhon ock dat/

So lang dar noch Beer iß int fakt/

Wy sint ja noch by sinnen.

Se gahn uth/ Truwloß iß quath/ Oleff suht dit/ fragt wat ehm schadt. 
Oleff Buhr:

Trüwloß wo ist? heffstu ein schroll?

Trüwl. Buhr:

Herr Hack de maeckt my rasen doll/

Wat gaff he my vör wörde.

Kompt he hir wedder in de Stuven/

He schall dar ein Ohrfieg uthkluven.

Oleff Buhr:

Wo nu Bror/ bistu dörde?

Woldestu einen Papen schlan?

Idt würd dy nümmermehr wolgahn/

Dar machstu dy vör schemen.

Trüwl. Buhr:

He mach sin ein Pap' edder Ap'/

He schall wiß sehn dat ick nich schlap'

Lett he my nicht bethemen.

Iß he denn beter alß Herr Hannß/

Edder alß ander Wiese Manns/

Dar ick ock offt mit drincke?

$\mathrm{O}$ dat ehm warde walg und weh'

Wol hefft idt doch ehe secht alß he/

Dat ick so övel stincke?

Dat ehm ankam de Störttensueck/

He schall bald föhlen wo ick rüeck.

Lath my menn mit ehm raden.

Oleff Buhr:

Min hartten Brörken holt doch frede/

Lath dy stüren up mine bede/

Wahr dy sülfest vör schaden. 
Kom mit my tho huß ahn rumor/

Maeck doch din Wyfften nehn verwohr/

Du weckst se kan so sorgen.

Trüwl. Buhr:

$\mathrm{Nu}$ Bror/ du meenst idt gut mit my/

Darumb gah' ick ock gern mit dy/

Will ehm up ditmal borgen:

Idt komt wol eins ein ander dach/

Dat ick ehn find in min gelach/

So schall he de süeck kriegen.

Oleff Buhr:

Dats recht/ dar heffstu minen sinn/

Kom/ lath uns gahn/ se kamen in/

Wy willen ditmal schwiegen/

Vnd gahn thor achtern dören uth/

Papen volck isz ein seltsam kruth,

Veel arger alsz de Netteln,

De henn' menn gern daran verbrennt/

De köfft se nich/ de se recht kennt/

De Düvel mach se ketteln.

Se gahn henn De Papen kamen inn.

H. Hanns:

Kam't in Herr Hack/ hir find' wy nehn/

254 Hört unß de Stuve nu alleen?

Wor sint de Buhren bleven?

H. Hack:

My dünckt se wehren satt van Beer;

Wenn Trüwloß lenger bleven wer'

So hadd ick mit ehm keven. 
Seeg gy nicht/ wo schrollsch sach he uth/

He iß ein schelm in siner huth;

Hadd' ick ehm by der kehlen/

Ick wold ehm geven sinen dehl

Am lieve/ he schold sine Seel

Dem leven Gott befehlen.

H. Hanns:

Wonu Herr Hack/ wats dat vör schnack?

Schold menn sich kehrn an solcken pack?

Wol wold mit dat volck kieven?

Wold gy juw wol mit Buhren schlan?

Dat wer' vör wahr nich wolgedahn/

Latht Buhren/ Buhren blieven.

H. Hack:

Ja/ wenn ick denck an unsen stand/

So wer' idt wol ein weinig schand;

Se sint nich unses gliecken/

Idt mach so henngahn up ditmal.

H. Hanns:

Herr Hack langet my her de Schael/

Latht uns dar eins in kiecken.

Drincket my tho den halven deht.

H. Hack:

Neen/ neen/ Herr Hannß/ ick bringt juw heel.

\section{H. Hanns:}

Drinckt uth dat juw Gott segen/

So veel alß in der bütten $\mathrm{i} ß /$

Dat Beer schmeckt wol. 
H. Hack:

Ja/ dat iß wiß/

Idt kan den halß wol fegen/

Idt schmeckt so liden wol na Hopp.

H. Hanns:

Ja/ dat föhl ick wol im kopp/

Dat gut west iß de Hummel.

Wo ick noch ein stund lenger sitt/

So will ick juw wol seggen dit/

Ick krieg ein guden Tummel.

H. Hack:

Idt wert my bald nicht beter gahn.

\section{H. Hanns:}

Dat schadt nicht/ wy sintt wol gewahn/

Morgen schalt nemant marcken/

Dat wy druncken gewesen sind/

Wenn menn uns manck den buhren findt/

Vörm Altar in der Karcken.

Wy hebbent gut mit den Postillen/

Könen daruth na unsen willen/

Mehr alß uns nödisch/ spreken/

Tho verdenen dat Jarlich lohn.

\section{H. Hack:}

Ja/ Gott sy danck/ dat kön' wy dhon/

Gar lichtlich/ ahn Kopp breken.

Wy Presters im Dörp sint mit freden/

Hebbent beter alß dein Steden.

H. Hanns: 
Ja truw'n hir iß gut wesen.

Vnse Thohörers sint sin schlicht/

Verstahn sich up de saken nicht/

De meist' hup kan nicht lesen.

All wo wy't maken/ so ist recht/

Se achten uns vör Gades Knecht/

Seggen ock wy sint Hillig/

Darumb holden se uns in Ehrn.

H. Hack:

Ja/ recht/ so moth menn se vexeren/

Idt iß nicht mehr alß billig/

Dat se uns holden ehren wert/

Darumb hebben wy iho studert/

Dat wy na unsem willen/

Mögen in ansehn leven frisch/

Vnd holden einen guden Disch/

Ock unsen Büdel füllen.

H. Hanns:

Ja/ schold menn hebben veel verwoht/

So möcht de Düvel syn Pastor/

Vnse Ampt wold nicht dögen/

Wenn idt nicht maeckd' den Büdel voll:

Averst nu hebb wy't recht und wol/

So/ alß wy’t wünschen mögen.

H. Hack:

Dats wahr/ wy hebben gude dage/

Leven in rouw und ahne klage/

Beter alß de Soldaten.

Dat Offer dricht uns grot gewinn/

Vnse schwatzen bringt Järlich in/

Mehr als der Advocaten. 


\section{H. Hanns:}

Ja/ wy hebben Authoritet/

Se menen de uns deit verdreet

Kan sin dag nicht gedyen.

Vor unsem Bann forchtt jeder sick/

Veel mehr alß vör des Bödels strick/

So schall menn Buhren brüyen.

\section{H. Hack:}

Still/ still/ schnackt doch so lude nicht/

Buhren sind lose Bosewichts/

Idt möcht uns einer hören

Vnd dragen disse wörde uth/

Dat wer' denn vör uns all nicht gut.

H. Hanns:

Den schold de Düvel rören.

Hir van genoch/ eins thom valet

Bringt my tho/ ick dho juw bescheet/

So gahn wy denn thosamen

Schlapen in unser Fruwen Armen/

Wy hebben nu gefüllt de Darmen/

257 Gott lacht unß wol bekamen.

A.

$S$.

A.S.P.S.A.

S.

A.

Alle Solcke Papen Sint Apen.

De fast in eren sünden schlapen/

Vn nich recht handlen by den Schapen.

Van ehnen iß nichts guds to hapen. 
Gy Arme Maden/

Mit sünd beladen/

Staht aff vam quaden/

Dhot gude daden/

Wahrt juw vör schaden/

Latet juw raden/

In tidt der gnaden

Van Gades baden.

Midet de Rotten

De erer spotten.

David Ioris Gottes knecht/

Hefft gesegt/ verstaht idt recht:

De Papen maken veel Apen/

De Düvel hefft se geschapen.

1.

Weh' juw Pastoren

De't Kaff vör't Koren

Hebben genamen:

Mit Juwen lehren

De Schrifft verkehren/

Wo will't juw bekamen?

2.

Gy dröge Kuhlen/

Gy blinde Vlen/

Wölfe un Bahren:

De Schap' gy biten/

Ja/ gantz tho riten/

Wo will gy doch fahren?

3.

$\mathrm{Na}$ er fleesch stah' gy/

In er sell gah' gy/

Ehr Melck gy drincken/

De Woll' gy plücken/ 
De huth affrücken;

Van laster gy stincken.

4.

Gy söken gewinn

Vn kamen nich in

259 Thor rechten döhren:

Vmb gelt gy spreken/

Dat gude breken/

De Lüde verföhren.

5.

Sehr veel gy lesen;

Doch iß juw wesen

Nich alß gy menen/

Mit grotem prangen

Gy Ehr entfangen/

Van groten und kleenen.

6.

Mit tituleren/

Nömt menn juw Heren/

Darna gy trachten/

Hoch gy erheven

De juw veel geven/

Sonst nemant mehr achten.

7.

All juw studeren

Vnd mediteren/

$\mathrm{Na}$ gelt gy richten;

Den Bueck tho füllen/

$\mathrm{Na}$ juwen willen/

Dat iß all juw dichten.

8.

Gy Herr Gotts deve/

Juw egen leve/ 
Hefft juw beseten:

Dat sath der Schlangen/

Hebb' gy entfangen/

Adams Appel eten.

9.

Packt juw gy Apen/

Gy Baals Papen/

Gy Hypocriten/

Gy falsch Propheten/

Wol hefft juw heten

Dat Volck tho beschiten?

10.

O latht juw raden/

Wahrt juw vör schaden/

$\mathrm{Nu} / \mathrm{nu} /$ by tiden;

Van't böß juw kehret/

Dat gud' begehret/

Wiel idt noch heet hüden.

11.

Erkennt de Warheit/

Seht Gottes Klarheit/

De Dach's angangen/

Vn wert bald kamen/

Dar na de Framen

Hebben ein verlangen.

12.

Alle Welt-wiesen/

Die sich sülfst priesen/

Möthen herunder:

All de Gottlaven/

Werden erhaven/

Dar wert menn sehn wunder. 
O latht juw lehren/

261 Gott recht tho ehren/

Mit Word und Wercken;

Hört Gottes baden/

In tidt der Gnaden/

Syt nicht alß de Fercken.

14.

Dit hefft Juw gesecht/

De trüw Gottes Knecht/

Den gy verdömen:

Sin lieff iß verbrannt/

Sin Seel in Gotts hand/

Ick darff ehn nich nömen.

J.O.T.A.

Ein Schreiben uber Meer gesandt/An die Gemein in Engelandt/

Aus einer alten Frawen Handt/Die ungenandt/Gott ist bekandt

B.

D.

B.

B.D.B.V.B.D.B.B.

D.

B.

Bekenn Dein Boßheit Vnd Besser Dich Bald,

Fairfax dein Loßheit und deine Gewalt/

Am König begangen/

Wird nun Lohn empfangen/

Wie du hast verdienet/

Denn dein ungluck grünet/

Zweiffel nicht daran/

264 Du Gottloser Mann. 
Ihr Engeländische Eydbrecher/

Göttlicher Ordnung wiedersprecher/

Wie habt ihr euch gestürtzet/

In spott/ für allen nah' und fern/

Da ihr dem König ewrem Herrn/

Des lebens Ziel verkürtzet.

Hat Satan euch dann gantz verblendt/

Daß ihr euch selbst so habt geschändt?

Wer hat jemals gelesen/

Daß solche Leute/ wie ihr seyt/

Auff Erden in der ChristenheitVor zeiten sind gewesen?

Ich bekenn es mit warheit frey/

Daß ich von solcher Tyranney/

Mein tag nicht hab gehöret:

Nein/ so alt ich geworden bin/

Hab ich kein Volck gesehn vorhin

Vom Teuffel so bethöret/

Das seinen König umbgebracht/

Vnd ein solch Parlament gemacht/

Alß ihr/ O tolle Thoren/

Vnd Parlamentische Auffrührer/

Rebellen/ Teuffels-Rädlein-führer/

Satan reitt euch mit sporen.

Der Herr hat euch zum fluch gemacht:

Da ewer itzo wird gedacht/

Werdet ihr angespeyet:

Denn ihr habt auß des Satans Rath/

Begangen ein Mördersche that/

O Leut vermaledeyet!

Sind keine Priester da im Reich/

Die auß der Schrifft recht lehren euch?

Vnd diese Wort erklären:

Fürchtet Gott und den König ehrt?

Mercket doch wie ihr seyt gelehrt!

Hast das den König ehren

Wenn man ihm seinen Kopff abschneidt/

Vnd die Seele vom leibe scheidt?

Seht doch was ihr begangen! 
Ein Gesalbter des Herren ist

Von euch ermordt/ O Teuffels list/

Was hastu angefangen?

O Engelant/ voll unverstand/

Dein schand wird aller welt bekand/

Bleibt auch zu allen zeiten:

Du hast dich schändlich/ wie ich merck/

$\mathrm{Zu}$ diesem unerhörten werck/

Vom Teuffel lassen reiten.

Ihr Ehrvergessne Engeländer/

Meyn-Eydge Gotts Ordnung-schänder/

Ihr Hirtten mit den Schafen/

Lebt ihr in solcher Gottes forcht?

Ist das dem wort des Herrn gehorcht?

Solte Gott euch nicht straffen?

Heist diß die Obrigkeit geehrt?

So hat der Teuffel euch gelehrt/

Bey dem ihr habt studieret.

Er gab euch ein die böse that/

Saß oben an in ewrem Rath/

Hats urtheil proclamieret.

Ich schreib ohn schew die warheit frey/

Vnd steh so lang ich leb/ihr bey/

O ihr Menschliche Teuffel!

Teuffelsche Menschen/ wilde Thier/

Ja ärger alß die Thier seyt ihr/

Von Gott verflucht ohn zweiffel/

Mit dem Verräther in Schottland/

Der euch den König zugesand/

Weh euch ihr übelthäter!

O Schottland/ sehr leid ist es mir/

Daß man auch hören soll von dir/

266 Du habst solche Verräther.

O Esel/ Lesel/ sieh' wie hast

Du (Wie Judas der lose Gast)

Deinen König geführet

Zur schlachtbank/ in der sünder händ/

Gabst stanck für danck/ daß dich Gott schänd! 
Mehr danck hätt ihm gebühret;

Der dich zum Grafen hat gemacht/

Vnd in grosses ansehn gebracht/

Den hastu hingegeben.

Er war from/ meynt du werst sein freund/

(Wie es auch scheint) warst aber feind/

Das kostet Ihm sein leben.

Sein Maystät hat auff wort gebawt/

Deiner falschheit zu viel getrawt/

Dadurch ist Er verrahten.

Traw wol und glaube leicht/ die beid

Machen auch offtmals hertzenleid/

Den hohen Potentaten.

Weh' dir du Schott Ischarioth/

Du bist schuldig ans Königs todt/

Hast geltsummen genommen/

Vnd deinen Herrn nach Engeland/

Den Phariserrn zugesand.

Weh' dir und auch dem krummen

Cromwel/ des Fairfax spieß gesell/

Der Hencker zieh' euch ab das fell/

Geb' ewerm Commandanten

Hammund/ auch seinen rechten lohn/

Hamans Galge/ zu spott und hoen/

Allen seinen verwanten.

Man hört noch täglich wie ihr mordt/

Wie lang wollt ihr so fahren fort/

Die Frommen zu betrüben?

Ihr schreittet zu weit übers ziel/

Machet der armen Waisen viel/

Heist das den Nähsten lieben?

Vom Weibe nemt ihr hin den Mann/

Meynt ihr Gott hab gefallen dran?

Glaubt frey/ straff wird Er senden:

Der Waisen seufftzen hört der Herr/

Der Wittwen tränen sammelt Er/

Nimpt sich an der Elenden.

Ihr habt in ewrem Königreich 
Derselben tränen viel auff euch/

Schwer werden sie euch fallen

Auffs hertz/ in ewer letsten noth/

Wann heran treten wird der tod;

Diß sag ich euch und allen.

Die lieb zur Obrigkeit macht/ daß

Ich euch und ewers gleichen haß/

Als Teuffels Mitgesellen/

Vnd ungetrewe Vnterthanen/

Ihr Engeländsche Wetterhanen/

Meutmacher und Rebellen:

Ich kan euch sonst nicht tituliern/

Nichts gutes ist an euch zu spührn/

Die Liebe nicht zufinden.

Ihr habt vergossen Königs blut/

Wie kan ein Christ diß heissen gut?

$\mathrm{O}$ ihr verkehrte blinden.

Habt ihr an David nicht gedacht/

Hat ders mit Saul also gemacht?

Wolt Er sein hand auch legen

An den Gesalbeten des Herrn?

Nein/ sprach Er/ daß sey von Mir fern.

Er ließ sich nicht bewegen

Zu tödten den/ der ihn doch hasst:

Er war ihm so nah daß er fasst

Den zipfel seines Kleides;

Ließ ihn dennoch gehn unversehrt/

Damit er Vnterthanen lehrt/

268 Köngen zu thun nichts leides.

Was gab Er auch fur Bottenbrot

Dem/ der zu ihm sprach Saul ist todt/

Vnd ich hab ihn erschlagen?

Must nicht dafur der armer Tropff/

Wieder einen blütigen Kopff

In seinem Grabe tragen?

Ja recht/ Gott geb euch gleichen lohn/

Weil ihr die Königliche Cron

Habt mit dem haubt geraubet. 
Der Herr ist Gerecht im Gericht/

Wirds lassen ungestraffet nicht/

Schrecklich wirds gehn/ das glaubet.

Ihr habt den Königlichen Rock/

(Verflucht sey ewer Beil und Block!)

Auß neid gemachet blütig.

Euch ewrem König wiedersetzt/

Sein Edles blut gering geschetzt/

Ihr Henckers Buben wütig!

Wisst ihr nicht daß ihr schüldig seyd/

$\mathrm{Zu}$ gehorchen der Obrigkeit/

Welche die Schrifft nennt Götter?

Wer sie nicht ehrt/ der unehrt Gott/

Vnd helt seine Gebott für spott.

Seyt ihr denn nu nicht Spötter?

O Spötters hauß wie will dirs gehn?

Gib acht du wirst bald wunder sehn;

Ein großes feur vom Herren

Das in Teutschland lang hat gebrand/

Komt nun zu dir in Engeland/

Dich im grund zu verzehren.

Dann wird geschändt dein Parlament/

Vnd du Fiarfax wirst im Elend

Für schmertzen lamentiren.

Es kompt daher ein grosse meng/

Wird Engeland dir machen eng/

Das wirstu sehn und spühren/

Ja fühlen/ merck wol was ich sag/

Dein unglück kompt/ nah' sind die tag/

Was gilt es? ich will wetten/

Von den vier Winden kompt ein Rauch/

Blitz/ Donner/ Sturm und Hagel auch/

Niemand wird dich erretten.

Schrecklich wirds gehn/ wie wiltu stehn/

Wann du das Volck wirst kommen sehn/

Des Königs blut zu rächen?

Du Mörder/ Lügner/ Schelm und Dieb/

Es mag dir seyn leid oder lieb/ 
Ich muß die Warheit sprechen.

Schelm tituliert dich jedermann/

Denn du hast wie ein Schelm gethan/

Schelm sind auch dein Gesellen/

Dieb/ Mörder/ Lügner/ Satan gleich/

Er ist ew'r Herr/ wird lohnen euch/

Hir oder in der Hellen.

Ihr wollt England im freyen stand

Gern sehn und seyn wie in Holland

Die Hoch Edle Herrn Staten:

Aber nein/ das geht euch nicht an/

Keiner von ihnen sagen kan

Solch Mord und Teuffelsch thaten.

Ihr habt den König decollirt,

Dem Reich den besten Schatz entführt/

Vbel wirds euch bekommen/

Ja eben wie dem Hund das graß/

Es ist euch gesagt/ mercket das.

Der Herr behüt die Frommen/

Halt über sie sein gnaden hand/

Ohn zweiffel sind noch in England

Auch viel/ die sich betrüben

Vber diesen schmählichen todt;

O Gott hilff allen auß der Noth/

270 Die ihren König lieben.

Kein Obrigkeit ist ohn von Gott/

Ein Christ helt willig ihr Gebott/

Wil gern obediiren/

Lehnet sich nicht (wie Fairfax hauff)

Wieder König und Fürsten auff/

Begehrt nicht zu regieren.

O lieben Leut/ weils Gott gebeut/

Gehorsam seit der Obrigkeit/

$\mathrm{Ja} /$ auch den wunderlichen/

Wenn sie schon wieder Eyd und Ehr/

Gehandelt hätte/ oder wer'

Vom rechten weg gewichen.

Stellt es Gott heim/ sein ist die Rach/ 
Suchet ihr Frieden/ jagt ihm nach/

Werdet nicht wiederspännig.

Greiffet dem Herrn nicht in das Schwerd/

Daß ihr nicht werdt dadurch verzehrt.

Bleibet stets unterthänig/

Der Herr ist nah'/ kompt zum Gericht/

Seyt guter Hoffnung/ zweiffelt nicht/

Befehlet ihm die sachen:

Er ist Gerecht/ trawt ihm nur schlecht/

So werdet ihr alß trewe Knecht

Nach trauren frölich lachen.

Hiemit ade.

Der sehn will/ seh'

Wie Gott dem alten Drachen

Zubinden wird den Rachen/

Das böse from/

Gerad das krom/

Das unrecht richtig machen/

Vnd all die sein

Gehorsam sein/

Bewahren und bewachen.

Amen.

Wer gern mit Alten Frawen streitt:

Der bleibt ein Narr seins lebens zeit

Seht doch/ da kompt ein Adeler

Auß dem Krug-hauß geflogen her/

$\mathrm{Zu}$ einer alten Frawen:

Tritt sein herein wie ein Captein/

Ansehnlich/ und bringt ein Brieflein

An Sie in seinen klawen.

Ob er wol ein Raub-vogel ist/

Scharffsinnig/ klug und voller list/

Helt Tauben keinen glauben:

Trawt doch die Alte Fraw das best/ 
Vnd glaubet fest/ auß ihrem Nest

Werd er kein Tauben Rauben.

Seyt freundtlich gegrüst J.J.A.

Sehr gern hat angenommen

Die alte Frawe A.O.H.

(Ein Freundinn aller Frommen)

Ewern Brief der Sie Reformirt

Vnd sein zur Sanfftmuth führet/

Die auffs höhst alle Menschen ziert/

Den Wittwen auch gebühret.

Sie erkennt das ihrs trewlich meynt/

Vnd lust zum friede traget;

Drumb nennet sie euch ihren Freund/

Weil ihr auch fried behaget.

Daß aber Sie im schreiben schendt/

Schelm und Dieb tituliret/

Die losen Leut im Parlament/

Denen kein Ehr gebüret/

Dran hat sie recht gethan/ thuts noch/

272 Vnd will darbey auch bleiben/

Bitt last es euch gefallen doch

Vnd tadelt nicht ihr schreiben.

Sie hat es noch kein mal berewt/

Wird es auch nicht betrauren/

Will schreiben warheit ungeschewt

Für Herrn/ Bürgern und Bauren.

Denn sie hat in der Heil'gen Tauff

Dem Teuffel abgesaget/

Darumb sie nicht/ wie Fairfax hauff/

Nach seiner freundtschafft fraget.

Die lobens werth sind/ lobt sie mit/

Liebt alle die Gott lieben/

Vnd hasst/ dawieder helfft kein bitt/

Die sich in boßheit üben:

Die losen leute sonderlich

Die ihren eigen Herren

Getödtet/ die wird sie/ weiß ich/ 
Ihr leben lang nicht ehren.

Schand sind sie wert/ schand haben sie/

Schand müssen sie behalten/

Werden verfluchet späth und früh/

Von Jungen und von Alten.

Ein rechter Christ kan Fairfax that

Nicht gut heissen noch preisen/

Der Ehr und Redlichkeit lieb hat/

Schelmen kein Ehr beweisen.

Wenn schon der Babst von Rom es thät/

Ja stunds auch im Calender;

Wird doch A.O.H. wie geredt/

Nicht ehren die Gottschänder.

Wie solts seyn möglich daß Sie könt

Die Teuffels-köpffe Ehren?

Sie macht' sich theilhafft frembder sünd/

Das lest Sie sich nicht lehren.

Sie bleibt bey warheit/ liebt das Recht/

Lest sich daran genügen/

Hat ihren eignen Kopff (ist schlecht)

Wie die Gänß im Land Rügen/

Achtet nicht mehr Welt-schand noch ehr/

Sitzet auch nicht gern Oben:

Drumb möget ihr frey ohn beschwer

Sie lästern oder loben/

Die ehr hab Gott/ sie bleibt ohn schand/

Weil sie den Herren ehret/

Vnd diß in ihrem Witwen-stand

$\mathrm{Zu}$ thun auch ander lehret.

Sie ist ein Feindinn der boßheit/

Bleibts auch/ wills recht entdecken/

Lest sich davon durch Satans neid/

Auch nicht durch Gecken schrecken.

Was Gott gefelt für gut sie helt/

Bleibet dabey ohn wancken/

Der sie gestellt hat in die Welt/

Kennt sie/ weis ihr gedancken.

Darumb rath ich euch/ last sie gehn 
Sicher auff ihren wegen/

Die wieder sie zum streit auffstehn/

Werden kein Ehr einlegen.

Wer sich an alten Kesseln reibt/

Gern streitt mit alten Frawen/

Derselb nicht unbesudelt bleibt/

Das sag ich euch in trawen.

Hiemit Ade/ flieht wieder hin/

Setzet euch frölich nieder/

Im Krug-hauß/ zur Fraw Krügerinn/

Erquicket ewer glieder;

Drinckt aller alten Frawen Schaal/

Daß Sie beym leben bleiben/

Sie werden euch dafür einmal

274 Dancken in ihrem schreiben.

Hanna die Prophetinne hat

Niemals gehört von solcher that

Alß Fairfax hat betrieben.

Hätt sie gekant solch Schelm und Dieb/

Sie hätt auß lieb zur waren Lieb

Scharff wieder Sie geschrieben.

Denn alle fromme Annen

Müssen solche Tyrannen

Verfluchen und verbannen/

Kein gut hertz kan Sie lieben.

Vale \& vive.

Lob-Liedlein

Zu Ehren der Schwedischen Cronen/ Vnd allen die darunter wohnen/

Gestellt den 7 Septembris, Anno 1644, in der Königlichen Statt Stockholm.

Im thon: Daphnis om en Sommner Natt/ etc. 
K.

S.

D.

L.

K.S.D.L.Z.L.D.S.K.

L.

D.

$\mathrm{S}$.

K.

Kommet Singet Dis Liedlein Zum Lob

Der Schwedischen Königinnen.

Gott erhalte die Hochlöblich Königin auch die ochedle Reichs Herrn.

1.

Großmächtigste Königin

Fräwlein Hochgeboren/

Durchleuchtigste Groß-Fürstin

Von Gott außerkoren/

$\mathrm{Zu}$ führen das Regiment/

Im Königreich Excellent;

Gott woll langes Leben

Ewer Maystät geben.

2.

O Ruhm-würdigs-Schweden-Reich/

Frew dich deiner Cronen;

Kein Königreich ist dir gleich

In dir ist gut wohnen;

Bey dir suchen schirm und schutz

Wider ihrer Feinde trutz

Frembde/ Wittwen/ Waisen/

Hoch bistu zu preisen.

3.

Trewlich meynt es Gott mit dir/

Gibt dir Glück für allen/ 
Vnd lesst/ des sind frölich wir/

Deine Feinde fallen/

Du gewinnest Städt und Land/

Wirst in aller Welt bekandt/

Gott laß deine Thaten

Ihm zum Lob gerathen.

4.

Tapffer Helden und Reichs-Räth

Mit Weißheit geziehret

Hat Königlich Mayestät/

Alles wird regieret

Durch Sie sehr wol und löblich/

Schweden ich preiß seelig dich/

Auch mich/ weil ich wohne

Vnter deiner Crone.

5.

Erfrewt euch der Herrlichkeit

Vnser Königinnen;

Kommet her von nah und weit/

Schweden/ Lappen/ Finnen;

Ihr Frantzosen hier im Reich/

Deutschen/ Russen/ allzugleich/

Helfft diß Reich erheben

277 Drinn wir friedlich leben.

6.

Haltet Fest/ seyt frewden voll/

Spielt lieblich auff Seyten/

Alles Volck in Schweden soll

Schweden Lob außbreiten/

Schweden Reich ist Lobens wert/

Schweden wird billich geehrt/

Schweden Reich florieret/

Schweden triumphieret. 
Die Hochlöblich Königin

Woll' der Herr bewahren

Für Vnglück/ und wie vorhin

Im Fried frölich spahren:

Auch die Hochedle Reichs Herrn,

Die des Landes Wolfart mehrn/

$\mathrm{Zu}$ lob seinem Nahmen

Lang erhalten/ Amen.

M.

G.

M.G.E.G.M.

G.

M.

Mein Gott Erhöre Gnädig Mich.

Diß bitt täglich von Hertzen ich

Anna Ovena Hoyers.

\section{Frewden-Liedlein/ Auff die glückliche Ankunft Ihr Königlichen Mayst.ten}

den 29 Augusti, Anno 1648, in der Königl. Residentz-Statt Stockholm/

Gestellt durch A.O.H.

1.

Frewet euch mit mir ihr Frommen/

Vnser Königin ist kommen/

Die Königliche Witwe/

Gott der alles wol regieret/

Hat Ihr Maystät hergeführet

$\mathrm{Zu}$ uns glücklich über See.

2.

Lieben Leut seyt frölich wieder/

Leget allen Vnmuth nieder: 
Denn wir sehn das Angesicht

Der hertzfrommen Königinnen/

Vnd Großmächtigsten Fürstinnen/

Wer wolt sich des frewen nicht?

Ihr getrewe Vnterthanen/

Schwinget nun die Frewden-fahnen/

Macht einen frölichen Hall/

Ihr Maystäten zu gefallen/

Schlagt die Seyten/ lasset schallen/

Tromlen und Trompetten all.

Wie lieblich ist anzuschawen/

279 Die Gestalt der schönsten Frawen/

Vnd das Königlich Fräwlein/

Das von Ihr Maystät geboren/

Vnd von Gott ist außerkoren/

$\mathrm{Zu}$ regieren die Gemein.

Wir sehn bey ein ander wohnen

Die zwey Königlich' Personen/

Ist das nicht ein grosse Frewd?

Welche uns in vielen Jahren/

Nicht hat mögen wiederfahren/

Solt man dann seyn traurig heut?

6.

Nein/ nun ist kein Zeit von trawren/

Frölich sind Bürger und Bawren/

Vnd auch ich bin frewden voll/

Hab zwey Gnädigst Königinnen/

Wie solt ich dann trawren können/

Stehn nicht meine Sachen wol? 
Ja/ Gott sey dafür gepreiset/

Er hat mir viel Gnad beweiset/

Mich als bey der Hand gefürt

Auß Holstein hieher ohn schaden:

Ich bin von Ihr Fürstlich Gnaden/

An Ihr Maystät commendirt.

8.

Ob wol ich viel Jahr gesessen/

Arm und Elend/ als vergessen/

Hab gewohnt bald hie bald dort/

In der Stadt und auff dem Lande/

Im betrübten Witwen Stande/

Hie an diesem frembden Ort.

9.

In Gefahr auch offt geschwebet/

Dennoch hat/ der ewig Lebet/

Mich errettet immerdar/

Seine Gnade lassen walten/

Vnd beym Leben mich erhalten/

Nun ins Vier und Sechszigst Jahr.

10.

Ihn wil ich stets rathen lassen/

Ihm befehlen meine strassen/

Der die seinen nicht verlest/

Führet wunderbar/ doch gnädig/

Machet aller Sorgen ledig/

Die ihm nur vertrawen fest.

11.

Hiemit schlies ich und wil beten/

Für die hohe Mayestäten/

Auch für die Herrn fern und nah/

Vnd fürs Edle Frawen-Zimmer/ 
O Gott sey ihr Schütz-herr immer/

281 Erhör gnedig A.O.H. 


\section{Zwey Geistliche Lieder}

\section{Das erste}

Auff den Nahmen der Gottliebenden/Edlen/Ehrn- und Aller-tugendreichsten Jungfrawen Catharino Ottersen Deroselben zu Ehren/ und freundlichem gefallen

gestellt und geschrieben den 23 Febr. Anno 1624. Zu Horstrowey in Testredey/

I.

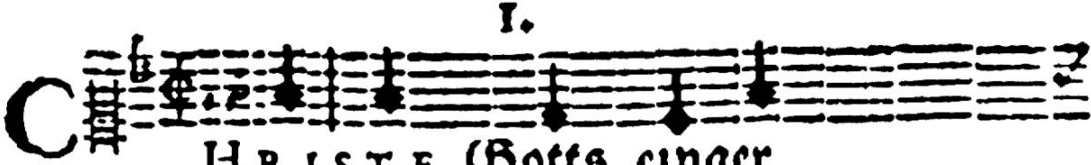
IH R IS TE Gotts cinger
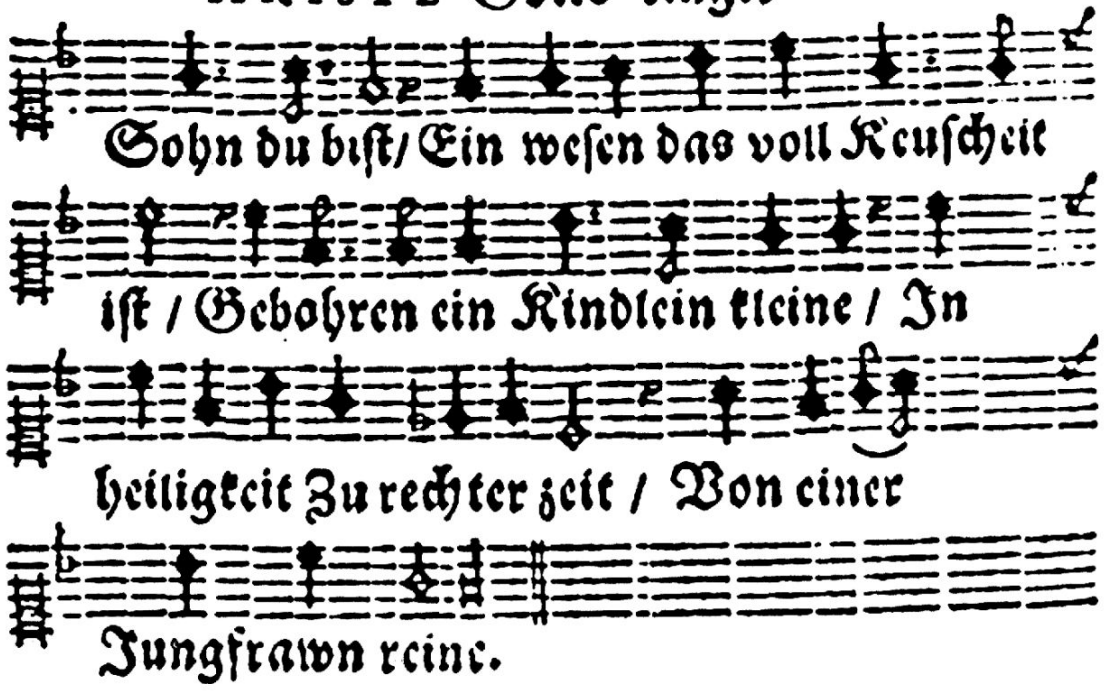

Christe Gotts einger Sohn du bist/

Ein wesen das voll Keuscheit ist/

Gebohren ein Kindlein kleine/

In heiligkeit 
Zu rechter zeit/

Von einer Jungfrawn reine.

Auff Erd nichts liebers dir gefellt/

Dann ein Mensch so sich Züchtig helt/

Vnd in der keuscheit lebet/

Bey tag und nacht

Stets bett und wacht/

282 Vnd heilig händ' auffhebet.

Trauter Jesu/ drumb komb auch ich

Dein dienerin und bitte dich/

Du wollst in mir zerstören

All eitelkeit

Vnd Weltlich frewd

So mein hertz möcht bethören.

Halt mich bey deinem wort allein/

Daß es mein högste frewd mög seyn/

Regier all meine glieder/

Das davon nicht

Was werd verricht/

So dir mag seyn zu wieder.

Augen und fleisches lust abwend/

Machs mit der hoffart auch ein end/

Dann dadurch/ wie man spühret/

Mit rew und schmertz

Manchs frommes hertz

Wird jämmerlich verführet.

Richte mein hertz/ sinn und gemüth

Durch deine Väterliche güt/ 
Daß ich mich nicht ergebe

Der wollust frewd/

Sondern allzeit

In reiner keuscheit lebe.

Im wort des Herrn ich g' schrieben sind/

Selig sind die reins hertzens sind/

Sie werden Gott anschawen

Mit grosser frewd

In ewigkeit/

Diß mercket ihr Jungfrawen.

Nach wollust folget rew und schmertz/

Diß bedenck wohl o frommes hertz/

Laß dich Gotts Geist regieren/

Nach Christi wort

Wollst immerfort

Den engen weg passieren.

Auff Gottes weg in deinem lauff

Steh nimmer still/ hör auch nicht auff

Mit fleisch und blut zu kämpffen/

Streit mit gewalt/

So wirstu bald

Das fewr der unzucht dempffen.

Ohn streit man keinen feind erlegt/

Auch kein Stadt zu gewinnen pflegt/

Man muß drumb erstlich fechten/

Also ein Christ

Muß sein gerüst

Zur lincken und zur rechten. 
Tapffer und mannlich ohn verdruß

Er sich zum kampff stets schicken muß/

Willig ohn wiederstreben

Im Christenthumb/

So wird er ruhm/

Haben in jenem leben.

Trewlich bey Christo halten steth/

Vnd was er in der tauff geredt

Mit allem fleiß nachkommen/

Auff solch arbeit

Die ewig frewd

284 Gibt Gott zu lohn den frommen.

Es muß doch hie gestritten seyn/

Darumb o Christ gib dich darein/

Schick dich zum überwinden/

In Gotts wort such/

Drinn wirst genug

Beyd wehr und waffen finden.

Ringet darnach/ sagt Christi wort/

Daß ihr mögt durch die enge pfort

Zum himmelreich eingehen/

Dann viel ich sag/

Streben darnach/

Bleiben doch draussen stehen.

So dann viel nicht kommen drein/

Die darnach strebn/ wie wils dann seyn/

Mit denen/ die verachten

Des Herren lehr/ 
Vnd nimmermehr

Ihr Seelen heyl betrachten.

Einm jeden sey hiemit gesagt/

Sein sach zu nehm'n in guter acht/

Vnd in keuscheit zu leben/

So er ohn klag

An jenem tag

In ewigr frewd wil schweben.

Nun wil ich Jesu lieber Herr

Befehlen dir mein zucht und ehr/

Durch deinen heilgen nahmen

Erhalte mich

Beständiglich

In wahrer keuscheit/ Amen.

\section{Das ander}

Ein arm gering Liedlein von betrachtung der jetzigen wunder Gottes/ so mit hauffen im schwange gehen/ und was darauff erfolgen wird/ gantz einfältig gestellet durch des Heiligen Geistes eigeben/

Anno 1635

von F.A.K. 

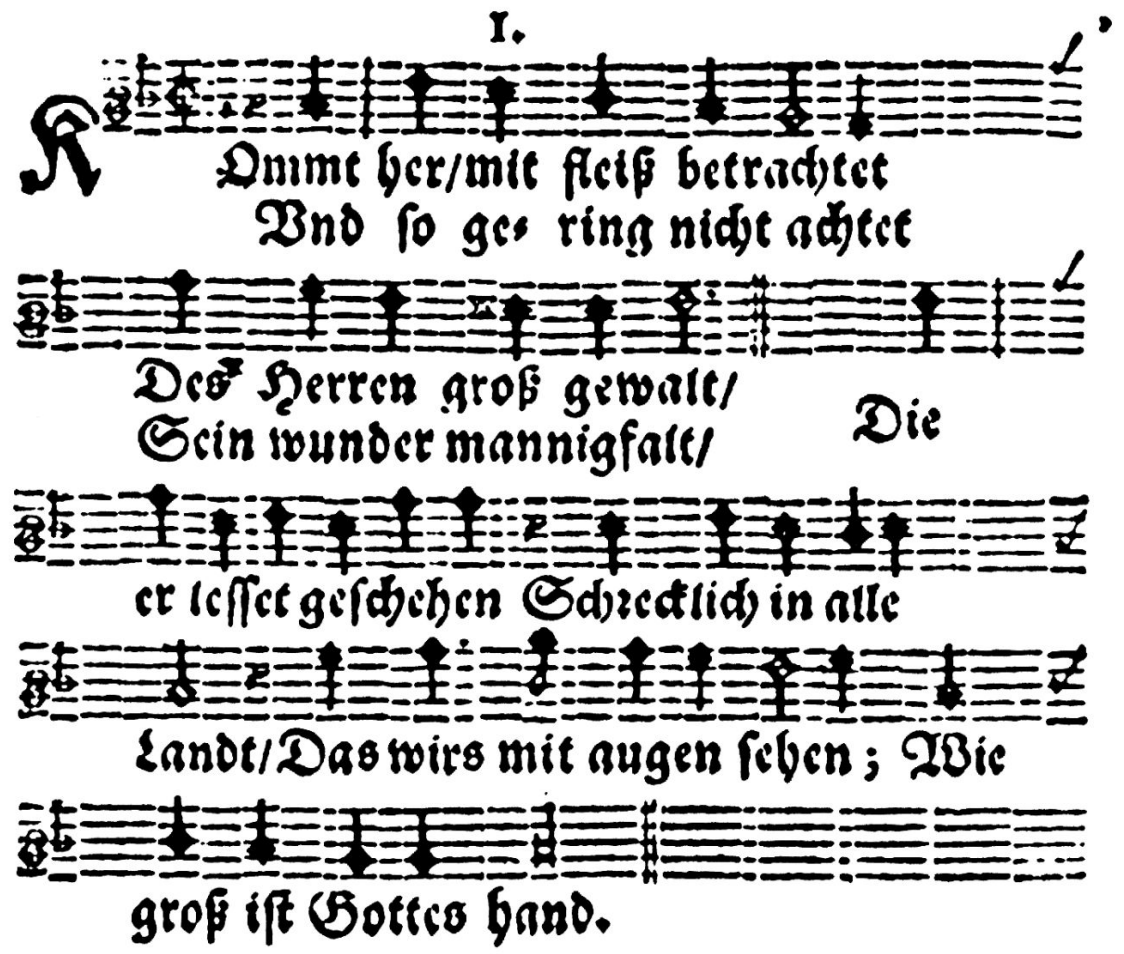

Kommt her/ mit fleiß betrachtet

Vnd so gering nicht achtet

Des herren groß gewalt/

Sein wunder mannigfalt/

Die er lesset geschehen

Schrecklich in alle Landt/

Das wirs mit augen sehen;

Wie groß ist Gottes hand.

Ihr Menschen groß und kleine

Alle ohn unterscheid/

Mann und Frawen gemeine

Gebt acht auff diese zeit/

Der Herr ist auffgestanden

Im grimm zu üben rach/ 
Wolt ihr nicht stehn mit schanden/

So betet unde wacht.

Betrachtet Gottes wunder/

Schawt sie mit augen an/

Landt und Volck gehen under;

Jung und Alt/ Fraw und Mann/

Bey tausenden hinfallen

Durch Gottes zornes fluth/

Das Vieh auch unter allen

Empfindet Gottes ruth.

Solches han wir erfahren/

Es ist uns wohl bekandt/

Wie Gott in diesen Jahren

Im Eyderstedt und Strandt/

In Dithmarschen daneben/

Vnd andern orthen mehr/

Die Leuth gebracht umbs leben

Durch ein brausendes Meer.

Schrecklich seyn sie umbkommen

Da sie es nicht gedacht/

Die fluht hat sie wegnommen

Gantz schnell in einer nacht/

Die da haben zuvoren

Wollen gelauben nicht/

Haben müssen im zoren

Erfahren Gotts gericht.

Es ist sehr zu beklagen/

Wenn man gedenckt daran/

In was schrecken und zagen

Gewesen jederman/ 
Da sie haben gesehen

Mit angest groß und schwer/

Ihr lieben Freund vergehen

287 Vnd ersauffen im Meer.

Was wollen wir dann sagen

Von dem das jetzt geschehn/

Da Gott in diesen tagen

Sein zorn hat lassen sehn/

$\mathrm{Ob}$ die leuthe vor allen

Allein gesündigt han/

Daß sie so schnell hinfallen

Vnd so plötzlich vergahn.

Ach nein ihr lieben Christen/

Sie seyn es nicht allein/

Sünd schand und bose lüsten

Sind jetzt so gar gemein/

Die Welt ist uberhäuffet

Mit grewel groß und viel/

Ein jeder jetz und läuffet

Nach seinem eignen will.

Christus ist außgerottet

Nach Danjels Prophecey/

Die Welt der Frommen spottet/

Acht es für phantasey/

Wann der Geist thut verkünden

Daß Gott zur straff bereit/

Die Welt fahrt fort in sünden/

Verharrt in sicherheit.

Der Glaube ist gestorben/

Die Christlich Lieb ist todt/ 
Die Menschen sind verdorben/

Sie sättig'n sich mit koth/

Der gantz eitelen dingen/

Die sie allein begehrn/

Kein plage kan sie zwingen

$\mathrm{Zu}$ fürchten Gott den Herrn.

Seit daß die Welt gestanden/

Ist nie gewest so groß/

Die sünd in allen landen/

Der Teuffel ist jetzt loß/

Sein bößheit thut er üben/

Erreget krieg und streitt

Die Menschen zu betrüben/

Weil bald ist auß sein zeit.

Der Herr hat außgegossen

Sein Schal voll zorn und grimm/

Sein pfeilen loß geschossen/

Man höret seine stimm

Im zorne schrecklich brüllen/

Wil jetzt sein wort erfüllen/

Weh dir gottloser Cham.

Es geht nach Christi worten/

Man hört von kriegs geschrey

Häuffig an allen orthen/

Das gericht kompt herbey/

Die noth thut sich anheben/

Alle Welt ist im streit/

$\mathrm{O}$ weh denen so leben

Ohne bußfertigkeit. 
Weil wir dann solche plagen

Mit ohren hören an/

So lasset uns beklagen

Die sünd so wir gethan/

Wo wir Vns nicht bekehren

Vnd hören Gottes stimm/

So wird uns von der erden

289 Vertilgen sein grimm.

Was wir von andern hören/

Wird uns auch treffen nun/

Gott wird uns auch verstören/

So wir nicht busse thun/

Darumb wer da wil leben

Vnd Gottes wunder sehn/

Der muß sich ihm ergeben

Auff seinen weg zu gehn.

Jetzunder ist verhanden

Die lang gewünschte zeit/

Da alles wird zu schanden/

Was in sünd und boßheit

Des Herren Güth verachtet/

Sein wunder außgelacht/

Sein wort nicht recht betrachtet/

Nun kompt die straff mit macht.

Nun werdet ihr befinden/

Die ihr euch Christen nennt/

Wie ihr durch ewre blinden/

So Gott nie recht erkendt/

Vom liechte abgeführet

Vnd irr gemachet seyn/ 
Ja gantz und gar bethöret

Jung und Alt/ Groß und Klein.

Ihr habt euch lang beruffen

Auff Gottes Wort und Schrifft/

Darüber ihr mit hauffen

Viel irrthumb hab't gestifft/

Wir sind die rechte Christen

Rühmen die Secten sich/

Vnd seyn doch Cainisten/

Die lieb haben sie nicht.

Darumb lest Gott verkünden

Das word von seinem Reich/

Er wil daß wir von Sünden

Auffstehen alle gleich/

Vnd seine Botten hören

Die uns anmelden all/

Daß Christus will einführen

Sein Braut zum Abendmahl.

O Babel es wird kommen

Dein fall auff einen tag/

Gott wird das Bluth der Frommen/

So lang geschryen rach/

Fördern von deinen händen/

Nun ist kommen die zeit/

In welcher die Elenden

Wieder werden erfrewt.

Ey wie wird sich erfrewen

Des Herren Braut Zion/

Wenn Christus wird vernewen

All Creatur sehr schon/ 
Ein newen bund auffrichten

Mit sein geschöpffen all/

Sünd und den todt vernichten/

Kein Teuffel mehr seyn soll.

Auch wird sich Gott erbarmen

Seines volcks Israel/

Die verstossenen armen

Wird er erleuchten schnell/

$\mathrm{Daß}$ sie werden erkennen

Ihrn König/ Davids Sohn/

Vnd ihn mit frewden nennen

291 Ihren Erlöser schon.

Gott wird sie wiederbringen

Zur Stadt Jerusalem/

Da sie werden lobsingen

Lieblich mit heller stimm/

$\mathrm{Da}$ alle welt von sünden

Ist frey und loß gemacht/

Ewig erlösung funden/

Das heyl herwieder bracht.

Dann wird eröffnet werden

Des Paradises pfort/

Vnd alles Volck auff erden

Wird eingehn zu dem orth/

Vom Baum des lebens essen

In grosser lust und frewd/

Bald all ihrs leids vergessen/

Eingehn zum leben new.

Mein hertz fur frewden springet/

Mein Seele in mir lacht/ 
Mein Geist auch Gott lobsinget

Wann ich die frewd betracht/

So in den tausend Jahren

Des reiches Jesu Christ

Den Heilgen außerkoren/

Von Gott bereitet ist.

O ihr weltlich Gelehrten/

Warumb glaubet ihr nicht/

Weh euch blinden Verkehrten

Nun trifft euch das gericht/

Weil ihr nicht wollet trawen

Hie Gottes Geist und Wort/

Muß es euch ewig rewen

In der verdamnuß dort.

Kommt her ihr außerkohren/

Erfrewet euch mit mir/

Die ihr auß Gott gebohren/

Nun bricht der tag herfür/

Die Sonne wird hell scheinen/

Die nacht muß untergehn/

Christus wird in den seinen

Sich herrlich lassen sehn.

Mein hertz sol ewig loben

Dich Jesu Heylandt mein/

In deinem thron daroben

Fur diß erkäntnuß dein/

So du mir hast gegeben/

Hilff daß ich tracht allzeit

In meinem gantzen leben

Nach dieser Seeligkeit. 


\section{Liedlein von den Gelt-liebenden Welt-Freunden}

Gestellet durch A.O.H.

Im thon des 130 Psalms. Zu dir von Hertzen grunde/etc.

1.

Geldt und Welt-Freund vertrawen/

Ist wie auff sandisch grund/

Ein hohes Schloß zu bawen/

Exempel machens kund/.

Das sie sehr unbeständig/

Vnd wanckelmütig sind/

Wenn das Glück wird abwendig.

Ihr keiner sich dann findt.

2.

Wir wissn in guten Tagen/

Wann das Glück scheint lieblich/

Von keinem Feind zu sagen

Freund/ Freund/ nennt jeder sich/

Man thut uns hoch erheben/

So lang der Beütel voll/

Vnd wir in Ehren schweben/

Glaub mir ich weis es wol.

Wir seynd lieb und wilkommen

All wo wir uns hin kehrn

Vnd werden angenommen/

Als wann wir Engel wehrn

Mit Reverentz sein zierlich

Setzt man uns oben an/

Proesentirt uns manirlich/

294 Viel dienst und Freundschafft an.

4.

Huth zücken sich tieff neigen/

Die Händlein küssen auch/ 
Krum bücken und Knie beugen

Ist der Welt-Freund gebrauch/

Wer sich daran wil kehren/

Ist mehr dann halb vexirt/

Traw nicht auch wann sie schweren

Ihr Freundschafft ist probirt.

5.

Man lest sich Bruder nennen/

Will stehn getrewlich bey/

Vnd sich nicht von uns trennen/

Wie groß die Noth auch sey/

Ja den Leib will man wagen/

Nicht allein Guth und Gelt/

Sind das nicht groß Zusagen?

Also gehts in der Welt.

6.

Mancher verheist darneben/

Daß er uns dienen woll'

Nicht allein weil wir leben/

Sondern sein Freundschafft soll

Bleiben bey unsern Erben/

Eydtlich er sichs verpflicht.

Ein Narr mag darauff sterben/

Ich traw den Worten nicht.

7.

Sie folgen nicht im Wercke

Wer sich darauff verlest/

Der ist nicht klug das mercke/

Solch Zusag gehn nicht fest/

Ich hab vor wenig Jahren

Dergleichen angehort/

Itzt muß ichs auch erfahren/

Das man vergist der Wort. 
8.

Noth lehrt die Freund recht kennen/

Im Fewr Goldt scheinbar wird/

Freund soll man niemand nennen

Man hab ihn dann probirt/

O Trübsal Edle Probe/

Du zeigst mir meinen Freund/

Machst auch/ drumb ich dich lobe/

Mir offenbar den Feind.

9.

Im Creutz bleibt nicht verborgen/

Wo Feindschafft steckt verdeckt/

Auch wird in Noth und Sorgen/

Getrew Freundschafft erweckt/

Im Glück kan mans nicht lernen

Gleich wie man nicht erkennt

Bey Sonnenschein die Sternen

Am hohen Firmament.

10.

Im Sommer sindt man Schwalben/

$\mathrm{Zu}$ Winter sind sie weit/

Also Freund allenthalben/

Auch in Glückseligkeit/

Wann das Glück herrlich blühet

Sind viel Freund umb uns her/

Ein jeder sich bemühet/

Vns zu erzeigen Ehr.

11.

Viel der Schwalben Gesellen/

Sehr offt bey uns einkehrn/

Vnd sich gantz freundlich stellen/

Sind frölich mit uns gern/

Wenn alles wol gerahten/

Vnd gedeckt ist der Tisch/ 
Wol schmecken unser Braten/

Die Freundschafft helt sich frisch.

12.

Wirds aber unklar Wetter/

Schneyt uns Vnglück ins Haus/

So verleurt sich der Vetter/

Die Freunde bleiben auß/

Frembd stelt sich auch der Schwager

Vnd kompt zu uns nicht mehr/

Wenn unser Supp ist mager/

Vnd unser Weinfaß lehr.

13.

Die offt fröliches Muhtes/

Mit uns gewesen seyn/

Vnd im Wolstand viel gutes

Haben genommen ein/

Seh'n wir im Vnglück fliehen

Vnd für uns ubergehn/

Den Huth in Augen ziehen

Wenn sie uns kommen seh'n.

14.

So pflegts die Welt zu machen/

Sehr freundlich sie sich stelt/

Wenn in all unsern Sachen

Fortun sich zu uns helt/

Kehrt aber die den Rücken/

Bald wendt die Weldt sich auch/

Helfft uns mit untertrücken

Also ist ihr Gebrauch.

15.

Diß ich vor wenig Jahren/

Sehr wol empfunden hab/

Darumb laß ich sie fahren/

Scheid' von der Freundschafft ab/ 
All ihr zusag sindt Lügen/

Ihr Lieb ist Heücheley/

Ihr Halten ist Betriegen

297 Vnd eitel Schelmerey.

Trauvv vvol hat mich vexiret/

Glaub leicht auch mannigmal/

Sie haben mich geführet

Vom Berg herab ins Tahl/

Mein Pferd hinweg geritten/

Itzt muß ich gehn zu Fuß/

Narren man nach alten Sitten/

Mit Kolben lausen muß.

K.

K.VV.K.

$\mathrm{K}$.

Kinder VVerdet Klug.

Exempel sind genug

An A.O.H. und mehr/

Seht euch nur wol umbher/

298 Vnd folget meiner Lehr.

\section{Liedlein}

Gestellt durch A.O.H.

Im thon: Wär Gott nicht mit uns/ etc.

1.

O Gott mein Herr wie wunderbahr

Spielestu mit den deinen/

Führest sie in Noth und gefahr/

Lesst sie ruffen und weinen/

Stellst dich frembd und von ihnen weit/

Daß sie fur großem hertzenleit/

Bald zu verzagen meynen. 
Gedencken du seyst gar von hauß/

Achtest nicht mehr ihr schreyen/

All' deine vorig gnad sey auß/

Wollst sie nicht mehr erfreuen/

Da sie doch an dich halten sich/

Vnd so von hertzen lieben dich/

Auch ihr boßheit bereuen.

3.

Du führst sie über Berg und Thal/

Durch ungluck vielerhande/

In großem trauren mannigmal

$\mathrm{Zu}$ Wasser und zu Lande;

Sie sind wie ein Schiff auff dem Meer/

Werden getrieben hin und her/

Ja/ offt durch ehr und schande.

4.

Aber O Herr wie sehr freundtlich

Lesstu dich darnach finden/

$\mathrm{Zu}$ rechter zeit erbarmstu dich/

Mach'st alles Leit verschwinden/

Ein augenblick das trauren wehrt/

Dein Ewig gnad bald wiederkehrt/

Vnd helfft uns überwinden.

Das ungewitter stillestu/

Vnd legst die wellen nieder/

Schaffst unserm hertzen Fried und Ruh'/

Erquickest unser glieder/

Nach großem Regen scheint die Sonn/

Nach traurigkeit kompt Freud und Wonn/

Drumb dancken wir dir wieder. 
6.

O Gott bereit dein lob in mir/

Fur deine gnad unzehlig/

Vnd was noch ist zu leben hir

Im fleische hinderstellig/

Das laß mich leben dir allein/

Dir geb' ich mich/ dein will ich seyn/

Mach mich dir recht gefällig.

7.

Du bist mein Helffer ja allzeit/

Ohn dich ist doch sonst keiner/

Regier mein tritt daß ich nicht gleit/

Hertzlich begehr ich deiner/

Bey dir ist Täglich mein gebeth/

Mein geist des Nachts auch mit dir redt/

Mein Gott erbarm dich meiner.

8.

Vollführ dein angefangen werck/

Vermehr was du hast geben/

Du bist mein Auffenthalt und Sterck/

Meins Lebens Liecht darneben/

Herr gib dich mir/ dir geb' ich mich/

Halt mich bey dir bestendiglich/

300 In deiner forcht zu leben.

9.

Gib krafft daß mich im guten lauff/

Nicht mehr auffhalt noch hinder/

Welt-freundtschafft und ihr Acker-kauff/

Oder die funff Joch Rinder/

Auff daß ich mög' in deinem Sahl

Schmecken das Herrlich Abendmahl/

Der Außerwehlten Kinder. 
Ihrer freyheit in dieser zeit

Auch frölich mit genießen/

Laß all mein thun in lieb und leit

$\mathrm{Zu}$ deinem Lob ersprießen/

Helff und thu du/ was ich nicht kan/

Mit dir Herr Jesu/ fang ichs an/

Mit dir will ichs beschließen.

Amen.

Neuw-Jahrs-Liedlein

I.

N.

I.

G.

G.

I.N.I.G.G.V.G.G.I.N.I.

$\mathrm{G}$.

G.

I.

$\mathrm{N}$.

I.

Im Namen Iesu Gebe Gott Vns Gut Gluck Im Newen Iahr.

I.

$\mathrm{N}$.

I.

S.

A.

I.N.I.S.A.V.A.S.I.N.I.
A.
S.
I. 
Im Namen Iesu/ Steht Auff Von Allen Sunden/ Im Newen Iahr.

1.

Steht Auff Von Allen Sünden

In diesen Newen Jahr/

Werdet sehend ihr blinden/

Das new Liecht scheinet klar/

302 Ehrbar und Redlich handelt/

In dieser Newen zeit/

Im newen leben wandelt/

Vnd des liechts Kinder seyt.

2.

Das fleischlich hertz beschneidet

Von aller bösen lust/

Euch von der Welt abscheidet/

Alß hochzeit Gäst euch ruft/

Hasset den Rock des fleisches/

Zieht an die g'rechtigkeit/

Ein Heilig's/ Reines/ Keusches/

Vnbefleckt Hochzeit kleid.

3.

Gehorsam euch einstellet

Dem lieben Gott zun ehrn/

Zun frommen euch gesellet/

Gehorcht der stimm des Herrn/

Lasst euch durch nichts auffhalten/

Meidet was hindern mag/

Folget nicht mehr dem alten

In diesem New-Jahr nach.

4.

Die Ochsen und den Acker

Vnd Irdisch lust nicht liebt/ 
Seyt im auffwarten wacker

Vnd im gebeth euch übt/

Der Breut'gamb ist verhanden/

Verschlafft die stunde nicht/

Wollt ihr nicht stehn mit schanden/

So habt ein brennend liecht.

5.

Beyzeit das öhl einkauffet/

Die Lampen fertig macht/

Hernach umb sonst ihr lauffet/

Drumb nehmt die stund in acht/

Denn wenn die zeit verflossen

So kommt ihr viel zu späth/

Daraußen bleibt verschlossen/

Der nicht bey zeit eingeht.

6.

Itzt hat man noch zu hoffen/

Wiewol ein kleine zeit/

Eilt/ weil die thür steht offen/

Verlasst all' eitelheit/

Stellt Ab Die Alte Sitten/

Wacht auff vom sunden schlaff/

So wird auff ewer bitten/

Gott wenden ab die straff.

7.

Amen Herr Jesu Amen/

In gnaden $\mathrm{zu}$ uns komm/

Vnd mach uns allzusamen

Heilig/ Gerecht und Fromm/

Laß uns mit dir anfangen

Alles in dieser zeit

Vnd durch dich auch erlangen/

Die Ewig Seligkeit. 
I.

$\mathrm{N}$.

I.

S.

A.

I.N.I.S.A.D.A.S.I.N.I.

A.

S.

I.

$\mathrm{N}$.

I.

Im Namen Iesu/ Stellt Ab Die Alte Sitten/ Im Newen Iahr.

A.O.H.

Finis. 